\title{
III. Die Koordination der Deklassierung jüdischer Fürsorgeempfänger
}

\section{Deutscher Gemeindetag und Reichsinnenministerium: Zur Abstimmung lokaler Praktiken (Sommer 1937)}

\section{Die Tagung des DGT-Wohlfabrtsausschusses in Heidelberg}

Durch das Bündeln kommunaler Initiativen via Deutschem Gemeindetag sollte sich der Druck auf die Ministerialebene bzw. auf die NS-Führung, antijüdische Maßnahmen auf dem Sektor der öffentlichen Wohlfahrt zu entwickeln, rasch verstärken. Am 13. Januar 1937 hatte Oberbürgermeister und DGT-Vorsitzender Fiehler die Münchner Vorschläge zur Ausgrenzung der jüdischen Armen der Berliner Geschäftsstelle des Deutschen Gemeindetages übersandt. In seinem Schreiben hieß es: „Beiliegender Antrag ist mir vom Referenten des städtischen Wohlfahrtsamtes unterbreitet worden. Ich ersuche denselben mit den zuständigen Stellen der Reichsregierung zu besprechen und eine klare Regelung der einschlägigen Fragen für das gesamte Reichsgebiet herbeizuführen. "Fiehler verfocht in seinem Brief die radikale Position des Münchner Verwaltungsrates Ortner: „Insbesondere bedarf der Prüfung die Frage, ob es weiter zulässig sein soll, daß Nichtarier in der gehobenen Fürsorge unterstützt werden, während deutschblütige und arische Ausländer von derselben grundsätzlich ausgeschlossen sind. Anregungen, wonach Juden künftig die gehobene Fürsorge, insbes[ondere] in der Kleinrentnerhilfe, versagt werden soll, sind mehrfach ergangen. Dem Vernehmen nach haben auch manche Städte bereits dahingehende Anordnungen erlassen. Ich halte es aber für notwendig, daß diese Frage von der Reichsregierung mit einheitlicher Wirkung für sämtliche Fürsorgeverbände geregelt wird. “1

Der geschäftsführende Präsident des Deutschen Gemeindetages, Jeserich, unterrichtete in seiner Antwort Fiehler Ende Januar 1937, daß man „bereits vor einiger Zeit bei dem Reichs- und Preußischen Minister des Innern die Herausgabe ministerieller Richtlinien für die Behandlung von Nichtariern in der öffentlichen Fürsorge beantragt ${ }^{“}$ habe. Er werde dem Minister die Münchner Vorschläge als zusätzliches Dokument zu den schon gelieferten Unterlagen, damit war offensichtlich die Gesetzesinitiative Martinis vom Februar 1936 gemeint, unterbreiten.2 Doch zunächst reagierte das Reichsinnenministerium nicht auf die Eingabe. Es empfahl den Fürsorgeverbänden im März 1937 lediglich, jüdischen Sozialhilfeempfängern die Emigration nahezulegen. ${ }^{3}$ Egal welches Motiv hinter diesem ab-

1 YV Jerusalem, M1DN, Nr. 168, Bl. 71-72: OB München an DGT Berlin am 13.1. 1937; vgl. auch Hanke, Juden in München, S. 265.

2 YV Jerusalem, M1DN, Nr. 168, Bl. 89: DGT/Abt. III an OB München am 27.1. 1937. Zur Initiative Martinis vgl. Kapitel II. 1.

3 Das gleiche Verfahren, so hatte man dem RArbM geraten, sollten die Arbeitsämter gegen- 
sonderlichen Vorschlag steckte, ob damit allein Vertreibung forciert oder Fürsorgekosten vermindert werden sollten, es war ein in jeder Hinsicht untaugliches Mittel. Das Ministerium wußte, daß Juden ohne finanzielle Mittel kaum über reale Auswanderungschancen verfügten.

Fiehler intervenierte wegen des Drängens seines Stadtrates Hilble von Anfang Mai 1937 offenbar noch einmal bei zentraler Stelle, um konzeptionelle Überlegungen auszulösen. ${ }^{4}$ Und so regte der Reichsinnenminister plötzlich in der zweiten Maihälfte an, schon auf der nächsten Tagung des Wohlfahrtsausschusses des Deutschen Gemeindetages die „künftige Behandlung der Juden in der öffentlichen Fürsorge" als Grundsatzfrage zu erörtern. ${ }^{5}$ Der DGT-Beigeordnete Schlüter nahm auf den "Wunsch“ des Ministers das Thema zusätzlich in die Tagesordnung der für Juni vorbereiteten Sitzung auf, worüber die Mitglieder des Ausschusses am 24. Mai informiert wurden. ${ }^{6}$ Den Initiator der Eingabe von 1936, den Vizepräsidenten der Hamburger Fürsorgebehörde Oskar Martini, beauftragte er, ein Grundsatzreferat zum Thema „Nichtarier in der öffentlichen Fürsorge“, den Spiritus rector der Eingabe von 1937, den Münchner Stadtrat Hilble, ein Koreferat „Richtlinien für die Behandlung von Nichtariern in der öffentlichen Fürsorge“ zu halten.?

Von Hilble erhielt Schlüter am 26. Mai 1937 aber eine Absage, weil er schwer erkrankt sei. Der Stadtrat starb wenig später. München sandte dem Deutschen Gemeindetag trotzdem ein Thesenpapier zu. Dieses war im wesentlichen identisch mit der umfassenden Vorlage vom Januar, die Fiehler dem Gemeindetag schon zugeschickt hatte, und deren diskriminierende Grundsätze - wie oben schon dargestellt - seit knapp zwei Wochen die Wohlfahrtspraxis in der bayerischen Landeshauptstadt regelten. Die neuen Münchner Vorschriften nahmen ein mögliches Resultat der kommenden Diskussion also einfach vorweg. ${ }^{8}$ Als Ersatz für Hilble bestimmte der Gemeindetag am 31. Mai den Nürnberger Stadtrat Plank. Ihn hatte man mit der Begründung ausgewählt, er gehe in den meisten Punkten mit den Münchner Ideen konform. Planks Ansichten kannte man in Berlin aus einer Stellungnahme, die jener dem Deutschen Gemeindetag ungebetenerweise nach Erhalt der Nachricht über die neue Tagesordnung des Wohlfahrtsaus-

über „jüdischen Empfängern von Arbeitslosenunterstützung“ anwenden; Akten der Partei-Kanzlei der NSDAP (im folg. AdP). Rekonstruktion eines verlorengegangenen Bestandes, hrsg. vom Institut für Zeitgeschichte. Bearbeiter Helmut Heiber/Peter Longerich, Mitarb. Volker Dahm u.a., München u.a. 1983, Teil I, Bd. 2 -Microfiche-, Nr. 10310313: RuPrMdI (Hering) an RArbM, StdF und RFM am 24. 3. 1937.

4 Vgl. Kapitel II. 2.

5 StA Hamburg, 351-10 Sozialbehörde I, VT 12.25, unfol.: RMdI an Martini am 24. 5. 1937; BA, R 36, Nr. 931, unfol.: Entwurf DGT/Abt. III an Martini und an Hilble am 22. 5. 1937 (abges. am 24. 5. 1937).

6 BA, R 36, Nr. 931, unfol.: Entwurf DGT/Abt. III an Ruppert und an Mitglieder des Wohlfahrtsausschusses am 22. 5. 1937 (abges. am 24. 5. 1937).

7 Ebenda: Entwurf DGT/Abt. III an Martini und an Hilble am 22.5.1937 (abges. am 24. 5. 1937).

8 YV Jerusalem, M1DN, Nr. 168, Bl.116-117: Stadt München an DGT (Schlüter) am 26. 5. 1937. 
schusses übermittelt hatte. ${ }^{9}$ Den als Berichterstatter bestellten Oskar Martini lud Ministerialrat Fritz Ruppert noch zusätzlich in das Reichsinnenministerium zu einer Vorverständigung "mit unserem Generalreferenten für die Judenfragen“, Ministerialrat Bernhard Lösener ${ }^{10}$, ein. Das Ministerium stellte hierfür vorab Material bereit. ${ }^{11}$ Martini erhielt auch die Münchner und Nürnberger Papiere. ${ }^{12}$

Die auf diese Weise gründlich vorbereitete Tagung des Wohlfahrtsausschusses des Deutschen Gemeindetages fand am 10. Juni 1937 in Heidelberg statt. ${ }^{13}$ Neben dem DGT-Vizepräsidenten Ralf Zeitler sowie Schlüter und Zengerling aus der DGT-Abteilung III nahmen Ruppert vom Reichsinnenministerium und der Fürsorgezuständige im Badischen Innenministerium, Oberregierungsrat Johannes Duntze ${ }^{14}$, teil. Unter den anwesenden Mitgliedern des Ausschusses, den Vertretern von Städten und Gemeinden, waren auch Fischer-Defoy (Frankfurt am Main) und Spiewok (Berlin). Als Gäste erschienen Stadtmedizinalrat Staatsrat Dr. Conti aus Berlin und Stadtrat Teutsch aus Leipzig. ${ }^{15}$ Die Referenten Martini und Plank eingeschlossen, trafen also ausgewiesene Hardliner der NS-Sozialpolitik in Heidelberg zusammen.

Martini hielt wie geplant das Referat über die „Behandlung der Juden in der öffentlichen Fürsorge". Er gab den Teilnehmern zunächst einen Überblick über die aktuelle „Rechtslage der Juden und Mischlinge“, sowohl generell wie auch speziell auf dem Gebiet der Sozialpolitik. Martini wies deutlich auf das Fehlen von Regelungen in der Fürsorge hin: Obwohl „bekanntlich in der Fürsorge sehr viel durch die Praxis, die ohne[hin] Leitgedanken aus den Grundanschauungen des nationalsozialistischen Staates zu entnehmen habe", geregelt werden könne, bleibe noch „eine Reihe von Fragen offen“, die "nur durch die Reichsgesetzgebung selbst oder entsprechende Ausführungsanweisungen der Reichsregierung

9 BA, R 36, Nr. 931, unfol.: Stadtrat Plank an DGT Berlin am 24. 5. 1937.

10 Geb. 27. 12. 1890 in Fürstenberg (Oder), ab April 1933-Ende 1942 im RMdI (seit Mitte 1933 Rassereferent für Judenfragen in Abt. I: Verfassung und Gesetzgebung). 1944-1945 verhaftet; vgl. Strauß, Walter: Das Reichsministerium des Innern und die Judengesetzgebung. Aufzeichnungen von Dr. Bernhard Lösener (Dokumentation), in: VfZ, 9 (1961), H. 3, S. 264-313.

11 StA Hamburg, 351-10 Sozialbehörde I, VT 12.25, unfol.: RMdI an Martini vom 24. 5. 1937.

12 Ebenda: Stadtrat Plank Nürnberg an DGT vom 24. 5. 1937; ebenda: Abschrift über die Verhältnisse in München (o. D.).

13 Vgl. kurz zu dieser Sitzung bereits Adam, Judenpolitik, S. 190-191; Gruner, Arbeitseinsatz, S. 33-35; Lohalm, Hamburgs öffentliche Fürsorge, S. 508. Erstmals ausführlicher analysiert bei Gruner, Fürsorge, S. 601-604.

14 Geb. 1901. Jurist, 1928-1934 Regierungsrat in Donaueschingen, 1934-1936 Landrat in Säckingen, ab 1936 im Badischen Innenministerium Referent für Fürsorge und Jugendwohlfahrt. Ab 1937 NSDAP-Mitglied. 1940-1946 Militärdienst und Gefangenschaft. Ab 1950 Ministerialrat für Fürsorge im württembergischen Innenministerium, 1958-1967 Leiter Sozialabteilung des Bundesinnenministeriums. Gestorben 1987.

15 Gäste außerdem Rechtsrat Amann (Heidelberg) und Bürgermeister Claes (Braunschweig); BA, R 36, Nr. 931, unfol.: Entwurf der Niederschrift über die Sitzung des DGTWohlfahrtsauschusses am 10.6.1937 in Heidelberg, vom 19. 10. 1937. Das am 25. 10.1937 verschickte Protokoll findet sich auch in: StadtA Göttingen, Sozialamt, Acc. Nr. 407/77, Nr. 47/1, unfol. Abdruck des Protokolls, in: Lohalm, Fürsorge und Verfolgung, Anhang, Dok. Nr. 1, S. 84-94. 
geordnet werden könnten". Nachdem er damit noch einmal klar die NS-Führung zur Verschärfung der antijüdischen Politik gedrängt hatte, verkündete er auch, wie das geschehen solle. Das NSDAP-Parteiprogramm fordere, Juden unter Fremdengesetzgebung zu stellen. Daraus ergebe sich, daß Juden künftig nin der Fürsorge im allgemeinen dem Ausländer gleichzustellen" seien. ${ }^{16}$

Martini zählte eine Reihe von Wohlfahrtsleistungen auf, von denen - dieser neuen Maxime folgend - die Juden in Zukunft ausgeklammert werden müßten: Die monatliche Barunterstützung sei „nach den für die Ausländerfürsorge geltenden Maßstäben" nur wie die Allgemeine Fürsorge zu bemessen. Gehobene Fürsorge solle damit wegfallen, ergänzende Leistungen aus der jüdischen Wohlfahrtspflege wären prinzipiell anzurechnen. Bei Sachleistungen müsse größte Zurückhaltung von den Wohlfahrtsämtern geübt werden. Krankenhilfe könne gezahlt werden, Wochenhilfe dagegen nicht. Hilfen zur Wiederherstellung der Erwerbsfähigkeit, Leistungen der vorbeugenden Gesundheitsfürsorge (Milchverbilligung, Kinderverschickung und Schulspeisung) sowie der Wirtschaftsfürsorge (Darlehen für Gewerbetreibende) seien zu streichen. Martini ließ Ausnahmen von dieser generellen Sperre zusätzlicher und aufbauender Hilfen nur bei Behinderten und Jugendlichen zu. Prinzipiell sei bei Juden „in der Praxis auf eine strenge und gründliche Prüfung der Hilfssbedürftigkeit " $z u$ achten. Jüdische Unterstützungsempfänger sollten von den lokalen Wohlfahrtsverbänden ausnahmslos in Pflichtarbeitsmaßnahmen eingegliedert werden. In „größeren Städten“ sei ihre Beschäftigung auf „Sonderarbeitsplätzen, die sich z.B. in Hamburg bewährt hätten, vorgesehen". Nach der Aufzählung der Leistungskürzungen ging er damit zum Thema der Separierung der jüdischen Armen über: In der Geschlossenen Fürsorge dürften Behinderte und Sieche nur noch in jüdischen Anstalten untergebracht werden, ebenso in der Fürsorgeerziehung die jüdischen Kinder und Jugendlichen. In der Jugendfürsorge plane man, die Amtsvormundschaft der Jugendämter durch Berufung jüdischer Einzelvormünder zu ersetzen, die „Schutzaufsicht" gefährdeter Jugendlicher grundsätzlich auf die Jüdischen Gemeinden und die Pflege jüdischer Kinder jüdischen Familien zu übertragen. Obwohl manche Wohlfahrtsämter gedrängt hätten, an jüdische Arme abgegebene öffentliche Leistungen zurückzufordern, sollten sie von der Befreiung der Rückerstattung nicht ausgeschlossen werden, denn letztere gelte nur rückwirkend und selbst für „Asoziale“. Martini schloß seine Proklamation einer „Rassentrennung“ im Fürsorgewesen mit dem Appell, daß der gewünschte Sonderstatus der Juden durch Ministerialerlasse zentral geregelt und vereinheitlicht werden solle, da „die Praxis schon an den meisten Orten das, was vorstehend angeregt sei“, allerdings bislang spontan und uneinheitlich realisiert habe. ${ }^{17}$

Die aktuelle Situation wurde allen Tagungsteilnehmern noch einmal deutlich am Koreferat von Stadtrat Plank über die Praxis in Nürnberg vor Augen geführt. Ohne legale Grundlage kürzte die Stadt Leistungen bei jüdischen Armen inzwischen sowohl in der Allgemeinen, in der Gehobenen als auch in der Kleinrentnerfürsorge pauschal um 20 Prozent mit dem zynischen Argument, daß in allen Fäl-

16 Ebenda, S. 86.

17 Ebenda, S. 87-90. 
len noch Vermögensreste bzw. Hilfen der Jüdischen Gemeinde „in Frage kommen". ${ }^{18}$ Schlüter von der DGT-Sozialabteilung bat die Anwesenden danach explizit, in der Diskussion auf die Vorschläge der Referenten zur „Änderung der gesetzlichen Bestimmungen“ näher einzugehen, insbesondere ob bei der „Behandlung der Juden grundsätzlich von der Behandlung der Ausländer" ausgegangen werden solle. An den folgenden Beiträgen weiterer Tagungsteilnehmer wurde noch einmal plastisch, welch unterschiedlichen Wege der Diskriminierung und Separierung die städtischen Wohlfahrtsbehörden bislang beschritten hatten: Kürzte Nürnberg bei allen jüdischen Armen, so Frankfurt am Main "nur" bei Zugewanderten. Berlin dagegen gewährte noch alle gesetzlichen, sperrte aber alle zusätzlichen Leistungen. Bezeichnenderweise erklärte Berlin „arische“ Untermieter von Juden als "asozial" und verweigerte ihnen die Sozialunterstützung. Berlin verlangte außerdem von jüdischen Hilfeempfängern generell unbezahlte Pflichtarbeit in isolierten Kolonnen. Leipzig zahlte eine Unterstützung ebenfalls nur gegen Ableistung von Pflichtarbeit. Auch über die Formen der "Arisierung" von mildtätigen Stiftungen wurde auf der Tagung gesprochen. Die Teilnehmer erfuhren, welcher Mittel und Tricks sich dabei die Kommunen Essen bzw. Frankfurt am Main bedienten. Hatte Plank berichtet, daß Juden aus Nürnberger Altenheimen ausgeschlossen seien, so schlug Dr. Rudolf Hartmann ${ }^{19}$ aus Hannover schließlich für die Geschlossene Fürsorge generell noch vor, alle derzeit in Anstalten lebenden Juden in einer separaten Einrichtung im Reich zusammenzufassen. ${ }^{20}$

Die radikalen Vorschläge sowie die in unterschiedlichem Maße vorangetriebene Ausgrenzung in der kommunalen Praxis veranlaßten Ministerialrat Ruppert (Reichsinnenministerium), abschließend noch einmal zu betonen, daß eine gesetzliche Vereinheitlichung der Diskriminierung der Juden in der Öffentlichen Fürsorge dringend notwendig sei. Er bat die Kommunalbeamten und den Deutschen Gemeindetag mit einer Material- und Ideensammlung in den Städten diese zentrale Maßnahme vorzubereiten. Wahrscheinlich, so Ruppert, sei eine Gleichstellung der Juden mit den Ausländern in der Fürsorgebehandlung die „zweckmäßigste" Methode. ${ }^{21}$

Die DGT-Beamten, Ministerialvertreter und Leiter der städtischen Wohlfahrtsämter wußten durch die Tagung des Wohlfahrtsausschusses nun im Detail Bescheid über Stand und die Methoden lokaler Diskriminierung und Separierung in der Offenen wie in der Geschlossenen Fürsorge. Die Tagung hatte eine Multiplikatorfunktion ersten Ranges, da die Mitglieder des Ausschusses zugleich auch Vorsitzende der regionalen Arbeitsgemeinschaften für Wohlfahrtspflege waren. Konsens bestand offensichtlich über das Vorhaben, die Ausgrenzung der jüdischen Armen deutlich zu forcieren. Die zentrale Ebene hatte durch die Sitzung

${ }^{18}$ Ebenda, S. 91. Das erst im Oktober gefertigte Tagungsprotokoll stützte sich offenbar stark auf die Ausarbeitungen der Teilnehmer. Vgl. mit fast identischem Wortlaut wie Tagungsprotokoll: BA, R 36, Nr. 931, unfol.: Stadtrat Plank an DGT Berlin am 24. 5. 1937.

19 Geb. 1880, gest. 1956.

20 Lohalm, Fürsorge und Verfolgung, Anhang, Dok. Nr. 1, S. 91-94.

21 Ebenda, S. 94. 
zudem einen deutlichen Impuls für eine generelle Neukonzeption auf dem Wohlfahrtssektor erhalten.

\section{Fürsorgeerziebung, Adoptionen, Pflegschaften: Diskussionen im Gemeindetag}

Die Tagung in Heidelberg hatte zudem in einigen Teilbereichen für "Fortschritte“ in der Ausgrenzungsdiskussion gesorgt. Die Einführung der "Rassentrennung“ in der Fürsorgeerziehung und im Vormundschaftswesen diskutierten Fürsorgebehörden und Deutscher Gemeindetag bereits seit Jahren, auch mit der Ministerialebene. Diese Debatte sollte sich nun 1937 wieder intensivieren, allerdings nicht mehr ausschließlich gegen jüdische Jugendliche gerichtet.

Anfang Dezember 1936 hatte der Oberpräsident der Rheinprovinz/Fürsorgeerziehungsbehörde auf eine Anfrage des Deutschen Gemeindetages wegen der Fürsorgeerziehung für einen „Negermischling" hin generalisierend festgestellt: „Hier hat die Frage der Arbeitsbeschaffung für nicht deutschblütige Jugendliche und ihrer evtl. zwangsweisen Unterbringung bisher noch nicht zu Schwierigkeiten geführt. Die Rheinische Provinzialverwaltung besitzt und kennt keine besonderen Anstalten oder Lager, in denen solche Jugendliche getrennt untergebracht sind. “ Allerdings, so der Oberpräsident, müsse das Problem der Arbeitsbeschaffung „nichtdeutschblütiger, insbesondere jüdischer und Zigeuner-abstämmlinge, [...] zentral gelöst werden".22 Diese Initiative nahm der Deutsche Gemeindetag zum Anlaß, „die Frage der Arbeitsbeschaffung und Unterbringung nicht deutschblütiger [...] Jugendlicher [...] im Reichs- und Preußischen Ministerium des Innern zur Sprache zu bringen“. ${ }^{23}$ Wie allerdings eine Aussprache von Zengerling mit dem zuständigen Sachbearbeiter im Ministerium am 25. Februar 1937 ergab, war wegen der geringen Zahl in Betracht kommender Fälle eine zentrale Regelung nicht geplant. ${ }^{24} \mathrm{Bei}$ den jüdischen Minderjährigen handelte es sich offenbar reichsweit um ca. 100 Fälle in Fürsorgeerziehung, die zur Hälfte in Heimen und Familien lebten. ${ }^{25}$ Die Kommunen waren anderer Auffassung. Das Thema spielte im Juni 1937 in Heidelberg eine prominente Rolle. Martini hatte grundsätzlich dafür plädiert, die Fürsorgerziehung jüdischer Jugendlicher nur noch in jüdischen Anstalten zu organisieren, außerdem statt der Amtsvormundschaft für uneheliche Kinder die Jüdischen Kultusgemeinden die Vormünder bestellen zu lassen. In Nürnberg war letzteres längst Praxis. ${ }^{26}$ Nach einer nochmaligen Rücksprache

22 Hervorhebung im Original; BA, R 36, Nr. 1442, Bl. 41: OP/Fürsorgeerziehungsbehörde Düsseldorf an DGT am 8. 12. 1936.

23 Ebenda, Bl, 43 u. RS: DGT/Abt. III an OB Königsberg am 15. 12. 1936.

24 Ebenda, Bl. 43RS: Handschriftl. Vermerk Zengerling (DGT/Abt. III) vom 25. 2.1937 auf Schreiben an OB Königsberg am 15. 12. 1936.

25 Ende März 1938 gab es nach amtlicher Statistik lediglich 95 jüdische Minderjährige in Fürsorgeerziehung, davon 48 in Heimen und 47 in Familien. Zwei jüdische Anstalten standen zur Verfügung, das Jüdische Jugendwohnheim in Berlin-Pankow und das Heim des Jüdischen Frauenbundes Neu-Isenburg in Hessen; Zahlen nach BA, R 22, Nr. 1915, B1. $244 \mathrm{u}$. RS: RMdI an RJM am 21. 2. 1939; vgl. auch BA, R 18, Nr. 5644, Bl. 243-244: Runderlaß RMdI/NW (Pfundtner) vom 21.7. 1939.

26 Lohalm, Fürsorge und Verfolgung, Anhang, Dok. Nr. 1, S. 87-91. 
Zengerlings mit dem Ministerium erfolgte zumindest für die Gruppe der „Negermischlinge" eine Regelung per Geheimerlaß im September 1937.27

Für das bereits in den Jahren zuvor stark ventilierte Thema der „Rassentrennung" bei Pflegschaften wurden verstärkt ebenfalls einheitliche Richtlinien verlangt. Im November 1936 hatte Reichsstatthalter Fritz Sauckel bereits für Thüringen angeordnet, daß „vierteljüdische“ Pflegekinder bei „arischen“ Eltern, „halbjüdische" Pflegekinder jedoch bei jüdischen oder „halbjüdischen“ Familien untergebracht werden. ${ }^{28}$ Das Jugendamt Sorau sondierte wenig später beim Deutschen Gemeindetag, ob „einem deutschblütigen Reichsangehörigen zugemutet werden“ könne, als Pfleger für jüdische Minderjährige bestellt zu werden, und ob nicht Bedenken existierten, daß ein Jugendamt einen jüdischen Pfleger bestimme und damit „einen Juden für ein öffentliches Vertrauensamt" vorschlage. Das Jugendamt bat um Aufklärung, inwieweit diese Frage aufgrund von vergleichbaren Vorgängen in anderen Städten bereits geklärt sei. Wenn nicht, solle wegen der "grundsätzlichen Bedeutung der Angelegenheit" eine zentrale Klärung herbeigeführt werden. 29

Den „Nürnberger Gesetzen“ folgend, reformierte der Reichsminister des Innern am 6. August 1937 jedoch zunächst das Verfahren bei Kindesadoptionen in rassistischem Sinne. Bisher galt ein Runderlaß vom Dezember 1933, nach dem höhere Verwaltungsbehörden gerichtlichen Verträgen zur Kindesannahme widersprechen sollten, wenn ein Vertragsteil „Arier" und der andere „Nichtarier" oder mit einem Nichtarier verheiratet war. ${ }^{30}$ Jetzt hieß es viel rigider: Bei Juden bzw. einem mit einem Juden verheirateten Vertragspartner auf der einen und deutschblütigen bzw. "Mischlingen II. Grades" auf der anderen Seite seien Adoptionen grundsätzlich abzulehnen. Bei Verträgen zwischen „Mischlingen I. Grades“ und Deutschblütigen bzw. „Mischlingen II. Grades“ behielt sich der Minister die Entscheidung persönlich vor. ${ }^{31}$

Diese Prämissen sollten aber auch auf die Praxis bei Pflegschaften angewendet werden. Nachdem sich das Kreisjugendamt Sorau erneut beim Gemeindetag erkundigt hatte, erhielt es Anfang September 1937 aus Berlin die Nachricht, daß die "mit dem Judenproblem zusammenhängenden Fragen" von den zuständigen Stellen noch bearbeitet würden. Obwohl der Gemeindetag bei Pflegschaften von Juden über jüdische Kinder keine Hindernisse vermute, habe er trotzdem das Ministerium noch einmal um Klärung gebeten. ${ }^{32}$

27 Der Erlaß lag dem Autor nicht vor, ist aber erwähnt in: BA, R 36, Nr. 1442, Bl. 47: Handschriftl. Vermerk Zengerling (DGT/Abt. III) vom 9. 9.1937 auf Schreiben DGT/Abt. III an DGT Hessen-Nassau am 10. 5. 1937.

28 Noakes, Development, S. 337.

29 BA, R 36, Nr. 1442, Bl. 48 u. RS: Kreisjugendamt Sorau an DGT am 28. 7. 1937.

30 RMinBliV, 1933 I, S. 1473.

31 RMinBliV, 1937 I, S. 1345. Der Erlaß reagierte auf Eingaben des Regierenden Bürgermeisters in Bremen vom 1.6. 1937 sowie des Oberpräsidenten der Provinz Brandenburg vom 30. 11. 1935; ebenda, S. 1348.

32 BA, R 36, Nr. 1442, Bl. 48 u. RS: DGT/Abt. I (Dr. Schöne) an Kreisjugendamt Sorau am 2. 9. 1937; vgl. ebenda, Bl. 50: DGT/Abt. III an RuPrMdI am 5. 9. 1937. 


\section{Die DGT-Umfrage zur „Behandlung “ jüdischer Kranker in städtischen Anstalten}

Schon seit Sommer 1936 hatten die öffentlichen Anstalten in Hamburg begonnen, sämtliche jüdischen Insassen in einem Heim der Anstalt Farmsen zu konzentrieren. ${ }^{33}$ Auch einige private Heil- und Pflegeeinrichtungen lehnten 1937 die Aufnahme von jüdischen Patienten ab, da sie steuerliche Nachteile befürchteten. Ein Beispiel stellten die Alsterdorfer Anstalten in Hamburg dar. ${ }^{34}$ Dort untergebrachte jüdische Insassen entließ man nach und nach..$^{35}$ Der Leiter der Anstalten überzeugte die Hamburger Sozialverwaltung, jüdische Behinderte nur noch in staatliche Einrichtungen einzuweisen. ${ }^{36}$ Die staatlichen Wohlfahrtsanstalten Hamburgs nahmen daraufhin die Mehrzahl der jüdischen Patienten auf. ${ }^{37}$

1935/36 hatte der Deutsche Gemeindetag vermehrt Anträge von Kommunen erhalten, die auf zentrale Weisungen zur Aufnahme und Behandlung von jüdischen Patienten in städtischen Hospitälern drängten. ${ }^{38}$ Der Gemeindetag hatte dieses Thema deshalb in seine allgemeine Anfrage beim Reichsinnenministerium eingebunden, wie in Zukunft mit Juden in städtischen Einrichtungen zu verfahren sei. ${ }^{39} \mathrm{Im}$ April 1937 erkundigte sich auch das Gesundheits- und Wirtschaftsamt Nürnberg in einer umfassenden, mehrteiligen Anfrage beim Gemeindetag nach der aktuellen Praxis der "Aufnahme und Behandlung von Juden" in städtischen Krankenhäusern. ${ }^{40} \mathrm{Da}$ eine Antwort aus dem Ministerium zu diesem Thema noch immer ausstand, folgte die Hauptabteilung III in Berlin der Nürnberger Anregung und veranstaltete am 14. April eine Umfrage bei mehreren Großstädten über vorhandene Beschränkungen bei der Aufnahme bzw. Unterbringung jüdischer Patienten. ${ }^{41}$

Offenbar direkt auf diese Umfrage des Deutschen Gemeindetages reagierend, entschied der Oberbürgermeister in Köln am 11. Mai 1937, „daß jüdische Kranke und jüdische Wohlfahrtsempfänger, die in einem Krankenhaus behandelt werden müssen, nicht mehr an städtische Krankenanstalten, sondern nur noch an das Israelitische Asyl überwiesen werden dürfen". ${ }^{42}$ Nur in Notfällen nahm man künf-

\footnotetext{
33 Lohalm, Fürsorge und Verfolgung, S. 36.

34 Die Anstalt berief sich auf ein Urteil des Reichsfinanzhofs im März 1937, mit dem dieser entschieden habe, gemeinnützigen Einrichtungen, die Juden zugute kamen, steuerliche Begünstigungen zu streichen; Friedlander, Der Weg zum NS-Genozid, S. 424. Dieses Urteil konnte ich bisher nicht finden. Allerdings gab es seit 1936 die schon erwähnte Rechtsprechung des Reichsfinanzhofes, der Einrichtungen, die Juden zugute kamen, Steuererleichterungen absprach; vgl. Kapitel II. 1.

35 Lohalm, Fürsorge und Verfolgung, S. 36.

36 Friedlander, Der Weg zum Genozid, S. 425.

37 Lohalm, Fürsorge und Verfolgung, S. 36.

38 Vgl. LA Berlin, Rep. 142/7, 3-10-11/Nr. 72, unfol.; vgl. Kapitel II. 1.

39 Vgl. Kapitel II. 2.

40 LA Berlin, Rep. 142/7, 3-10-11/Nr. 72, unfol: OB Nürnberg an DGT Berlin am 8. 4. 1937.

41 Ebenda: Ergebnis der DGT-Umfrage vom 14. 4., vom 21. 5. 1937.

42 Vfg. des Beigeordneten des Gesundheitswesens vom 11.5.1937; zit. nach Jüdisches Schicksal in Köln 1918-1945. Katalog zur Ausstellung des Historischen Archivs der Stadt Köln/NS-Dokumentationszentrum, Red. Horst Matzerath, Köln (1989), S. 204.
} 
tig noch Juden in städtischen Hospitälern auf. Bei eintretender Transportfähigkeit verlegte Köln diese Patienten unverzüglich in eine nichtstädtische Anstalt. ${ }^{43}$

Die Umfrageergebnisse vom Frühsommer 1937 demonstrieren, wie schon so oft, ein sehr unterschiedliches Vorgehen in den Kommunen: Dortmund, Frankfurt am Main und Leipzig nahmen jüdische Patienten für eine stationäre Betreuung weiterhin in ihre Anstalten auf. Alle drei wiesen aber darauf hin, daß jüdische Kranke meist konfessionelle bzw. jüdische Einrichtungen bevorzugten. In München konnten, wenn Raummangel herrschte, Juden bis auf Fälle von Lebens- oder Ansteckungsgefahr abgewiesen werden. In Breslau gab es in zwei Krankenhäusern (TBC und Nervenkranke) keine Beschränkungen, in den anderen wurden nur noch vom Fürsorgeamt betreute Juden zugelassen. In der ambulanten Versorgung akzeptierte die Stadt generell nur noch Juden, die städtische Wohlfahrtsleistungen erhielten, während Dortmund, Frankfurt am Main, Leipzig und München hier noch keine Ausnahmevorschriften kannten. Zur Absonderung jüdischer Patienten hieß es: In Breslau isoliere man jüdische Kranke, allerdings gebe es keine grundsätzliche Unterbringung in Einzelzimmern, da dies eine Bevorzugung gegenüber den „arischen“ Patienten bedeute. In München war eine getrennte Unterbringung vorgeschrieben. In Dortmund nahm man jüdische Kranke nur in die allgemeine Abteilung auf. Wohlfahrtspatienten isolierte man in jedem Fall, Privatpatienten kamen in Einzelzimmer. In den Krankenhäusern Frankfurts am Main separierte man Juden, wenn dies von nichtjüdischen Patienten gewünscht wurde. Falls keine Entlassung möglich sei, würden sie in Einzelzimmern untergebracht. Nur in Leipzig verzichtete man bisher auf eine Absonderung. ${ }^{44}$

Das Umfrageergebnis zeigt, daß die Diskriminierung jüdischer Patienten bereits verbreitet war, entweder durch Aufnahmeverweigerung oder Isolierung. Nur für Wohlfahrtspatienten, d.h. Kranke, die von der öffentlichen Hand finanziell unterstützt wurden, galten keine Aufnahmebeschränkungen, doch auch sie wurden in einigen Fällen in den Krankenhäusern separiert. Die Frage der Isolierung jüdischer Patienten in öffentlichen Anstalten spielte dann kurze Zeit später auch eine Rolle auf der oben bereits angesprochenen Heidelberger Tagung des Gemeindetages. Stadtmedizinalrat Conti berichtete dort, daß in mehreren Berliner Krankenhäusern separate Stationen für Juden eingerichtet worden seien, was zu Problemen mit „arischen“ Pflegern und Schwestern geführt habe. ${ }^{45}$ Danach fanden aber offenbar keine weiteren Verhandlungen im Deutschen Gemeindetag zu diesem Thema statt. Ohnehin herrschte Konsens über eine ausgrenzende „Behandlung " jüdischer Patienten in städtischen Hospitälern, außerdem wartete man weiter auf eine das unterschiedliche Vorgehen vereinheitlichende Weisung des Reichsinnenministeriums. Doch auf der zentralen Ebene war man sich noch nicht einig, mit welchen Mitteln und Methoden die Verfolgung der Juden vorangetrieben werden sollte und welche Gebiete dabei Vorrang haben würden.

43 LA Berlin, Rep. 142/7, 3-10-11/Nr. 72, unfol.: OB Köln an DGT Berlin am 4. 6. 1937.

44 Ebenda: Ergebnis der DGT-Umfrage vom 14. 4., vom 21. 5. 1937, S. 1-6.

45 Lohalm, Fürsorge und Verfolgung, Anhang, Dok. Nr. 1, S. 93. 


\section{Die Radikalisierung der Verfolgung (Herbst 1937 - Frühjahr 1938)}

\section{Zentrale Planung und antijüdische Kommunalpolitik}

Das Hauptziel und zugleich Grundproblem der antijüdischen Politik blieb die Vertreibung. Das Problem der wachsenden Verarmung der jüdischen Bevölkerung und der damit verbundenen Abhängigkeit von öffentlichen Mitteln beschäftigte die NS-Verantwortlichen immer stärker. Auf einer Besprechung, die am 18. Oktober 1937 im Reichsinnenministerium stattfand, stellten die Anwesenden einen "starke[n] Rückgang der jüdischen Auswanderung" fest, obwohl 105000 Juden bereits bis zu diesem Zeitpunkt emigriert waren. Die Vertreter verschiedener Ministerien, des Hauptamtes Sicherheitspolizei und der Behörde des Stellvertreters des Führers wollten deshalb gemeinsam darauf hinwirken, „den Auswanderungswillen der Juden in Deutschland durch innenpolitische Maßnahmen zu erhalten". Die Kehrseiten einer solch verschärften antijüdischen Politik sahen die Ministerialvertreter auf der Sitzung allerdings sehr deutlich: Noch mehr Repressalien würden „in erster Linie die reichen Juden zur Auswanderung bringen [...], während die nicht vermögenden Juden in noch größerem Umfange als bisher der Fürsorge zur Last fallen" ${ }^{46}$ Zuvor hatte man in den Ministerien schon Zwangsmaßnahmen als Ausweg diskutiert. Die „Auswanderung mittelloser Juden“ solle durch Zuschüsse zu den Reisekosten gefördert werden, die man „wohlhabende[n] Zionisten" abverlangen wollte. Diese Vorschläge stellte man jedoch auf Anraten des Stellvertreters des Führers zugunsten eines Gesamtplans für die Bildung eines „jüdischen Sondervermögens zur Förderung der Auswanderung minderbemittelter Juden" zurück. ${ }^{47}$

Die Vorbereitung der Annexion Österreichs radikalisierte die Überlegungen in der NS-Führung zusätzlich. Eine Reihe lange diskutierter antijüdischer Gesetzesvorhaben sollte deshalb beschleunigt in die Tat umgesetzt werden. Das Wirtschaftsministerium, von Göring im Zusammenhang mit den Personalveränderungen in Militär und Regierung als Interim übernommen, betrieb nun zentral die bisher weitgehend lokal praktizierte Verdrängung der Juden aus Wirtschaft und Gewerbe ${ }^{48}$, das Innenministerium bereitete ihre Stigmatisierung mit Zwangsnamen, die Kennzeichnung ihrer Betriebe sowie Berufsverbote für jüdische Ärzte und Juristen vor ${ }^{49}$, das Propagandaministerium entwarf in Hitlers

46 BA, 21.01, Nr. B 6269, Bl. 65-67: Vermerk des RuPrMdI über Sitzung vom 28. 10. 1937.

47 StdF an RArbM am 19. 7. 1937; zit. in: AdP, Teil I, Bd. 2 -Microfiche-, Nr. 10310344-45: RArbM an RFM und RuPrMdI am 21.8. 1937.

48 Diese Entwicklung seit Herbst 1937 ist ausführlich dargestellt bei Genschel, Helmut: Die Verdrängung der Juden aus der Wirtschaft im Dritten Reich, Göttingen u.a. 1966, S. 140176. Vgl. zum folgenden auch Adam, Judenpolitik, S. 172-177; Longerich, Politik der Vernichtung, S. 155-160.

49 BA, R 18, Nr. 5519, Bl. 3: Schnellbrief RMdI (Entwurf) vom Januar 1938; außerdem RGBl., 1938 I, S. 9; AdP, Teil I, Bd. 1 -Microfiche-, Nr. 10113867/1-7: Pfundtner (RMdI) an Lammers am 18. 12. 1937. 
Auftrag ein Besuchsverbot „deutsche[r] Theater- und Kulturveranstaltungen “ für Juden. ${ }^{50}$

Auch die Kommunen verschärften ihre Ausschluß- und Separierungsbestimmungen. Allein in der Messestadt Leipzig galten zu Beginn des Jahres 1938 über ein Dutzend antijüdische Bestimmungen, die Reichsmaßnahmen vorgriffen. Neben Benutzungsbeschränkungen in städtischen Bädern und den Restriktionen in der städtischen Wohlfahrt zählte dazu das Verbot jeglicher Geschäftstätigkeit städtischer Stellen mit Juden. Land wurde an diese nicht mehr verpachtet, auf Schlachthöfen und in der Mitteldeutschen Börse war die Tätigkeit jüdischer Händler untersagt, auf Messen und Märkten beschränkt. Juden durften das Leihhaus und die städtischen Bücherhallen nicht betreten, ihre Kinder nicht an der Kinderspeisung teilnehmen. Leipzigs Behörden bereiteten im Frühjahr 1938 die Isolierung jüdischer Schüler in einer geräumten katholischen Volksschule ebenso vor wie die Erfassung aller jüdischen Geschäftsinhaber in stadteigenen Häusern und ein Verbot „jüdischer" Gaststätten. ${ }^{51}$

Die Wirkung der geplanten Gesetze wie der lokalen Maßnahmen mochte zwar den Druck für den einzelnen erhöhen, das die Emigration behindernde Problem der Pauperisierung großer Teile der jüdischen Bevölkerung entschärfte es nicht, im Gegenteil. Schon die Verfolgung während der beiden Jahre nach den „Nürnberger Gesetzen" hatte die wirtschaftlichen und sozialen Grundlagen der jüdischen Minderheit weiter stark angegriffen. ${ }^{52}$ Durch permanente "Arisierungen“ in vielen Orten und systematische Behinderungen der Gewerbetätigkeit durch Kommunen ${ }^{53}$ war der jüdische Mittelstand gezwungen, Geschäfte und Firmen zu verkaufen..$^{54}$ Bis 1937 hatte sich so die Zahl der jüdischen Einzelhändler im Reich gegenüber 1933 halbiert. ${ }^{55}$ Die meist geringen Erlöse reichten oft nicht aus, neue Existenzen zu gründen.

Man war sich auf der Ministerialebene allerdings einig, daß zuerst die Emigration der jüdischen Armen mit allen Mitteln gefördert werden müsse. Diese Auffassung vertrat auch der Sicherheitsdienst der SS, der mehr und mehr eine strategische Perspektive in der antijüdischen Politik einzunehmen begann: Die Vertreibung armer Juden war das Ziel, auf welches der SD die "gesamte Judenpolitik“ eingeschworen wissen wollte. ${ }^{56}$ Die Judenreferate von SD und Gestapo diskutierten bereits Anfang 1938 gemeinsam die sozialen Folgen der neuen radikalen Poli-

50 Goebbels, Joseph: Die Tagebücher des Joseph Goebbels. Sämtliche Fragmente, hrsg. von Elke Fröhlich im Auftrag des Instituts für Zeitgeschichte und in Verbindung mit dem Bundesarchiv, Teil I: Aufzeichnungen 1924-1941, Bd. 3, München u. a. 1987, S. 346: Eintrag vom 26. 11. 1937.

51 Gruner, NS-Judenverfolgung und die Kommunen, S. 98-106.

52 Arbeitsbericht der Reichsvertretung der Juden in Deutschland für das Jahr 1937, (Berlin 1938), S. 68-70. Vgl. allgemein zu diesem Prozeß Vollnhals, Selbsthilfe sowie Barkai, Boykott.

53 Vgl. Darstellung am Beispiel der Markthändler Gruner, Deutscher Gemeindetag, S. 267274.

54 Arbeitsbericht der Reichsvertretung der Juden in Deutschland für das Jahr 1937, (Berlin 1938), S. 66.

55 Barkai, Boykott, S. 122-124.

56 Gruner, NS-Judenverfolgung und die Kommunen, S. 98-99. 
tik, denn sie befürchteten eine weiter steigende Inanspruchnahme der Öffentlichen Fürsorge. ${ }^{57} \mathrm{Um}$ auf lange Sicht Wohlfahrtskosten zu sparen, beabsichtigte deshalb das Geheime Staatspolizeiamt Berlin, den Fürsorgebehörden zu empfehlen, einmalige Beihilfen an vor der Emigration stehende jüdische Wohlfahrtsempfänger zu zahlen. Diese Zahlungen sollten bis zum sechsfachen der monatlichen Unterstützung betragen. Die kurzfristig höheren Ausgaben rechneten sich für Wohlfahrtsämter durchaus angesichts der langfristigen Ersparnis nach dem Ausscheiden aus der Öffentlichen Fürsorge durch die Emigration. ${ }^{58}$

Doch gerade Lokalbeamte teilten die strategischen Besorgnisse regionaler bzw. zentraler Behörden oft nicht, daß zu viel Repression die Armut verstärke und diese wiederum die Vertreibung behindere. Das kann folgendes Beispiel illustrieren: Viele Juden, die Geschäfte oder Posten verloren, fanden die einzige Möglichkeit eines eigenständigen Erwerbs im Vertretergewerbe. Die Warnung des Oberpräsidenten in Sachsen, daß bei Ablehnung eines Gewerbescheins Juden dem Reich zur Last fallen würden, fegte der Polizeipräsident in Magdeburg 1937 mit der Bemerkung vom Tisch: „So etwas liegt dem Juden nicht, und die jüdische Gemeinde sorgt bestimmt für ihre Mitglieder. Die Gefahr der Inanspruchnahme öffentlicher Mittel besteht daher nach meiner Auffassung und Beobachtung nicht. Sollte diese Gefahr aber wirklich eintreten, so wird es meiner Meinung nach immer noch besser sein, dem Juden durch ein schärferes Anfassen den Aufenthalt im deutschen Reich unbequem zu machen, als durch eine milde Handhabung der Bestimmungen die öffentliche Sicherheit und Ordnung einer Gefahr auszusetzen. " 59

Wird hier zum einen sehr deutlich, wie weit Wahrnehmungen bzw. Interessen der zentralen, regionalen und lokalen Ebene, aber auch verschiedener Institutionen, ob Polizei oder Kommune, auseinanderklaffen konnten, so läßt sich zum anderen ablesen, mit welchen Mitteln und Methoden man die sozialen Folgen der eigenen antijüdischen Politik in den Griff bekommen wollte. Beides verdeutlicht erneut den Gestaltungsspielraum, der sich den beteiligten Behörden - auch auf dem Fürsorgesektor - bot.

\section{Der Gemeindetag und die rassistische Revision der Fürsorge-Richtsätze}

Obwohl Mitte November 1937 Ruppert (RMdI) und Zengerling (DGT) noch einmal in einer Unterredung den zentralen Plan, deutsche Juden durch Gleichstellung mit Ausländern im allgemeinen Fürsorgerecht zu deklassieren, bekräftigten, sollte es weiter zu keiner zentralen Regelung kommen. Ungeachtet des wiederholt geäußerten, eigenen Interesses an der Ausgrenzung der jüdischen Armen unternahm das Reichsinnenministerium zunächst nichts, denn es wollte dieses Vorha-

57 YV Jerusalem, 051/OSOBI, Nr. 2 (500-3-315), Bl. 206: Vermerk SD-Judenreferat über Sitzung am 10.1.1938.

58 Sauer, Verfolgung, Teil II, Nr. 372, S. 131: Runderlaß Gestapa Berlin in Erlaß der Stapo(leit)stelle Stuttgart vom 26. 1. 1938. Zu Frankfurt vgl. Dokumente Frankfurter Juden, VI 25, S. 293: Bericht Bergel.

59 LHA-SA Magdeburg, C 20 Ib, Nr. 2523 IV, Bl. 165: Polizeipräsident in Magdeburg (i.V. Rumstieg) an Regierungspräsident in Magdeburg am 5. 4. 1937. 
ben in eine umfassende, nationalsozialistische "Neuordnung " des gesamten Fürsorgesystems einbinden. ${ }^{60}$

Im Deutschen Gemeindetag wollte man darauf nicht warten und gründete kurz darauf einen speziellen Unterausschuß seines Wohlfahrtsausschusses, um grundsätzliche Fragen der Reorganisation des Fürsorgewesens von Wohlfahrts- und Finanzspezialisten diskutieren zu lassen. ${ }^{61}$ Man befürchtete das Versanden der Gesetzesinitiative auf dem Instanzenweg, deshalb wollte man dieses bürokratische Verfahren auf elegante Weise umgehen. Die Deutsche Arbeitsfront hatte mit Bezug auf die verbesserte wirtschaftliche Lage gerade wegen zu niedriger FürsorgeRichtsätze ${ }^{62}$ sowohl beim Gemeindetag wie beim Stellvertreter des Führers interveniert. ${ }^{63} \mathrm{Nach}$ der Reichsfürsorgeverordnung stellten die Fürsorgeverbände zur Bemessung des notwendigen Bedarfs der von ihnen zu versorgenden Armen Richtsätze unter Einrechnung der lokalen Lebenshaltungskosten auf. Für einzelne Regionen stand nun eine Anhebung der Richtsätze in Aussicht. Diese Veränderung sollte als Hebel für eine informelle Diskriminierung genutzt werden.

Auf der Sitzung des DGT-Wohlfahrtsausschusses am 13. Januar 1938 in Berlin wurde genau dies erörtert. Vizepräsident Zeitler eröffnete den Mitgliedern und Gästen, den Vertretern von Gemeindetag und Reichsinnenministerium zunächst aber, daß wenige Tage zuvor der „Entwurf eines Wandererfürsorgegesetzes im Kreise von Sachverständigen im Ministerium des Innern besprochen [worden sei]. $\mathrm{Da}$ dieses Gesetz ein Teilproblem der Asozial[en]frage lösen wolle, sei damit zu rechnen, daß in baldiger Frist auch die übrigen für eine zweckmäßige Behandlung der Asozialen notwendigen Gesetze: Ergänzung der R[eichsfürsorgeverordnung] und Bewahrungsgesetz folgen würden" ${ }^{64}$ Danach berieten die Teilnehmer einen von der Deutschen Arbeitsfront vorgelegten Entwurf für eine Neugestaltung der Fürsorge-Richtsätze. Martini (Hamburg) kritisierte, daß - abgesehen von der finanziellen Mehrbelastung durch eine generelle Anhebung der Richtsätze - noch eine Reihe „schwerwiegender anderer Bedenken“ bleibe. Er unterbreitete folgenden grundsätzlichen Vorschlag: „Wenn die heutige Wohlfahrtspflege den Grundsätzen der nationalsozialistischen Weltanschauung Rechnung tragen will, so kann sie Art und Maß der Leistung nicht mehr nach der auf äußerliche Merkmale abgestellten Zugehörigkeit zu dieser oder jener Gruppe von Hilfsbedürftigen ableiten, sondern sie muß von dem völkischen, biologischen und sozialen Wert des Einzelnen ausgehen." Martini plädierte dafür, künftig zwei Gruppen von Unterstützungsempfängern zu bilden: „Die erste Gruppe würde die sogenannte aufbauende

60 Vermerk Zengerling (DGT) über Besprechung mit RMdI am 12.11.1937; nach Adam, Judenpolitik, S. 192. Vgl. AdP, Teil I, Bd. 2 -Microfiche-, Nr. 10312468: RMdI-Schreiben vom 16. 8. 1938.

61 DGT/Abt. III Rundschreiben vom 22. 11. 1937; nach Schoen, Armenfürsorge, S. 184.

62 Allgemein zur differenzierten lokalen Handhabung der Richtsätze und zur Diskussion seit 1933 über die Änderung der Richtsätze, eine Debatte, die seit 1936 besonders im Deutschen Gemeindetag und in der Fachpresse geführt wurde, vgl. Schoen, Armenfürsorge, S. 172-180.

63 DAF an DGT am 6. 10. 1937; nach Schoen, Armenfürsorge, S. 183.

64 BA, R 36, Nr. 932, unfol.: Protokoll Sitzung DGT-Wohlfahrtsausschuß am 13. 1. 1938, S. 4. 
und Alters-Fürsorge umfassen, in welcher außer einwandfreien Sozial- und Kleinrentnern auch alle sonstigen schutzbedürftigen und würdigen Personen, insbesondere soweit ihre Arbeitskraft erhalten sei und soweit sie für die Erziehung und den Unterhalt von Kindern zu sorgen haben, unterstützt würden." Diese Personengruppen würden bislang meist noch in der niedrigeren Allgemeinen Fürsorge betreut. In die zweite Gruppe, so Martini, gehörten hingegen „die sozial und politisch unterwertigen Elemente, insbesondere Unwirtschaftliche, Asoziale, Arbeitsscheue und Fremdstämmige". ${ }^{65}$ Ruppert unterstützte am Ende der Tagung den Vorschlag Martinis, diese - sozialrassistische - Klassifizierung der Armen in der Fürsorge einzuführen. Diese Reorganisation durch die Praxis sei „auch im Rahmen des Gesetzes" möglich. ${ }^{66}$ Damit hatte man via Richtsatzdiskussion einen informellen Ausgrenzungskompromiß zwischen Städten und Gesetzgeber erreicht. Der Deutsche Gemeindetag unterrichtete die Deutsche Arbeitsfront darüber Ende Januar 1938 und betonte im Sinne der neuen Prämissen, daß eine undifferenzierte regionale Anhebung der Fürsorge-Richtsätze, „Ausländern, Juden, Volksfeinden, Asozialen" zugute kommen würde.67

Den Vorschlägen Martinis folgend, wies das Reichsinnenministerium den Reichsstatthalter in Hamburg schon drei Wochen später an, bei der regionalen Neugestaltung des Richtsatzsystems alle diejenigen Gruppen in die Allgemeine Fürsorge einzustufen, die zwar nicht „asozial“ seien, aber "keinen Anlaß bieten, ihnen eine besondere, über das allgemeine Maß hinausgehende Fürsorge zuteil werden zu lassen (auch Juden und in der Regel Ausländer)“. Beide Gruppen wurden daraufhin im Stadtstaat Hamburg prinzipiell von der Gehobenen Fürsorge ausgeschlossen. Jüdische Arme erhielten ab derm 1. April 1938 nur noch einen Richtsatz von 36 RM, das bedeutete gegenüber der Gehobenen Fürsorge eine Kürzung von monatlich 5,40 RM pro Person. „Asoziale“ bekamen gar nur 31,30 RM. In der Gehobenen Fürsorge sollten nur noch diejenigen Personen mit höheren Leistungen unterstützt werden, „deren Arbeitskraft aus arbeitsmarktpolitischen Gründen erhalten werden muß oder die nach den Grundsätzen des nationalsozialistischen Staates als wertvolle Volksteile förderungswürdig sind (erbgesunde Familien)“ ${ }^{6} 6$

Diese Hamburger Neuregelung stufte Juden erstmals in einer ganzen Region de facto wie Ausländer ein. Die Forderung nach ihrer Deklassierung im Fürsorgewesen kam im Vorjahr vom Leiter der Wohlfahrtsbehörde ebenjenes Stadtstaates, der dies als Vorreiter jetzt praktizieren sollte. Neu war, daß diese grundsätzliche Revision der Fürsorgepraxis kein lokaler Alleingang war, sondern auf einer ministeriellen Direktive basierte, ausgelöst von der Diskussion im Wohlfahrtsausschuß des Deutschen Gemeindetages.

Die Kommunen und ihre Wohlfahrtsämter hofften nun, bestärkt durch die Hamburger Richtsatz-Regelung, auf eine rasche zentrale Weisung zur Ausgren-

65 Ebenda: Protokoll Sitzung DGT-Wohlfahrtsausschuß am 13. 1. 1938, S. 14-15.

66 Ebenda, S. 23.

${ }^{67}$ DGT/Abt. III an DAF vom 27. 1. 1938; zit. nach Schoen, Armenfürsorge, S. 181.

68 GStAPK Berlin-Dahlem, I. HA, Rep. 151, Nr. 2311, Bl. 242: RMdI an Reichsstatthalter Hamburg vom 5. 2. 1938. 
zung der jüdischen Armen aus der Öffentlichen Wohlfahrt. Doch Anfang März 1938 ließ das Reichsinnenministerium verlauten, daß eine reichseinheitliche Richtlinie vorerst nicht zu erwarten sei. Das Ministerium stellte aber den lokalen Behörden frei, jetzt informell - zum Beispiel durch die Abwälzung ihrer Wohlfahrtslasten auf jüdische Stellen - Tatsachen zu schaffen. ${ }^{69}$ In diesem Zusammenhang genehmigte das Ministerium am 24. März, daß die Bezirksfürsorgeverbände (BFV) künftig die karitativen Hilfen jüdischer Organisationen bei der Bemessung ihrer Leistungen an jüdische Arme „in vollem Umfang“ berücksichtigen konnten. ${ }^{70}$ Sie konnten somit die vorgesehenen öffentlichen Ausgaben automatisch um diese Beträge kürzen. Das Verfahren hatte seine Vorbilder in der Wohlfahrtspraxis von Leipzig und Hamburg, die schon seit 1934 und 1935 nach dieser Maxime handelten. ${ }^{71}$ Der geschäftsführende Präsident des Deutschen Gemeindetages, Jeserich, übermittelte den Ministerialerlaß seinen Landes- und Provinzialdienststellen Ende März 1938 und bat, den Fürsorgeverbänden hiervon „streng vertraulich Kenntnis zu geben" ${ }^{72}$ Die lokale Fürsorge reagierte schnell. Die Berliner Wohlfahrtsämter rechneten bereits ab 1 . April alle Hilfen jüdischer Stellen voll an.73 Mit dieser Methode sollte offensichtlich zugleich verhindert werden, daß Jüdische Gemeinden den realen Einkommensverlust jüdischer Hilfsbedürftiger infolge der Deklassierung in der städtischen Fürsorgepraxis wettzumachen versuchten, indem sie die Hilfen jüdischer Wohlfahrtsstellen erhöhten.

\section{Städtische Politik gegenüber jüdischen Obdachlosen und "Asozialen“}

Armut, Arbeitslosigkeit und vor allem die jahrelange Verfolgung hatten die Binnenwanderung der noch in Deutschland lebenden jüdischen Bevölkerung verstärkt. Diese war hauptsächlich vom Land in die größeren Städte gerichtet. Viele hatten es aber schwer, schnell in der erforderlichen Raumgröße und Miethöhe adäquate Wohnungen zu finden. Umzüge unter solchen Bedingungen produzierten zumindest zeitweise Obdachlosigkeit und damit Fürsorgebedürftigkeit unter manchen der in die Städte zuziehenden Familien.

Dieses Problem hatte inzwischen offenbar eine neue, traurige Qualität erreicht, denn Vertreter der Judenreferate des SD und der Gestapo debattierten es zu Beginn des Jahres 1938. Der SD wies darauf hin, daß von den SD-Oberabschnitten "ein starker Zuzug der Juden in die Stadt gemeldet werde", und betonte, hierdurch sei „ein sehr starkes Anwachsen des jüdischen Proletariats in den Großstädten und eine Überbelastung der Wohlfahrtsinstitutionen der Juden und evtl. der Fürsorgestellen des Reiches zu befürchten“. Der Gestapovertreter antwortete,

69 Adam, Judenpolitik, S. 192.

70 RMdI-Erlaß vom 24.3.1938 erwähnt in: Dienstblatt der Stadt Berlin, 1938 Teil VII, S. 116, Nr. 106: Vfg. Landeswohlfahrtsamt Berlin (Breitenfeld) vom 31. 3. 1938.

71 Vgl. Kapitel II. 1.

72 YV Jerusalem, M1DN, Nr. 168, Bl. 143: Rundschreiben DGT/Abt. III vom 31. 3. 1938; vgl. StadtA Göttingen, Sozialamt, Acc. Nr. 407/77, Nr. 47, 1, unfol:: DGT-Provinzialdienststelle Hannover an BFV-Provinz Hannover am 13. 4. 1938.

73 Dienstblatt der Stadt Berlin, 1938 Teil VII, S. 116, Nr. 106: Vfg. Breitenfeld (Landeswohlfahrtsamt) vom 31. 3. 1938. Vgl. Gruner, Judenverfolgung in Berlin, S. 47. 
daß „bereits eine dementsprechende Anfrage vom Stellvertreter des Führers eingegangen sei, daß aber von Kontrollmaßnahmen der Polizeibehörden abgesehen werden soll, weil die Überlastung im Augenblick nicht getragen werden kann“. Der Sicherheitsdienst der SS bat die Gestapo, die Angelegenheit trotzdem im Auge zu behalten. ${ }^{74}$

Wie oben angesprochen, hatten seit 1935 einige Großstädte zuziehenden Juden die Unterstützung versagt und sie in Obdachlosenasyle eingewiesen. Doch Zuzug bildete nicht allein den Grund für Obdachlosigkeit. Viele Hauseigentümer, darunter auch städtische Wohnungsbaugenossenschaften, kündigten inzwischen die Verträge mit jüdischen Mietern. ${ }^{75}$ Hinzu kam die finanzielle Not vieler Mieter, die zur Wohnungsaufgabe führte. Fürsorgebehörden waren daran nicht unbeteiligt. In Leipzig strich das Fürsorgeamt inzwischen nicht mehr nur jüdischen Armen, sondern sogar „arischen“ Fürsorgeempfängern, „die bei Juden in Untermiete wohnen", die Mietbeihilfen. In der Dienstanweisung vom Februar 1938 hieß es, „daß es nicht mehr verantwortet werden kann, daß öffentliche Gelder mittelbar in jüdische Hände fließen. [...] Falls der jüdische Hauptmieter auch hilfsbedürftig ist, ist er zu veranlassen, jüdische Untermieter zu nehmen oder eine billigere Wohnung zu mieten. Um die Verbindung von Ariern mit Juden in der Fürsorge auch sonst zu lösen, ist bei arischen Hilfsbedürftigen, die noch bei Juden in Untermiete wohnen, auch dann auf einen Umzug zu einem arischen Hauptmieter hinzuwirken, wenn neben der laufenden Unterstützung keine besonderen Mietbeihilfen gewährt werden." ${ }^{76}$ Wegen Arbeitslosigkeit und Gewerbeverlust lebten aber viele jüdische Familien selbst in kleinen Wohnungen inzwischen von Einnahmen aus Untermietsverhältnissen. Fielen diese aus, konnten manche ihre Wohnungen nicht mehr bezahlen und wurden obdachlos.

Solche Familien konnten die städtischen Fürsorgeämter nicht abweisen. Die Magdeburger Polizeibehörde drängte deshalb den Deutschen Gemeindetag, allein den Jüdischen Kultusgemeinden die Unterbringung und Versorgung hilfsbedürftiger jüdischer Obdachloser aufzutragen. ${ }^{77}$ Daraufhin startete am 5. Februar 1938 der Gemeindetag eine Umfrage über das Vorgehen gegenüber obdachlosen Juden in fünfzehn Großstädten. Vizepräsident Zeitler zitierte darin das Magdeburger Schreiben: Es gebe zwei mögliche Methoden zur Lösung des Problems, nämlich Einzelpersonen ins Städtische Asyl und Familien in Notunterkünfte einzuweisen. Doch bei „jeder Art dieser Unterbringung obdachloser Personen“ sei „die Ein-

${ }^{74}$ An der Aussprache nahmen Herbert Hagen, Eichmann, Theodor Dannecker vom SD und Horst Freytag für das Gestapa teil; YV Jerusalem, 051/OSOBI, Nr. 2 (500-3-315), Bl. 201-207: Vermerk Hagen (SD II 112) über Sitzung am 10. 1. 1938, vom 11. 1. 1938. Zur geringen personellen Ausstattung der Gestapo und ihrer bisher immer überschätzten Allmacht vgl. Paul, Gerhard/Mallmann, Klaus-Michael (Hrsg.): Die Gestapo. Mythos und Realität, Darmstadt 1995 sowie dies., Die Gestapo im Zweiten Weltkrieg.

75 Vgl. Führer, Karl Christian: Mit Juden unter einem Dach? Zur Vorgeschichte des Gesetzes über Mietverhältnisse mit Juden, in: 1999. Zeitschrift für Sozialgeschichte des 20. und 21. Jahrhunderts, 7 (1992), H. 1, S. 51- 61 sowie Gruner, Reichshauptstadt, S. 238.

76 StadtA Leipzig, AFS, Nr. 1759, unfol.: Dienstanweisung vom 24. 2. 1938, S. 4.

77 LA Berlin, Rep. 142/7, Nr. 1-2-6/Nr. 1, unfol.: Verwalter der städtischen Polizei Magdeburg an DGT am 22. 1. 1938. 
weisung von Juden unerwünscht“. Die Kommunen sollten die grundsätzliche Frage beantworten, ob „die Unterbringung von obdachlosen Juden nicht den jüdischen Kultusgemeinden zur Pflicht gemacht werden “ könne. ${ }^{78}$

Die Umfrage ergab, daß in Chemnitz, Dresden, Düsseldorf, München und Nürnberg eine solche Praxis längst üblich war, denn diese Städte verwiesen jüdische Antragsteller prinzipiell an die örtlichen Jüdischen Gemeinden. In Wuppertal sorgte in der Regel ebenfalls die lokale Kultusgemeinde für ihre Mitglieder. Nur selten seien kurzfristig obdachlose Juden aufgenommen worden, diese könnten „erforderlichenfalls“ isoliert werden. ${ }^{79}$

In anderen Städten wurden Juden nicht abgewiesen, aber immer isoliert, so in Köln und Chemnitz. Die Stadt München hatte Juden per Hausordnung die Benutzung der Städtischen Asyle verboten. ${ }^{80} \mathrm{Ab}$ dem 17. Januar 1938 galt ein solches Verbot für „Angehörige jüdischer Rasse“ auch in der „Städtischen Herberge für Frauen", in die bedürftige Frauen und obdachlose Mütter vom Münchner Wohlfahrtsamt eingewiesen wurden. ${ }^{81}$ Die Breslauer Behörden wiesen die jüdischen Armen nicht ab. Sie brachten sogar noch obdachlose Juden und Nichtjuden gemeinsam unter, was aber wohl nur selten vorkam: „Muß jedoch einmal ein Jude beherbergt werden, so wird er in dem gleichen Schlafsaal untergebracht, in dem auch die übrigen Obdachlosen übernachten. Diese haben bisher, da sie zum größten Teil asozial sind, an dem Zusammenwohnen mit einem Juden keinen Anstoß genommen, zumal sich die Juden zurückhaltend benehmen. Eine besondere Unterbringung obdachloser Juden stößt aus wirtschaftlichen Gründen (besondere Heizung und Beleuchtung) auf Schwierigkeiten." ${ }^{\text {82 }}$

Breslau und Berlin befürworteten ausdrücklich den Vorschlag Magdeburgs, künftig die jüdischen Kultusgemeinden zu verpflichten. Köln verlangte sogar eine generelle Separierung: „Die Unterbringung von obdachlosen Juden durch die jüdischen Kultusgemeinden, wie überhaupt die Behandlung der Juden durch ihre eigenen Einrichtungen müßte das Ziel der zu treffenden Maßnahmen sein. "83 Obwohl auch in Frankfurt am Main die jüdischen Stellen für die Unterbringung jüdischer Obdachloser bereits die Verantwortung trugen, äußerte sich die Stadt angesichts der sozialen Wirkungen der Judenverfolgung skeptisch, „ob den jüdischen Kultusgemeinden ganz allgemein die Unterbringung obdachloser Juden zur Pflicht gemacht werden kann, [...] da ihre Mittel immer mehr zusammenschrumpfen. Es muß deshalb damit gerechnet werden, daß die jüdischen Kultusgemeinden und die private jüdische Fürsorge über kurz oder lang nicht mehr in der Lage sein werden, ihre bisherigen Aufgaben durchzuführen ${ }^{*}{ }^{84}$ In Leipzig, wo man für eine Isolierung im Versorgungsfall votierte, alle zuziehenden Juden aber

78 StadtA Leipzig, Kap. 1, Nr. 122, Bl. 56: DGT Berlin an OB Leipzig am 5. 2. 1938.

79 LA Berlin, Rep. 142/7, 1-2-6/Nr. 1, Bd. 2, unfol.: Ergebnis DGT-Umfrage vom 5. 2. 1938, S. $1-7$.

80 Ebenda.

81 Hanke, Juden in München, S. 266.

82 LA Berlin, Rep. 142/7, 1-2-6/Nr. 1, Bd. 2, unfol.: Ergebnis DGT-Umfrage vom 5. 2. 1938, S. 1-7.

83 Ebenda.

84 Ebenda, S. 4. 
in Baracken einwies und sie dort nur mit 75 Prozent des Regelsatzes unterstützte, sprach man sich aus einem anderen Grund gegen die Übertragung der Verantwortung an jüdische Stellen aus: Diese würden in einem solchen Falle dem Zuzug hilfsbedürftiger Juden unkontrolliert Tür und Tor öffnen. ${ }^{85}$

Aus der Umfrage ging auch hervor, daß einige Städte jüdische geringer als ,arische " Obdachlose bewerteten, während andere sie mit „Asozialen" auf eine Stufe stellten. Ein Jahr zuvor, im August 1937, hatte der Deutsche Gemeindetag nach einer Anfrage des Oberbürgermeisters der schlesischen Stadt Hindenburg auch eine Umfrage über die Art der Unterbringung ,asoziale[r] Obdachlosen-Familien“ gestartet. In Hindenburg plante man, solche Familien in „Bewahrungskolonien oder Asozialensiedlungen" zu konzentrieren. Datteln und Karlsruhe verfügten über keine entsprechenden Pläne. In Köln wurden die Familien getrennt, die Männer ins Obdachlosenasyl, die Frauen und Kinder in ein Heim einquartiert. In Lübeck herrschte das gleiche Prinzip. Stettin hatte schon zu Beginn des Jahres 1936 eine Kolonie außerhalb der Stadt errichtet, in die alle vom Wohlfahrts- bzw. Jugendamt als asozial bezeichneten Familien einquartiert wurden. Familien mit vier Personen erhielten lediglich eine Wohnküche, Familien mit sechs Personen eine Stube und Küche zugewiesen. Stettin forderte darüber hinaus "gesetzliche Maßnahmen“, um „diese Familien, die doch nur eine Gefahr für ihr[e] Umwelt und für die Allgemeinheit bilden, in festen Gewahrsam zu bringen ". 86

Gegen Ende des Jahres 1937 verschärfte sich diese Politik, nicht zuletzt durch die Mitwirkung der NSDAP. Am 11. Dezember 1937 wies der Gauleiter und Reichsstatthalter in Sachsen, Mutschmann, an, „asoziale“ Familien von den Städten erfassen zu lassen, wie auf einer Sitzung der sächsischen „Arbeitsgemeinschaft für Verwaltungsfragen " bekanntgegeben wurde. ${ }^{87}$ Diese Aktion wurde durch das Rassepolitische Amt der NSDAP durchgeführt. Behörden, darunter die Wohlfahrtsämter, mußten hierfür dessen Fragen beantworten. ${ }^{88}$ Ein NSDAP-Kreisamt für Kommunalpolitik in Kamenz/Sachsen beschwerte sich wenig später, daß ,asoziale Elemente" nicht ihrem Verhalten entsprechend in Wohnbaracken abgesondert werden könnten. ${ }^{89}$ Der Ruf nach einer Unterbringung der "Asozialen“ in

85 StadtA Leipzig, Kap. 1, Nr. 122, Bl. 71: Vermerk vom 30. 3. 1938 sowie ebenda, Bl. 56RS -57: Fürsorgeamt an HVA in Antwort auf DGT-Anfrage am 17. 2. 1938. In Frankfurt am Main versuchte der Polizeipräsident das Problem mit einer Zuzugssperrverordnung zu lösen, was jedoch an der Priorität einer reichseinheitlichen Regelung scheiterte; Dokumente Frankfurter Juden, VIII 6, S. 375: Polizeipräsident an OB am 30. 6. 1938.

86 BA, R 36, Nr. 881, Bl. 28-30: DGT/Abt. III an OB Hindenburg am 28. 2. 1938. Zur Behandlung der "Asozialen“ durch die kommunale Fürsorge vgl. Ayaß, Asoziale, bes. S. 105-137.

87 StadtA Leipzig, AFS, Nr. 2085, Bl. 148: Nachtrag der DGT-Landesdienststelle Sachsen vom 18. 12. 1937 für die Sitzung der ArbG für Verwaltungsfragen der sächsischen Städte über 500000 Einwohner am 22. 12. 1937; vgl. ebenda, Kap. 1, Nr. 21 A, Bd. 7, Bl. 40: Niederschrift über Sitzung der ArbG für Verwaltungsfragen der DGT-Landesdienststelle Sachsen am 22. 12. 1937, S. 9.

88 StadtA Dresden, Fürsorgeamt, Nr. 639, Bl. 39: Sitzung der Abt. Arbeitslosenversicherung am 24. 1.1938.

89 BA, NS 25, Nr. 86, Bl. 16RS: NSDAP-Reichsleitung/HA für Kommunalpolitik „Vertrauliche Berichtsauszüge“, IV. Sendung vom 15. 4. 1938, S. 8. 
Konzentrationslagern wurde laut. Interessierte Städte, z.B. in Schwaben, scheuten aber vor einer Einweisung der von ihnen als asozial bezeichneten Klientel zurück, weil die Fürsorgeämter erhöhte Kosten wegen des notwendigen Unterhalts der Angehörigen während eines $\mathrm{KZ}$-Aufenthalts erwarteten. ${ }^{90}$

Obdachlose waren also nicht die einzige Gruppe, gegen die man nun verschärft vorging. Die Wohlfahrtsbehörden verknüpften die Diskriminierung jüdischer Bedürftiger immer stärker mit dem sogenannten Asozialenproblem. Die Gleichsetzung von Juden mit „Asozialen“ hatte sowohl in der politischen Propaganda wie in der Praxis der NS-Wohlfahrtspflege Tradition. Wohlfahrtsverbände, Kommunen und auch der Deutsche Gemeindetag beteiligten sich also nicht von ungefähr in den ersten Monaten des Jahres 1938 aktiv an den im ganzen Reich durchgeführten Razzien gegen „Arbeitsscheue und „Asoziale“.

\section{Kooperation von Polizei und Fürsorge: Vier Aktionen gegen "Asoziale"}

In der ersten Hälfte des Jahres 1938 fanden in ganz Deutschland mehrere miteinander korrespondierende Aktionen gegen sogenannte Asoziale statt, mit deren Hilfe Zehntausende in Konzentrationslager verschleppt wurden, um dort für den Vierjahresplan Arbeiten zu verrichten. ${ }^{91}$ Im Zuge dieser von Polizei, Arbeitsverwaltung und Fürsorgebehörden gemeinsam organisierten Razzien wurden auch viele Juden verhaftet. ${ }^{92}$ Ausgangspunkt für diese Maßnahmen war der von Reichsinnenminister Frick unterzeichnete Erlaß über die „Vorbeugende Verbrechensbekämpfung durch die Polizei“ vom 14. Dezember 1937. Ab jetzt konnte die polizeiliche Vorbeugehaft für „Berufsverbrecher“ auch gegen „Asoziale“ verhängt werden. ${ }^{93}$

Eine erste zentrale Aktion speziell gegen „Arbeitsscheue“ initiierte Himmler im Januar 1938 persönlich. ${ }^{94}$ Arbeitsämter, aber auch Wohlfahrtsämter sollten bei der Gestapo alle diejenigen arbeitsfähigen Männer denunzieren, die zweimal ihnen zugewiesene Arbeit abgelehnt hatten, darunter auch entsprechende Fürsorgeempfänger. Auf diese Gruppe hatte die Polizei bisher keinen Zugriff, auch nicht durch den oben erwähnten Himmler-Erlaß. Die Gestapo hatte die angezeigten Erwerbslosen in „Schutzhaft" zu nehmen und für mindestens drei Monate im KZ Buchenwald zu internieren. Nach mehrfacher Verschiebung kamen durch die als

90 Ebenda, Bl.4RS: NSDAP-Reichsleitung/HA für Kommunalpolitik „Vertrauliche Berichtsauszüge“, I. Sendung vom 1.1.1938, S. 8.

91 Ausführlich zu diesen Aktionen vgl. Ayaß, Asoziale, S. 139-175 sowie ders., „Ein Gebot der nationalen Arbeitsdisziplin“. Die Aktion „Arbeitsscheu Reich“ 1938, in: BNSGSP, Bd. 6, Berlin 1988, S. 43-74; Buchheim, Hans: Die Aktion „Arbeitsscheu Reich“, in: Gutachten des Instituts für Zeitgeschichte, Bd. II, Stuttgart 1966, S. 189-195; Drobisch, Klaus: Die Verhaftung „Asozialer" und Krimineller und ihre Einweisung in Konzentrationslager 1933/34 und 1937/38, in: Faschismus und Rassismus. Kontroversen um Ideologie und Opfer, hrsg. von Werner Röhr in Zusammenarbeit mit Dietrich Eichholtz u.a., Berlin 1992, S. 192-205.

92 Zur Einbeziehung der Juden vgl. Gruner, Geschlossener Arbeitseinsatz, S. 41-45.

93 Abdruck, in: Gemeinschaftsfremde, Dok. Nr. 50, S. 94-98.

94 RFSS-Runderlaß vom 26. 1. 1938, Abdruck in: ebenda, Dok. Nr. 56, S. 115-116. 
„Arbeitsscheu Reich“ bezeichnete Aktion im April 1938 landesweit 2000 Männer in ein Konzentrationslager. ${ }^{95}$

In der zweiten Aktion ging es um die Insassen von Herbergen, Wanderarbeitsstätten und sonstigen Einrichtungen der Wanderfürsorge. Mit ihrer „arbeitseinsatzmäßige[n] Erfassung" wurden die Arbeitsämter Mitte Februar beauftragt.96 Um dem Nachdruck zu verleihen, befahl am 28. März Himmler den Polizeibehörden, diese Erfassung wenn notwendig mit Zwangsmaßnahmen durchzusetzen. ${ }^{97}$ Diese Aktion gefährdete auch viele Juden, die nach Verlust ihres Arbeitsplatzes oder ihrer gewerblichen Existenz sich als Vertreter Minimaleinkommen gesichert hatten. Sie waren über Land unterwegs und nutzten aus Geldmangel solche Fürsorgeeinrichtungen. 98

$\mathrm{Zu}$ einer weiteren Aktion kam es infolge einer Besprechung zwischen dem Hauptamt Sicherheitspolizei (Zindel), dem Deutschem Gemeindetag (Zengerling) und dem Reichsinnenministerium (Ruppert) am 14. März 1938.99 Das Ministerium ordnete noch am gleichen Tag an, daß die Bezirksfürsorgeverbände alle Wohlfahrtsempfänger zu melden hätten, die nach Paragraph 20 der Reichsfürsorgeverordnung in geschlossenen Fürsorgeanstalten und Arbeitshäusern zwangsweise zur Arbeit untergebracht waren. ${ }^{100}$ Die Gestapo sollte dann über die Einweisung der Registrierten "zur anderweitige[n] Verwertung ihrer Arbeitskraft " in einem Konzentrationslager entscheiden. ${ }^{101}$

Von den ersten drei Erfassungsaktionen waren Juden mehr zufällig als gezielt betroffen. Anders lag der Fall bei der vierten, diesmal durch die Kriminalpolizei durchgeführten „Asozialen“-Aktion. Seit Ende Februar 1938 waren auf Anordnung Reinhard Heydrichs ${ }^{102}$, dem Chef der Sicherheitspolizei und des Sicherheitsdienstes der SS (CdS), alle mehrfach Vorbestraften im Reich registriert worden. ${ }^{103} \mathrm{Zu}$ diesem Zweck hatte er Anfang April den Kreis der „Asozialen“ erstma-

95 Ayaß, Asoziale, S. 140-147; Buchheim, Aktion, S. 189-191; Drobisch, Verhaftung, S. 197.

96 Brandenburgisches Landeshauptarchiv (BLHA) Potsdam, Pr. Br. Rep. 41 Schlichow, Nr. 16, Bl. 38-39: RAfAA-Erlaß von Mitte Februar 1938. Allgemein zu diesem Komplex vgl. Schoen, Armenfürsorge, S. 99-100.

97 RMinBliV., 1938, S. 578.

98 Barkai, Boykott, S. 133.

99 BA, R 36, Nr. 1860, unfol.: Abschrift Vermerk Pfundtner (RMdI) vom 14. 3. 1938 mit Erlaßentwurf und Anmerkungen für RFSS und RArbM.

100 Ohne Pflichtarbeiter und Entmündigte.

101 StadtA Dresden, Fürsorgeamt, Nr. 630, Bl. 64-65: RMdI-Erlaß vom 14. 3.1938 in Erlaß des Sächs. MdI vom 21. 3. 1938. Abdruck des Runderlasses vom 14. 3. 1938, in: Gemeinschaftsfremde, Dok. Nr. 60, S. 119-120. Vgl. Ayaß, Das Arbeitshaus Breitenau, S. 289290; ders., Asoziale, S. 145-146.

102 Geb. 7. 3. 1904 in Halle, 1922-1931 Marinelaufbahn, 1931 NSDAP- und SS-Mitglied, ab 1932 Chef des SD, ab 1933/34 leitete er die Gleichschaltung der politischen Polizei der Länder, seit 1936 CdS, ab Sept. 1939 Chef des RSHA, ab Sept. 1941 stellv. Reichsprotektor von Böhmen/Mähren. Nach Attentat in Prag am 4. 6. 1942 gestorben.

103 BLHA Potsdam, Pr. Br. Rep. 2 A, I Pol, Nr. 2124, Bl. 207 u. RS: Erlaß Kripoleitstelle Berlin an Regierungspräsident in Potsdam am 21.2. 1938; vgl. ebenda, Pr. Br. Rep. 41 Brieske, Nr. 96, unfol.: Landrat Calau an alle Ortsbehörden mit diesem Erlaß am 4. 3.1938. 
lig definiert, und zwar sehr weitgefaßt. ${ }^{104}$ Am 1. Juni 1938 ordnete Heydrich dann an, daß in der dritten Juniwoche jede Kripoleitstelle „mindestens 200 männliche arbeitsfähige Personen (asoziale)“, darunter verstand er Landstreicher, Bettler, Zigeuner, Zuhälter und Personen mit mehreren Vorstrafen, festzunehmen und in Konzentrationslager zu Zwangsarbeitszwecken einzuliefern habe. ${ }^{105}$ Juden wurden hier erstmals als eigenständige Zielgruppe aufgeführt, denn Hitler hatte persönlich wenige Tage zuvor angeordnet, im „Reichsgebiet asoziale und kriminelle Juden" festnehmen. ${ }^{106}$ Heydrich entschied daraufhin, den Auftrag Hitlers mit der schon vorbereiteten „Asozialen-Aktion“ zu verknüpfen. Er verfügte, im Rahmen der Razzia auch vorbestrafte männliche Juden in ein Konzentrationslager zu überführen. Und zwar gleich sämtliche Vorbestrafte, selbst wenn ihnen nur eine geringe Ordnungsstrafe wegen Verkehrsdeliktes anhing. Die Verhaftungen im Rahmen der Juni-Razzia gegen „Asoziale“ trafen deshalb über 2500 deutsche Juden, ein Viertel der insgesamt über 10000 Opfer. ${ }^{107}$

Gegen die vier Erfassungsaktionen ${ }^{108}$, mit denen Zigtausende angeblich gemeinschaftsfremde Menschen in Konzentrationslager gebracht wurden, gab es kaum Proteste von seiten der Kommunen, ebensowenig wie gegen die zunächst spontane, später systematische Verhaftung von Juden durch die Polizei. Eher fühlte man sich sogar bestätigt, denn seit Ende 1937 lag eine gegen Juden im Wandergewerbe gerichtete Initiative des Deutschen Gemeindetages beim Stellvertreter des Führers. ${ }^{109}$ Einige Kommunen begrüßten daher ausdrücklich die Verhaftungswelle, weil sie durch die KZ-Haft lediger Hilfsbedürftiger Wohlfahrtskosten einsparten, andere hießen den disziplinierenden Effekt der Razzien auf die pflichtarbeitenden Unterstützten willkommen. ${ }^{110}$ Nur gegen die „Durchkämmung“ der Arbeitshäuser erhoben sich bei den für diese Anstalten verantwortlichen Kommunen Gegenstimmen, freilich nicht wegen der Menschen, sondern wegen befürchteter Kompetenzverluste gegenüber der Polizei. ${ }^{111}$ Die Polizeibehörden erhielten zudem gerade in dieser Phase per Gesetz neue Befugnisse zur Überwachung jüdischer Organisationen. Zwischen Gestapo und Öffentlicher Fürsorge entstand für die nächsten Jahre mit der Kontrolle der jüdischen Wohlfahrt und ihrer Sammlungen ein völlig neues Konfliktfeld. ${ }^{112}$

104 CdS-Erlaß vom 4. 4. 1938, Abdruck in: Gemeinschaftsfremde, Dok. Nr. 62, S. 124-126. 105 CdS- Schnellbrief vom 1. 6. 1938, Abdruck in: ebenda, Dok. Nr. 66, S. 134-135. Zu dieser Aktion vgl. Ayaß, Asoziale, S. 147-165. Zur Einbeziehung der „Zigeuner" vgl. ebenda, S. 196-197.

106 YV Jerusalem, 051/OSOBI, Nr. 88 (500-1-261), Bl. 30: Vermerk SD-Judenreferat vom 8. 6. über Sitzung im Sicherheitshauptamt am 1.6. 1938.

107 Zum Vorgang ausführlicher: Gruner, Geschlossener Arbeitseinsatz, S. 43.

108 Ayaß geht demgegenüber von nur zwei Aktionen aus, der Aktion Arbeitsscheu im April und der Juni-Aktion. Die Aktion gegen das Wandergewerbe erwähnt er nicht, außerdem meint er, daß die übrigen zwei Gestapo-Erfassungsaktionen in eine Verhaftungsaktion mündeten; Ayaß, Asoziale, S. 139-175.

109 Adam, Judenpolitik, S. 178. Adam ordnet dies jedoch in den allgemeinen Zusammenhang "Wirtschaftsmaßnahmen gegen Juden" ein.

110 Ayaß, „Ein Gebot der nationalen Arbeitsdisziplin“, S. 50-51; ders., Asoziale, S. 143-145.

111 BA, R 36, Nr. 1860, unfol.: Zengerling (DGT) an OB Görlitz vom 24. 3. 1938;

112 Vgl. Kapitel IV. 2. 


\section{Zur Situation der jüdischen Woblfabrt und der jüdischen Bevölkerung}

Die Jüdischen Organisationen litten aufgrund der Verfolgung unter großen Finanzproblemen, die durch ein neues Gesetz im Frühjahr 1938 eklatant verschärft wurden. Am 28. März erkannte der NS-Staat allen Jüdischen Gemeinden die Eigenschaft ab, Körperschaften öffentlichen Rechts zu sein. Das bedeutet in erster Linie, daß umfangreiche staatliche Steuervergünstigungen gestrichen wurden. ${ }^{113}$ Die Jüdischen Gemeinden und ihre Wohlfahrtsorganisationen unterlagen außerdem statt einer Aufsicht durch die höheren Verwaltungsbehörden nun der direkten Kontrolle der Polizei. ${ }^{114}$ Zugleich sollten die Mittel der jüdischen Wohlfahrt stärker überwacht werden, insbesondere ihre Spendensammlungen. Nominell beaufsichtigte die Kommunalabteilung des Reichsministeriums des Innern neben der öffentlichen und freien Wohlfahrtspflege auch die Veranstaltung öffentlicher Sammlungen. Das Hauptamt Volkswohlfahrt der NSDAP verlangte im April 1938, das Sammlungsgesetz für eine effektive Überwachung anzuwenden, was bisher unterblieben war, da Sammlungen innerhalb der jüdischen Gemeinschaft als nicht öffentlich und daher als nicht genehmigungspflichtig galten. ${ }^{115}$ Die Kommunalabteilung des Reichsinnenministeriums wollte dem Antrag in Absprache mit dem Judenreferenten Lösener widersprechen: Ein solches Verfahren behindere die Sammlungen und damit auch die Bereitstellung von Mitteln für die Emigration. ${ }^{116}$ Doch Staatssekretär Stuckart verschloß sich den Argumenten der Referenten und betonte, daß eine solche Genehmigung aufgrund des neuen „Stand[es] der Judenpolitik" notwendig sei. ${ }^{117}$ Bis zum Sommer entstand ein entsprechender Erlaß mit Zustimmung des Stellvertreters des Führers. ${ }^{118}$

Die Jüdische Winterhilfe mußte aber sowieso dem WHW-Reichsbeauftragten Hilgenfeldt jederzeit Rechenschaft ablegen, ${ }^{119}$ und ihre lokalen Aktivitäten wurden von der Gestapo observiert. ${ }^{120}$ Von 375000 noch in Deutschland ${ }^{121}$ wohnenden Juden hatte die Jüdische Winterhilfe im Winterhalbjahr 1937/38 77231 Personen versorgt. Sie betreute inzwischen 18400 Bedürftige, die das sechzigste Lebensjahr vollendet hatten, das war schon ein Viertel der Gesamtzahl. ${ }^{122}$ Aufgrund zunehmender Emigration vor allem jüngerer Juden war der Anteil verarmter älterer Menschen überproportional gestiegen. Die Pauperisierung nahm vor allen in

113 RGBl., 1938 I, S. 338 . Vgl. dazu Arbeitsbericht der Reichsvertretung der Juden in Deutschland für das Jahr 1938, (Berlin 1939), S. 19.

114 Vgl. BLHA Potsdam, Pr. Br. Rep. 60, Nr. 471, Bl. 63 u. RS: Stadtpräsident Berlin an RMdI am 14.6. 1938.

115 BA, 15. 01, Nr. 27713, Bl. 446-447: HA Volkswohlfahrt an RMdI am 5. 4. 1938. Vgl. zu folgendem: Gruner, Berichte, S. 309.

116 BA, 15. 01, Nr. 27713, Bl. 447-448: Entwurf RMdI/Abt. V vom April 1938.

117 Ebenda, Bl. 448 u. RS: Handschriftl. Vermerk Stuckart auf Entwurf RMdI/Abt. V vom April 1938.

118 Vgl. ebenda, Bl. 451: RMdI/Abt. VW-Erlaß vom 13. 7. 1938.

119 Vgl. ebenda, Bl. 432-434: Richtlinien für die JWH 1937/38.

120 BLHA Potsdam, Pr. Br. Rep. 2 A, I Pol., Nr. 1919, Bl. 249-251: Erlaß Gestapa Berlin vom 14. 11.1936.

121 Jetzt das oberschlesische Abstimmungsgebiet eingeschlossen.

122 Informationsblätter, hrsg. von der Reichsvertretung der Juden in Deutschland, 6 (1938), Nr. 5/6, S. 45-46. 
kleineren Orten ein unerträgliches Ausmaß an. Es gab bereits Kleingemeinden, in denen von 35 Juden 30 als Bedürftige mit Lebensmitteln, Brennstoffen, Kleidung oder billigem Essen aus Wohlfahrtsküchen im Rahmen des Winterhilfsprogrammes unterstützt werden mußten. ${ }^{123}$ In Köln versorgten die Helfer jedes fünfte Gemeindemitglied, das waren insgesamt 2500 Bedürftige. An sie wurden 10000 Kilo Brot, 17000 Pakete Mehl, die gleiche Menge Zucker, 16000 Portionen Frischfisch, 20000 Eier, 5000 Liter Frischmilch für Schulkinder sowie 8000 Zentner Braunkohle aus Sachspenden verteilt. 124

Mit laufenden Leistungen, also unabhängig von der Winterhilfsaktion, unterstützten jüdische Wohlfahrtseinrichtungen im Jahr 1938 rund 40000 Arme. Sie zählten damit fast genauso viele Notleidende wie 1937, obwohl sich die jüdische Bevölkerung um Zehntausende Emigranten verringert hatte. ${ }^{125}$ Insgesamt wandelte sich das traditionelle Aufgabenfeld der jüdischen Fürsorge, da für die aus Verfolgung und Emigration resultierenden akuten Probleme eine Infrastruktur erst zu schaffen war: „Die Wanderfürsorge der Jüdischen Wohlfahrtspflege, die eng mit dem Hilfsverein der deutschen Juden als der für ganz Deutschland zuständigen Spitzenorganisation [...] zusammenarbeitete, mußte denen, die nicht in der Lage waren, auch nur einen kleinen Teil der Auswanderungskosten zu übernehmen, helfen, Auswanderungsanträge wurden geprüft, eigene Zuschüsse, wenn nötig und möglich, gewährt, Anträge für Zuschüsse bei dem Städtischen Fürsorgeamt eingereicht. Diese Gruppen der Auswanderer mußten auch meistens mit neuer Kleidung, mit Bettwäsche usw. versehen werden." ${ }^{126}$ Jugendliche aber auch immer mehr erwachsene Erwerbslose wurden für Ausbildungskurse und Berufsumschichtungen, die als Emigrationsvorbereitung dienten, materiell unterstützt. ${ }^{127}$ Aufgrund der Flucht von Familienmitgliedern blieben immer mehr ältere Menschen, die nicht mehr auswandern konnten, unversorgt zurück. Die Jüdischen Gemeinden in Deutschland verfügten 1937/38 aber nur über 3406 Alten- und 401 Siechenheimplätze, weshalb man begann, sogar Waisenheime zu Altenheimen umzubauen. ${ }^{128}$

Die Situation der jüdischen Wohlfahrt wie der jüdischen Bevölkerung in Österreich stellte sich nach der gewaltsamen Angliederung an das Deutsche Reich im März 1938 als noch weit schwieriger dar. Zum einen war der Anteil armer Menschen an der jüdischen Bevölkerung in Österreich schon vor 1938 deutlich höher gewesen als 1933 in Deutschland, zum anderen sollte dort in wenigen Monaten

123 Arbeitsbericht der Reichsvertretung der Juden in Deutschland für das Jahr 1938, (Berlin 1939), S. 22; vgl. Adler-Rudel, Selbsthilfe, S. 164.

124 Jüdisches Schicksal in Köln, S. 196.

125 Judenpolitik des SD, S. 195, Dok. Nr. 32: Lagebericht SD II 112 für das Jahr 1938.

126 LBI/A New York, Memoir Coll.: Bericht Bergel, S. 33. Vgl. Adler-Rudel, Selbsthilfe, S. 164.

127 LBI/A New York, Memoir Coll.: Bericht Manfred Fackenheim-Field, S. 3. Vgl. Bericht Szanto, in: Richarz, Monika (Hrsg.): Jüdisches Leben in Deutschland, Bd. 3: Selbstzeugnisse zur Sozialgeschichte 1918-1945, Stuttgart 1982, S. 225.

128 Informationsblätter, hrsg. von der Reichsvertretung der Juden in Deutschland, 6 (1938), Nr. 5/6, S. 45-46. 
das an Verfolgungspolitik durchgesetzt werden, was im Altreich in mehreren Jahren entwickelt worden war.

\section{Exkurs: Fürsorge und Judenverfolgung in Wien im Frïbjabr 1938}

In Österreich lebten in den dreißiger Jahren ca. 190000 Menschen jüdischer Religion, davon 90 Prozent in dessen Hauptstadt Wien. Über diese brach die Verfolgung im März 1938 mit bisher unbekannter Wucht herein: Straßenterror, Haussuchungen, Beschlagnahme von Vermögen, willkürliche "Arisierungen“ bzw. Stillegungen von Geschäften und Fabriken sowie Massenentlassungen prägten die

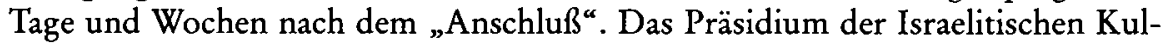
tusgemeinde Wien wurde noch in den ersten Tagen verhaftet. Außer Notspeisungen und Krankenfürsorge verbot man jede Tätigkeit jüdischer Organisationen.129

Auch die Wiener Kommunalverwaltung beteiligte sich aktiv an der Verfolgung. Der neue Bürgermeister, Ing. Dr. Hermann Neubacher ${ }^{130}$ besetzte führende Positionen in der Kommunalverwaltung mit alten Nationalsozialisten und entließ sofort jüdische Beamte, Angestellte und Arbeiter. Das traf auch die Fürsorge, wie folgender Fall zeigt: Im Wiener Bezirksjugendamt Brigittenau erschien am 19. März 1938 der Leiter der Bezirksfürsorgestelle, Mick, in Begleitung des NSDAP-Amtswalters Krofian. Mick unterrichtete den Leiter des Jugendamtes, daß er Krofian die Aufsicht über das Amt übertrage. Krofian solle auch die Fürsorgerinnen überwachen. Die den Bezirksjugendämtern zugeteilten jüdischen Fürsorgerinnen seien bereits beurlaubt. Zugleich stellte Mick „auf eigene Verantwortung" die Auszahlungen von Pflegebeiträgen an Juden ein.131

Über die Behandlung jüdischer Unterstützter zog die Magistratsabteilung 15, das Wiener Wohlfahrtsamt, nur Tage nach dem „Anschluß“ - offenbar telefonisch - Erkundigungen in den städtischen Bezirken ein. ${ }^{132}$ Bald darauf veranstaltete das Amt eine zweite Umfrage über die generelle Praxis der Wohlfahrtspflege. Neben der Höhe gezahlter Unterstützungen und dem Verhältnis der Öffentlichen Wohlfahrt zur NSV wollte man zudem wissen, ob „bezüglich der Juden Weisungen gegeben worden seien". ${ }^{133}$

An den Antworten läßt sich die teilweise abrupte Änderung im Verhalten der städtischen Fürsorge gegenüber jüdischen Wiener Armen in vielen Wiener Stadtbezirken ablesen. Der II. Bezirk meldete schon am 19. März 1938, daß dort keine

129 Zum folg. vgl. Gruner, Wolf: Zwangsarbeit und Verfolgung. Österreichische Juden im NS-Staat, Innsbruck u.a. 2000 sowie Rosenkranz, Herbert: Verfolgung und Selbstbehauptung. Die Juden in Österreich 1938 bis 1945, Wien-München 1978.

130 Geb. 1893, 1933 Eintritt in die NSDAP (SA). Galt als Wirtschaftsexperte für Südosteuropa. Oktober 1942 Wirtschaftssonderbeauftragter des Reiches in Griechenland, Oktober 1943 Sonderbevollmächtigter des Auswärtigen Amtes für den Südosten.

131 Abteilungsvorstand Senatsrat Dr. Rieder an den Bürgermeister am 21. 3. 1938; Abdruck bei Safrian, Hans/Witek, Hans: Und keiner war dabei. Dokumente des alltäglichen Antisemitismus in Wien 1938, Wien 1988, S. 32.

132 Wiener Stadt- und Landesarchiv (im folg. Wiener StadtuLA), MA 212, A 21, Karton 12, R 11/1, unfol.: Vermerk Wohlfahrtsamt Wien vom 24.3.1938; vgl. ebenda: Vermerk MA 15 vom 14. 4. 1938.

133 Ebenda: Vermerk Wohlfahrtsamt Wien vom 19. 3. 1938. 
Juden mehr erschienen.134 Im IV. Bezirk wurden „Juden über Verfügung des kommissarischen Leiters der Bez[irks-]Vorstehung nicht befürsorgt, sie werden an die israel[itische] Kultusgemeinde gewiesen ". ${ }^{135}$ Im V. Bezirk hatten die Beamten die Fürsorgebücher der jüdischen Unterstützten eingezogen und diese erhielten schon um den 24. März keine Leistungen mehr. ${ }^{136}$ Der Bezirk XIII berief sich auf „Weisungen der M[agistrats]abt[eilung] 15“, die besagten, daß „Juden, die derzeit einreichten“, nichts bekämen. Das schien aber offensichtlich "noch" nicht zu stimmen. ${ }^{137}$ Der Bezirk XIV antwortete lapidar, „womöglich abgewiesen“. Man bat den Magistrat zugleich um strenge Richtlinien. ${ }^{138}$ Im Bezirk XVI wurden jüdische Anträge abgelehnt, Erhaltungsbeiträge bei Arbeitsunfähigkeit und Pflegebeiträge für Kinder aber noch belassen. Die gleiche Praxis herrschte im XX. Bezirk. ${ }^{139}$ Im III. Bezirk versorgte das Fürsorgeamt jüdische Arme „nur in den dringendsten Fällen “. ${ }^{140}$ Im Fürsorgeamt XIX wurden Juden unterschiedlich behandelt. Dort erfolgte die Bewilligung nach Entscheidung des NSV-Referenten. Allerdings ersuchte auch dieser Bezirk um zentrale „Weisung bezüglich der Juden “. ${ }^{141}$ Die Fürsorgeämter der Bezirke I, VI, VII, X, XV, XVIII und XXI betreuten jüdische Wohlfahrtsempfänger zunächst normal weiter. ${ }^{142}$

Das teilweise radikale Vorgehen gegen die jüdischen Armen komplettierend, entschied am 28. März 1938 der Wiener Magistrat, sämtliche „Kontrahenten“ der Stadt zur Konfessionsangabe aufzufordern, um nichtarische Heilmittellieferfirmen und Ärzte „auszuscheiden“. Das bezog sich ausdrücklich auf die Verträge mit Fürsorgeeinrichtungen. ${ }^{143}$ Damit hatte Wien schon nach wenigen Wochen auch in der antijüdischen Fürsorgepolitik die Entwicklung in Deutschland deutlich überholt, ohne daß davon auszugehen ist, daß in der dortigen Kommunalverwaltung auf allen Ebenen bereits lupenreine Nationalsozialisten saßen.

Die Situation der jüdischen Armen war zu diesem Zeitpunkt in Wien weit gravierender als im Altreich. 60000 der rund 180000 Wiener Juden galten im April 1938 als fürsorgebedürftig, also fast jeder Dritte. In Deutschland war es zu diesem Zeitpunkt „nur“ jeder Achte. ${ }^{144}$ Viele jüdische Arme erhielten in Wien keine städtische Fürsorge mehr, die jüdischen Stellen aber waren geschlossen. Als das Internationale Rote Kreuz auf die dramatische Lage aufmerksam wurde, mußte sich der Geschäftsführende Präsident des Deutschen Roten Kreuzes an den Reichsinnenminister wenden und um die Wiederzulassung der jüdischen Fürsorge in

134 Ebenda.

135 Ebenda: Vermerk Wohlfahrtsamt vom 25. 3. 1938.

136 Ebenda: Vermerk Wohlfahrtsamt vom 24. 3. 1938.

137 Ebenda: Umfrageantwort Fürsorgeamt Bezirk XIII vom 6. 4. 1938.

138 Ebenda: Umfrageantwort Fürsorgeamt Bezirk XIV vom 6. 4. 1938.

139 Ebenda: Umfrageantwort Fürsorgeamt Bezirk XVI vom 5.4.1938; ebenda: Vermerk Wohlfahrtsamt Wien vom 29.3.1938.

140 Ebenda: Umfrageantwort Fürsorgeamt Bezirk III vom 28. 3. 1938.

141 Ebenda: Umfrageantwort Fürsorgeamt Bezirk XIX vom 5. 4. 1938.

142 Ebenda: Umfrageantworten Fürsorgeämter Bezirke VII, XV, XVIII vom 5. und 6. 4. 1938; ebenda: Vermerke des städtischen Wohlfahrtsamtes vom 24., 25. und 29. 3. 1938.

143 Ebenda, Karton 26, R 41/1, unfol.: Vermerk Armenfürsorge über telef. Rücksprache mit Kommissär Lang (Abt. 44) am 28. 3. 1938.

144 Zahlen nach: Judenpolitik des SD, S. 200, Dok. Nr. 32: Lagebericht SD II 112 für 1938. 
Wien bitten. ${ }^{145}$ Staatssekretär Stuckart (RMdI) veranlaßte daraufhin, daß „derselbe Sach- und Rechtszustand hergestellt wird, der im Altreichsgebiet gilt". Das bedeutete, daß eine jüdische Institution, im Altreich war das die Zentralwohlfahrtsstelle, parallel zur Öffentlichen Fürsorge belassen werden mußte, um die Betreuung hilfsbedürftiger Juden in Österreich zu ergänzen. Wie in Deutschland seien Juden dort aber vom Winterhilfswerk auszuschließen und hätten eine eigene Organisation aufzubauen. ${ }^{146}$

Das Beispiel Wien beweist deutlich den Radikalisierungsschub in der Verfolgung. Diskutierten die deutschen Fürsorgeverbände und Städte seit Jahren darüber, Juden in der Fürsorge als „Asoziale“ oder Ausländer zu behandeln und damit zu deklassieren, so handelte man in Wien viel radikaler. In mehreren Stadtbezirken schlossen die Fürsorgeämter Juden von allen Bezügen aus. Noch bildete brüske Ausgrenzung aber nicht die generelle Haltung unter den Wiener Fürsorgebeamten, denn einige Bezirke taten dies ja nicht. Da manche Bezirke nach Richtlinien des Magistrats verlangten, erschien der Ausgrenzungsvorgang weder unumkehrbar noch unsteuerbar; er demonstriert gleichwohl den großen Spielraum jenseits zentraler Vorgaben in der Praxis lokaler Behörden auch in Österreich.

\section{Lokale und zentrale Maßnahmen in der Öffentlichen Fürsorge (Sommer 1938)}

\section{Die „Würzburger Richtlinien“ des Deutschen Gemeindetages}

Nach den Erfahrungen der „wilden“ Verfolgungen in Österreich ging man in der NS-Führung verstärkt zur Koordinierung der Verfolgungspläne über. Um Vertreibungsmaßnahmen und Aufrüstungsinteressen in Einklang zu bringen, lud Göring Ende April 1938 zu einer Strategiesitzung ein. Er wollte „Auffassungen“ und "Wünsche“ der anderen Minister sowie der Parteispitze für das weitere Vorgehen erfahren und vor allem die geplante "Verwertung " jüdischen Vermögens diskutieren. ${ }^{147}$ Am 26. April hatte der NS-Staat bereits die Anmeldepflicht sämtlichen individuellen Vermögens der jüdischen Bevölkerung im Wert von über 5000 RM angeordnet. Mit dieser zentralen Erfassung wurde deren Enteignung logistisch vorbereitet. ${ }^{148}$ Ministerialbeamte im Reichswirtschaftsministerium hatten einen Tag zuvor darüber abschließend diskutiert. Eigentlich sollte auf jener Sitzung auch erörtert werden, „was aus den Juden nach ihrer Ausmerzung aus dem Wirtschaftsleben werden soll, insbesondere [...] die Frage der Versorgung fürsor-

145 Österreichisches Staatsarchiv/Archiv der Republik (im folg. ÖStA/AdR) Wien, BürckelMaterie, Nr. 1762, unfol.: Präsident Deutsches Rotes Kreuz an RMdI am 23. 4. 1938.

146 Ebenda: RMdI an Reichskommissar Bürckel am 9. 5. 1938.

147 AdP, Teil I, Bd. 2 -Microfiche-, Nr. 20400487: Schnellbrief Görings vom 26. 4. 1938.

148 „VO über die Anmeldepflicht jüdischen Vermögens" vom 26. 4. 1938; RGBl., 1938 I, S. 414 . 
gebedürftiger Juden, ihre Auswanderung bzw. Abschiebung“, was jedoch aus Zeitgründen nicht geschah. 149

Daneben kam es zu neuen antijüdischen Bestimmungen unterschiedlicher Ministerien auch im Bereich der Fürsorge- und Sozialpolitik. Das Reichsarbeitsministerium führte ab 1. April 1938 für alle von der Öffentlichen Fürsorge unterstützten Kleinrentner einen monatlichen Extra-Zuschuß von 12 bis $16 \mathrm{RM}$ ein. Von dieser Sozialzulage schloß es aber Juden aus. ${ }^{150}$ Ab 29. April ordnete das Reichsinnenministerium an, daß wenn ein Elternteil Jude sei, kinderreiche Familien keine Fahrpreisermäßigungen der Deutschen Reichsbahn mehr erhielten. ${ }^{151}$ Bald darauf verbreitete der sächsische Innenminister, daß auf Anweisung des Reichsministeriums bei Juden und „Mischlingen I. Grades“ generell Anträge auf Fahrpreisermäßigungen abzulehnen seien. ${ }^{152} \mathrm{Ab}$ Mai verloren auf Anordnung des Reichsführers der Kassenärztlichen Vereinigung jüdische Ärzte endgültig die Zulassung zur Behandlung im Fürsorgewesen. ${ }^{153}$ Wenig später wies der Reichszahnärzteführer an, daß jüdische Zahnärzte nun nicht einmal mehr jüdische Hilfsbedürftige behandeln durften. Das lief der allgemeinen Separierung entgegen, denn jetzt mußten wieder „arische“ Zahnärzte die armen Juden medizinisch versorgen. ${ }^{154}$

Vor dem Hintergrund der von zentraler Seite radikalisierten Politik versammelten sich am 23. April 1938 in Königsberg die Mitglieder der Ostdeutschen Arbeitsgemeinschaft für Wohlfahrtspflege des Deutschen Gemeindetages, der der Leiter des Berliner Landeswohlfahrtsamtes Spiewok vorstand. Unter den Teilnehmern wurde das Fehlen einer gesetzlichen Grundlage für die „Ausschaltung der Nichtarier aus der gehobenen Fürsorge “ erneut öffentlich beklagt. ${ }^{155}$ Einen Tag zuvor hatte aber in Erfurt eine Diskussion in der Mitteldeutschen Arbeitsgemeinschaft für Wohlfahrtspflege stattgefunden, durch die diese Frage eine neue Wendung bekommen sollte. Auf der Tagung wurde ein erster Entwurf neuer Richtlinien des Deutschen Gemeindetages zur Bemessung der Leistungen der Öffentlichen Fürsorge öffentlich vorgestellt und debattiert. Bereits in der Präambel hatte man sozialrassistische Prinzipien festgezurrt: „[In der Fürsorge] ist die nationalsozialistische Grundforderung zu beachten, daß alle Maßnahmen des Staates der Gesundheit, der Kraft und der Zukunft des Deutschen Volkes zu dienen haben. Das Wohl des Einzelnen ist soweit zu fördern, als damit gleichzeitig dem Gesamtwohl gedient wird. Ziel und Grundsatz sind, Art und Maß der Hilfe nach dem Wert des Einzelnen für das Volksganze zu bestimmen. Die Fürsorge muß die Grundsätze einer gesunden Erb- und Rassepflege beachten. Danach ist dem sozial

149 BA, 31.01, Nr. 15514, Bl. 292: Vermerk über Sitzung im RWM vom 25. 4. 1938.

150 Erlaß vom 25. 3. 1938; RMBliV., 1938, S. 571. Vgl. Dienstblatt der Stadt Berlin, 1938 Teil VII, S. 117-118, Nr. 108: Vfg. Landeswohlfahrtsamt Berlin vom 2. 4. 1938.

151 Abdruck in Vfg. des Polizeipräsidenten von Berlin vom 16. 5. 1938; Amtliche Nachrichten des Polizeipräsidiums in Berlin, 1938, Nr. 18 vom 30. 5. 1938, S. 54.

152 StadtA Leipzig, Kap. 1, Nr. 122, Bl. 82: Runderlaß Sächs. MdI vom 19. 5. 1938.

153 Adam, Judenpolitik, S. 188; Kümmel, Ausschaltung, S. 75.

154 StadtA Leipzig, AFS, Nr. 1798, Bl. 195RS: Rundschreiben OB/Fürsorgeamt Leipzig vom 10.6. 1938.

155 BLHA Potsdam, Pr. Br. Rep. 55, VII a, Nr. 10, B1. 8: Niederschrift über die Sitzung vom 23.4. 1938. 
vollwertigen Volksgenossen, insbesondere dem kinderreichen Familienvater einer erbgesunden Familie nicht nur eine ausreichende, sondern zugleich auch eine aufbauende und vorbeugende Fürsorge zu gewähren. Bei Hilfsbedürftigen, denen es an Bereitschaft und Fähigkeit zur selbstverantwortlichen Einordnung in die Volksgemeinschaft noch fehlt, ist dagegen die Fürsorge auf zielsichere und straffe Erziehung abzustellen, während Unverbesserlichen und Gemeinschaftswidrigen gegenüber mit festen, notfalls harten Maßnahmen durchzugreifen ist." 156 Sowohl in der kommunalen Fürsorge wie im Deutschen Gemeindetag zeigten sich die Aktivisten also nicht mehr gewillt, die scheinbare Tatenlosigkeit der Ministerialebene hinzunehmen.

Mit den vorgeschlagenen Richtlinien wollte man sich ein Instrument verschaffen, um insbesondere jüdische Hilfsempfänger bei der Versorgung nicht nur vor Ort, sondern generell im Reich deklassieren zu können. Die endgültige Fassung der Richtlinien beschlossen die Vorsitzenden aller regionalen Arbeitsgemeinschaften für Wohlfahrtspflege des Deutschen Gemeindetages - also u. a. Martini, Plank und Fischer-Defoy - auf einer gemeinsamen Sitzung am 14. Mai 1938.157 Am 25. Mai stellte der Deutsche Gemeindetag auf der Tagung seines Wohlfahrtsausschusses in Würzburg offiziell die neuen Richtlinien vor, in denen nunmehr für Juden wie bisher für Ausländer eine prinzipielle Beschränkung auf die Leistungen der Allgemeinen Fürsorge vorgeschrieben wurde. 158

In den Richtlinien, die sich an den Vorschlägen Martinis auf der Sitzung des DGT-Wohlfahrtsausschusses vom Januar 1938 orientierten, stand: „III. Ermittlung des Bedarfs. Es entspricht nationalsozialistischer Anschauung, alle Maßnahmen der Fürsorge auszurichten nach dem Wert, den der einzelne für die Volksgemeinschaft hat. [...] Daher ist in erster Linie ausreichend, aufbauend und vorbeugend denjenigen zu helfen, die für das Volksganze wertvoll sind. Hierzu gehören grundsätzlich alle nach Anlage, Wesensart, Leistung und Haltung einwandfreien und anständigen Volksgenossen, die durch Alter, Erwerbsunfähigkeit oder durch unverschuldete Erwerbslosigkeit oder durch persönliche Bindungen (alleinstehende Mütter mit Kindern) an der Führung des Lebens aus eigenen Kräften dauernd oder vorübergehend verhindert sind. Im einzelnen sind aufgrund ihrer früheren Leistungen und Opfer für die Volksgemeinschaft hierher zu zählen: 1. Kriegsbeschädigte und Kriegshinterbliebene, sowie Opfer der Bewegung, 2. Kleinrentner, 3. Sozialrentner, 4. sonstige alte und erwerbsunfähige Personen, die trotz wirtschaftlicher Lebensführung auf die öffentliche Fürsorge angewiesen sind. Das gleiche gilt für alle einwandfreien Volksgenossen, deren Arbeitskraft und Leistungsfähigkeit zu erhalten ist oder die nach den Grundsätzen des nationalsozialistischen Staats als wertvolle Volksteile förderungswürdig sind. Für diese Gruppe sind die Richtsätze der gehobenen Fürsorge anzuwenden. Alle sonstigen Hilfsbedürftigen sind mit den Richtsätzen der allgemeinen Fürsorge zu unterstüt-

156 LA Berlin, Rep. 142/7, 0-1-16/Nr. 185, unfol.: DGT-Richtlinien aufgestellt von der Mitteldt. ArbG für Wohlfahrtspflege am 22. 4. 1938.

157 StadtA Leipzig, AFS, Nr. 2085, Bl. 157: Vorbericht des DGT für die Würzburger Tagung, vom 19. 5. 1938.

158 BA, R 36, Nr. 933, Bl. 145-148RS: Niederschrift zur Sitzung am 25. 5. 1938. 
zen. Mit diesen Richtsätzen sind auch Juden und Ausländer zu unterstützen, wobei deutschstämmige Ausländer gegebenenfalls auch der gehobenen Fürsorge teilhaftig werden können." Noch unter den Sätzen der Allgemeinen Fürsorge sollten „asoziale“ Bedürftige unterstützt und möglichst in Geschlossener Fürsorge untergebracht werden. 159

Die in der Folgezeit „Würzburger Richtlinien“ genannten Fürsorgemaximen legte der Gemeindetag dem Reichsinnenministerium mit der Bitte vor, bei positiver Begutachtung diese per Runderlaß zu verbreiten. Man begründete die Neufassung mit der lokal stark differierenden Entwicklung der Richtsätze seit 1933 und den hierdurch entstandenen Mißstimmungen bei den Wohlfahrtsempfängern. Die neuen Richtlinien intendierten, "die durch die Rechtsprechung des Bundesamts für das Heimatwesen bereits eingeleitete Entwicklung einer den nationalsozialistischen Grundsätzen entsprechenden verschiedenen Behandlung rassisch wertvoller Personen einerseits und erbunwertiger oder nicht vollwertiger Personen andererseits zu fördern“. .60

Der Staatssekretär im Reichsinnenministerium, Johannes Pfundtner 161 , übersandte den Entwurf am 27. Juli 1938 dem Reichsarbeitsministerium und dem Stellvertreter des Führers mit der Bitte um Stellungnahme. Er plädierte in seinem Brief für die neuen Richtlinien, weil diese einer auf NS-Grundsätzen basierenden Handhabung der Öffentlichen Fürsorge dienten. Sie seien das „Ergebnis eingehender Beratungen des Wohlfahrtsausschusses des Deutschen Gemeindetages und insbesondere eines aus dem genannten Ausschuß gebildeten Unterausschu[sses], dem besonders Sachverständige, mit unmittelbarer praktischer Fürsorgetätigkeit befaßte Persönlichkeiten aus Stadt und Land angehört haben ". Sein Ministerium, so Pfundtner, unterstütze besonders "vom sozialpolitischen Standpunkt aus" in allen wesentlichen Belangen den Vorschlag des Gemeindetages, insbesondere die Übernahme aller „einwandfreien Volksgenossen“ in die Gehobene Fürsorge. Sein Ministerium werde jedoch den vom Gemeindetag gewünschten Runderlaß an die

159 Ebenda, Bl. 146RS: Niederschrift zur Sitzung am 25. 5. 1938, Anlage A: Richtlinien für die Bemessung der Leistungen der Öffentlichen Fürsorge. Teilw. abgedruckt, in: Gemeinschaftsfremde, Dok. Nr. 65, S. 133-134. Vgl. zur Verbreitung der Richtlinien: NordrheinWestfälisches Hauptstaatsarchiv (im folg. NW-HStA) Düsseldorf, RW 53, Nr. 66, unfol.: Sitzung der Rhein. ArbG für Wohlfahrtspflege am 8.11. 1938 in Krefeld, S. 1-5.

160 Zit. nach dem DGT-Schreiben in: BA, R 36, Nr. 1118, unfol.: RMdI/VW I an das RArbM am 27. 7. 1938 (Abschrift), S. 1-3.

161 Geb. 15. 07. 1881 in Gumbinnen (Ostpreußen). Studium Jura und Volkswirtschaftslehre, Referendariat, Gerichtsassistent, Regierungsrat, 1914-1918 Kriegteilnehmer (EK I u.a.), Hauptmann der Reserve, Geh. Regierungsrat und Vortragender Rat im RWM, 1925-1933 Rechtsanwalt und Notar, dann Staatssekretär im RMdI. Im Zuge der Veränderungen im RMdI 1943 (Himmler wird Minister) versetzte Hitler Pfundtner in den Wartestand. Pfundtner war verheiratet und hatte vier Söhne (1941). NSDAP-Mitglied Nr. 1010584, Aufnahme am 1.3.1932. Er schrieb Aufsätze in Tageszeitungen, seit 1919 auch naturund verwaltungsrechtliche Artikel, gab „Das neue deutsche Reichsrecht“ und die „Verwaltungsakademie" heraus, 1 . Vorsitzender des Präsidiums des Nationalen Klubs Berlin. Mitglied des NSFK, NSV, NS-Rechtswahrerbund, Reichsbund der Kinderreichen (Ehrenring), Dt. Reichskriegerbund „Kyffhäuser", Bund heimattreues Ost- und Westpreußen e.V.; BA, R 2 Pers., Pfundtner, Johannes (Mitgliedskarte Braunes Haus, Mitgliedsausweis, Parteistatistische Erhebung 1939, Pk). 
Fürsorgeverbände wegen der durch die Richtlinien potentiell steigenden Finanzbelastung der Städte und Gemeinden lediglich als Empfehlung und nicht als verbindliche Vorschrift herausgeben. „Hinsichtlich der Juden“, so Pfundtner abschließend, „wäre lediglich zu sagen, daß hier eine gesetzliche Regelung unmittelbar bevorstehe". 162

Dieser Hinweis verweist auf die generell veränderte Haltung der zentralen Ebene in der antijüdischen Politik. Die Kommunen hatten via Deutschem Gemeindetag zwar zum wiederholten Male keine verbindliche Ministerialregelung erwirkt, doch sollten die inoffiziell durch das Reichsinnenministerium anerkannten „Würzburger Richtlinien“ eine hinreichende Grundlage für die von den Städten gewünschte Verschärfung ihrer sozialrassistischen Ausgrenzungspraxis bilden.

\section{Die städtische Woblfahrt: Kennzeichnung, Separierung und Deklassierung}

Erfassungs- und Kennzeichnungsmaßnahmen dienten vielen Städten in dieser Phase zur Trennung von Nichtjuden und Juden in städtischen Einrichtungen, in der kommunalen Wirtschaft, im Wohnungswesen sowie auf dem Wohlfahrts- und Gesundheitssektor. ${ }^{163}$ In München registrierte seit dem Frühjahr 1938 das städtische Wohlfahrts- und Stiftungsreferat noch einmal alle jüdischen Unterstützten. Zunächst mußten alle Bezirke beim Bezirksfürsorgeverband München-Stadt die Zahl der laufend in Kleinrentnerfürsorge bzw. -hilfe jüdischen Versorgten melden ${ }^{164}$, im Juli fand dann eine namentliche Erfassung naller in Unterstützung stehende[n] Nichtarier, einschl[ießlich] Mischlinge 1. Grades" statt. ${ }^{165}$ Im August entschied die Münchner Fürsorge, daß jüdischen Armen nach dem Wegfall des Mietsteuererlasses seit dem 1. April 1938 zwar die Mietbeihilfe I als reichsgesetzliche Regelung weiterhin zu gewähren sei, die Hälfte der Mietbeihilfe II jedoch nur, "wenn der für die Juden geltende strengste Maßstab" dies zuließe, keinesfalls aber die zweite Hälfte, da diese eine freiwillige Leistung sei. 166

Quasi parallel, Ende März/Anfang April, startete auch die Stadtverwaltung in Berlin eine Offensive zur Erfassung und Separierung jüdischer Hilfsbedürftiger. Bereits ab 6. Januar hatten die letzten jüdischen Wohlfahrtsärzte in der Hauptstadt ihre Tätigkeit einstellen müssen, denn ab 1. Januar 1938 erloschen reichsweit die Zulassungen jüdischer Ärzte bei den Ersatzkassen. Und in Berlin war die Ersatzkassenpraxis mit der wohlfahrtsärztlichen Tätigkeit gekoppelt.167 Anfang April bestimmte die Stadt in Übereinstimmung mit der Kassenärztlichen Vereini-

162 BA, R 36, Nr. 1118, unfol.: RMdI/VW I an das RArbM am 27. 7. 1938 (Abschrift), S. 1-6. Zu den ministeriellen Vorgängen vgl. NW-HStA Düsseldorf, RW 53, Nr. 66, unfol.: Sitzung der Rhein. ArbG für Wohlfahrtspflege am 8.11.1938 in Krefeld, S. 5.

163 Gruner, NS-Judenverfolgung und die Kommunen, S. 104-106.

164 YV Jerusalem, M1DN, Nr.168, Bl. 144: Vermerk Stadt München/Dezernat 6 vom 6. 4. 1938.

165 Ebenda, Bl. 145: Vfg. Ortner (Dezernat 6) vom 6. 7. 1938; vgl. ebenda, Nr. 121, Bl. 54.

166 Ebenda, Nr. 168, Bl. 146: Vfg. Dezernat 6 vom 10. 8. 1938.

167 Dienstblatt der Stadt Berlin, 1938 Teil VII, S. 8, Nr. 13: Rundvfg. Lippert (OB) vom 6. 1. 1938. Vgl. zum folg. Gruner, Judenverfolgung in Berlin, S. 46-55. 
gung Deutschlands/Landesstelle Berlin nun zwanzig jüdische Ärzte für die separate Behandlung wohlfahrtsbedürftiger Juden. Ab 1. April wurden Krankenscheine für jüdische Hilfsbedürftige durch den Satz ${ }_{n} J u d e !$ Gültig nur für zugelassene jüdische Wohlfahrtsärzte" gekennzeichnet ${ }^{168}$ Am 8. April übertrug die Kommune die „krankenanstaltsmäßige Versorgung der Juden (Hilfsbedürftige, Kassenkranke, Selbstzahler) “ den jüdischen Krankenhäusern und Heilanstalten. Städtische Hospitäler und der städtische Bettennachweis durften ab jetzt die „Rasseeigenschaft" von Erkrankten feststellen, um jüdische Kranke an jüdische Anstalten zu verweisen. Die Behandlungskosten jüdischer Hilfsbedürftiger in jüdischen Einrichtungen wurden von den Fürsorgebehörden bis zur Höhe der Kassensätze nach der Reichsversicherungsordnung beglichen, ohne jedoch Ermäßigungsmöglichkeiten anzuwenden. ${ }^{169}$ Stadtmedizinalrat Conti verfügte Ende April, daß bei Juden, die doch in städtische Anstalten wegen medizinischer Unabweisbarkeit oder Überfüllung jüdischer Heime aufgenommen werden mußten, die Einweisungsscheine deutlich mit Rotstift durch das Wort „Jude“ markiert werden sollten. ${ }^{170}$ Isoliert wurden danach die jüdischen Armen allenthalben in Berlin. Selbst im Städtischen Arbeits- und Bewahrungshaus Rummelsburgi71 hatte man die jüdischen Insassen, ob dem Arbeitszwang Unterliegende oder Fürsorgebewahrte, im Laufe des Jahres in „Sonderabteilungen innerhalb der Anstalt zusammengefaßt". Das Hauptgesundheitsamt überwies der Rummelsburger Einrichtung zusätzlich „eine größere Anzahl jüdischer Hospitalisten aus anderen städtischen Hospitälern". ${ }^{172}$

In einer seiner letzten Handlungen bestimmte der aufgrund kommunalinterner Konflikte wegen seiner hohen NSV-Position scheidende Leiter des Landeswohlfahrtsamtes Berlin, Spiewok, daß ab 27. April 1938 die städtischen Wohlfahrtsämter registrieren sollten, welche Unterstützten Juden seien. Sie seien im Krankheitsfalle mit extra gelbfarbigen Vordrucken der ärztlichen Versorgung zu überweisen. ${ }^{173}$ Am 25. Mai forderte das Landeswohlfahrtsamt dann das städtische Wahlamt auf, ihm ein Verzeichnis der Berliner Juden und „Mischlinge“ zur Verfügung zu stellen. Mit der am 20. Juli der Fürsorge übergebenen Liste konnten die Sach-

168 Dienstblatt Berlin, 1938 Teil VII, S. 113-114, Nr. 104: Vfg. Steeg (i.V. OB) vom 30. 3.1938.

169 Ebenda, S. 121, Nr. 111: Vfg. Plath (i.V. OB) vom 8. 4. 1938.

170 LA Berlin, Rep. 214, Acc. 794, Nr. 13, unfol.: Vfg. Conti (i.V. OB) vom 27. 4. 1938.

$171 \mathrm{Zu}$ Funktion, Einweisungspraxis und Bedingungen in dieser im 19. Jahrhundert erbauten, aber seit 1934 von der Stadt als Bewahranstalt genutzten Anstalt: Ayaß, Asoziale, S. 9296.

172 LA (Sta) Berlin, Rep. 47-08, Nr. 113, Bl. 44-45: Bericht des Städt. Arbeits- und Bewahrungshauses für die Zeit vom 1.4. 1938 bis 31. 3. 1939. Am 1. April 1939 waren dort von insgesamt 447 männlichen Insassen fünf Juden, von 105 weiblichen sechs Jüdinnen, am 1. Juni von 443 männlichen Insassen 13 Juden, von 106 Frauen sieben Jüdinnen, am 1. August von 421 männlichen Insassen 25 Juden, von 100 Frauen sieben Jüdinnen. Ab November 1939 waren bis zum Ende März 1940 von rund 440 männlichen Insassen durchgängig 29 Juden, von rund 80 Frauen sieben Jüdinnen. In dieser Zeit starben insgesamt 106 Männer und 9 Frauen, davon sechs Juden; ebenda, Bl. 55-57: Anhang zum Bericht des Städt. Arbeits- und Bewahrungshauses vom 1. 4. 1939 bis 31. 3. 1940.

173 Dienstblatt der Stadt Berlin, 1938 Teil VII, S. 147, Nr. 140: Rundvfg. vom 27. 4. 1938. 
bearbeiter letzte, noch nicht registrierte Juden unter den Sozialhilfeempfängern in den Bezirken feststellen und deren Akten bzw. Karteikarten entsprechend kennzeichnen. ${ }^{174}$ Auf dieser Grundlage ließ Mitte August der neue Leiter des Landeswohlfahrtsamtes, Fritz Behagel, einen statistischen Überblick über die unterstützten Juden in den verschiedenen Fürsorgegruppen anfertigen. ${ }^{175}$ Der einleitend beschriebene Personalwechsel in der Führung des Berliner Landeswohlfahrtsamtes vom Mai 1938 wirkte also keineswegs bremsend auf dessen antijüdische Politik. Am 11. August verbot Behagel Juden den Zutritt zu den öffentlichen, d.h. im Winter von der Stadt für Hilfsbedürftige unterhaltenen Wärmeräumen. ${ }^{176} \mathrm{Am}$ 20. September verfügte er darüber hinaus, daß bedürftige Juden ab nächstem Winter keine städtischen Brennstoffbeihilfen (Kohlengutscheine) mehr erhielten. Nur in Ausnahmefällen und auf besonderen Antrag hin durften ihnen Barunterstützungen ausgezahlt werden. 177

Das Landeswohlfahrtsamt in Berlin unterstützte im September 1938 rund 7500 jüdische Arme. 2700 jüdische Berliner bezogen noch Gehobene Fürsorge, davon 130 Kriegsbeschädigte oder deren Hinterbliebene. Außerdem bekamen 1632 Wohlfahrtserwerbslose, 115 Pflegekinder und 2392 "sonstige Hilfsbedürftige“ Leistungen von den Wohlfahrtsämtern. 327 jüdische Arbeitslosenhilfeempfänger erhielten zusätzliche Leistungen von der städtischen Fürsorge, 130 Jugendliche zusätzliche Hilfen vom Jugendamt (monatlich $15 \mathrm{RM}$ ). ${ }^{178}$

Der Anteil jüdischer Armer an der Zahl der Fürsorgebedürftigen lag aufgrund der Auswirkungen der Verfolgung generell weit über dem Anteil der jüdischen Bevölkerung an der Gesamtzahl der Einwohner Berlins, der aufgrund der Emigration vieler Menschen inzwischen weniger als 3 Prozent betrug. Unter den von der städtischen Fürsorge unterstützten Wohlfahrtserwerbslosen zählte man in allen Berliner Bezirken durchschnittlich 13,4 Prozent Juden und Jüdinnen, bei den zusätzlich unterstützten Arbeitslosenhilfeempfängern 12,2 Prozent, bei sonstigen Hilfsbedürftigen acht Prozent. Nur in den Kategorien, die entweder bereits von Ausschlußmaßnahmen betroffen waren, wie bei den Pflegekindern (1 Prozent), oder die sich nicht änderten, wie bei Kriegsbeschädigten (3,3 Prozent), lagen die Anteile im Rahmen des Normalen. Weit gravierender noch zeigt sich die grassierende Armut bei der Analyse einzelner Stadtteile: In den Bezirken mit starker jüdischer Bevölkerung lag ihr Anteil an Wohlfahrtserwerbslosen mittlerweile bei über 20 Prozent, in Berlin-Mitte mit 27,8 Prozent und in Berlin-Charlottenburg mit 23 Prozent am höchsten. Jüdische Arbeitslosenhilfeempfänger waren in den Bezirkswohlfahrtsämtern Wilmersdorf mit 31,4 Prozent und Berlin-Mitte mit

174 LA Berlin, Rep. 214, Acc. 794, Nr. 13, unfol.: Auszug aus Besprechung am 25. 5. 1938; ebenda: Auszug aus Besprechung am 20.7.1938.

175 Ebenda: OB/Landeswohlfahrtsamt an Bezirksbürgermeister vom 16. 8. 1938.

176 Dienstblatt der Stadt Berlin, 1938 Teil VII, S. 248, Nr. 261: Vfg. Landeswohlfahrtsamt vom 11.8. 1938. Danach jedes Jahr neu erlassen; vgl. ebenda, 1939 Teil VII, S. 252, Nr. 242: Vfg. vom 3. 8. 1939.

177 Ebenda, 1938 Teil VII, S. 271, Nr. 290: Vfg. Behagel (Landeswohlfahrtsamt) vom 20.9. 1938.

178 BA, R 41 RArbM, Nr. 155, Bl. 124 u. 130: Sonderbericht (Lippert) vom 5.1. 1939 zum Wirtschaftslagebericht für Berlin. 
40,7 Prozent überproportional vertreten. Bei den sonstigen Hilfsbedürftigen lagen Prenzlauer Berg mit 17,1 und wiederum Mitte mit 15,2 Prozent Juden an der Spitze. ${ }^{179}$ Die städtischen Ausgaben für jüdische Arme betrugen in Berlin im Oktober 1938 insgesamt 294000 RM (ohne Kreis-Mietbeihilfen). Jüdische Wohlfahrtserwerbslose bekamen je Partei monatlich 43,20 RM, Kleinrentner 44 RM, sonstige Hilfsbedürftige 38,50 RM, Pflegekinder 22,70 RM, Sozialrentner 22 RM und Kriegsbeschädigte 21,20 RM. Das waren noch ungefähr die gleichen Sätze wie bei nichtjüdischen Fürsorgeempfängern. ${ }^{180}$

Im Gegensatz zu Berlin, wo jüdische Kriegsbeschädigte also weiterhin in der Gehobenen Fürsorge unterstützt wurden, verweigerte in Hamburg das zuständige Amt für Kriegsbeschädigte und Kriegshinterbliebene ab Juli 1938 „Nichtariern" diesen Anspruch. Unter Berufung auf die - wie oben erwähnt - Juden versagten, zusätzlichen Zuschüsse im Rahmen des Kleinrentnergesetzes ordnete der Amtsleiter, Dr. Emil Spargel, ihren Ausschluß „unter Anwendung des nationalsozialistischen Rechtsguts" an. ${ }^{181}$ Nicht nur das angesprochene Gesetz, auch die regionale Neugestaltung der Fürsorgerichtsätze konnte hierfür der Wohlfahrtsbehörde als Argument dienen, die für den Stadtstaat als erster Region eine sozialrassistische Abstufung der Leistungen vorsah. ${ }^{182}$

\section{Die Verschärfung der Pflichtarbeitsprogramme}

Jüdische Bedürftige erhielten in vielen Orten selbst gekürzte Wohlfahrtsleistungen nicht mehr "umsonst“. In Hamburg wurden "Juden, Zigeuner, Schausteller und Wanderer" von der Stadt bevorzugt genötigt, Unterstützungszahlungen abzuarbeiten. Die dortige Sozialbehörde sah im Frühjahr 1938 grundsätzlich keine Notwendigkeit einer "besonderen Betreuung" dieser Gruppen. ${ }^{183}$ In Kooperation mit dem Landesarbeitsamt Nordmark begann Hamburg sogar, separate Lager für jüdische Pflichtarbeiter außerhalb des Stadtgebietes einzurichten. ${ }^{184}$

In Berlin hatte im Zuge der statistischen Erfassung aller jüdischen Armen von Mitte August 1938 der Leiter des Landeswohlfahrtsamtes, Behagel, verlangt, Pflichtarbeiter gesondert auszuweisen. ${ }^{185}$ Das konnte von den Bezirken zugleich

179 Ebenda, B1. 129.

180 Ebenda, Bl. 124 u. 130.

181 Zit. nach Lohalm, Fürsorge und Verfolgung, S. 31.

182 Vgl. Kapitel III. 2 sowie Lohalm, Fürsorge und Verfolgung, S. 41.

183 StA Hamburg, 351-10 Sozialbehörde I, AW 27.90, unfol.: Vermerk Fürsorge über Sitzung am 15. 3. 1938.

184 Ebenda, AW 40.30, unfol.: AFÜ-Vermerk vom 13.12.1937 über eine Besprechung mit dem Arbeitsamt Hamburg am 22. 11. 1937, AFÜ-Vermerke vom 13. und 16. 7.1938 sowie Vermerk über eine Besprechung zu Arbeitsmaßnahmen im Arbeitsamtsbezirk Stade vom 6. 8. 1938; vgl. dazu Lohalm, Hamburgs öffentliche Fürsorge, S. 505. In Frankfurt/

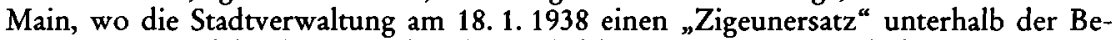
zugsnorm eingeführt hatte, strebte das Wohlfahrtsamt an, „die beschäftigungslosen $\mathrm{Zi}$ geuner und Zigeunerinnen sobald als möglich in Arbeit unterzubringen“; Wippermann, Leben in Frankfurt zur NS-Zeit, S. 77, Dok. Nr. 4: Fürsorgeamt/Abt. Wohnungsfürsorge an $\mathrm{OB}$ am 17. 1. 1938; vgl. Zimmermann, Rassenutopie und Genozid, S. 82.

185 LA Berlin, Rep. 214, Acc. 794, Nr. 13, unfol.: OB/Landeswohlfahrtsamt an Bezirksbür- 
als Aufforderung interpretiert werden, die Pflichtarbeitsprogramme auszuweiten. Berlin-Neukölln meldete 193 unterstützte Juden, darunter 44 Pflichtarbeiter. Sozial- und Kleinrentner, Kinder in Pflege sowie Kriegsbeschädigte abgerechnet, mußten also fast die Hälfte aller jüdischen Fürsorgeempfänger in diesem Bezirk Pflichtarbeit leisten. ${ }^{186}$ In ganz Berlin zählte man Ende September 1938685 jüdische Pflichtarbeiter. Noch erhielten sie, wie die „arischen" Pflichtarbeiter, monatlich einen Ernährungszuschlag von zehn RM. ${ }^{187}$ Arthur Aron verrichtete im Bezirk Schöneberg Pflichtarbeit. Da er sechs Kinder hatte, reichte die städtische Unterstützung auch mit diesem Zuschlag weder hinten noch vorn. Seine Frau mußte deshalb einen Antrag auf zusätzliche Hilfe bei der Jüdischen Wohlfahrt stellen: „Mein Mann macht [...] 3 Tage Pflichtarbeit für M[ar]k [0],55 täglich, wodurch ich noch mehr Ausgaben habe. Denn mit Margarinestullen kann er nicht arbeiten den ganzen Tag. " 188

Ungeachtet der auf der Heidelberger Sitzung des DGT-Wohlfahrtsausschusses im Juni 1937 ausgesprochenen Empfehlung, gegen jüdische Fürsorgeempfänger generell Pflichtarbeit zu verhängen, gab es bisher keinerlei zentrale Regelung für die lokale Praxis. Anfang Juni 1938 forderte das Hauptverwaltungsamt Frankfurt am Main deshalb vom Deutschen Gemeindetag eine grundsätzliche Stellungnahme, wie die Belastung der Öffentlichen Fürsorge und damit der Stadtgemeinden durch „arbeitsfähige Nichtarier in laufender Wohlfahrtsunterstützung“, von denen es allein 350 in Frankfurt am Main gäbe, zu verhindern sei. Die Stadt schlug vor, man könne „besondere zusätzliche und gemeinnützige Fürsorgearbeiten für Juden einrichten“, das würde aber die „Annahme der Juden auf Grund eines Arbeitsvertrages und ihre Entlohnung nach den Bestimmungen des Gemeindearbeitertarifs" bedingen. Ein Ergebnis, das offenbar nicht erwünscht war. ${ }^{189}$ Nach einer neuen Erinnerung durch die Stadtverwaltung 190 antwortete Dr. Schmiljan (DGT-Abteilung III) am 1. August 1938 den Tatsachen entsprechend, daß bisher Juden bei den meisten Kommunen sowieso unbezahlte Pflichtarbeit leisten müßten. $\mathrm{Da}$ aber die Anfrage aus Frankfurt am Main in „engem Zusammenhang mit der Neugestaltung der Fürsorge für Juden“" stehe, habe er "auf sie bei kürzlichen Verhandlungen im Reichsministerium des Innern über eine gesetzliche Gesamtregelung der Stellung und Behandlung der Juden in der öffentlichen Fürsorge hingewiesen. Wie die zuständigen Ministerialsachbearbeiter zum Ausdruck gebracht haben, wird man auch einer Lösung des Problems der Beschäftigung arbeitsfähiger hilfsbedürftiger Juden die gebotene Aufmerksamkeit schenken “. ${ }^{191}$ Etwas resoluter formulierte zwei Monate später Schlüter die Auffassung des Deutschen

germeister vom 16.8.1938 sowie ebenda: Bericht Bezirksbürgermeister Neukölln vom 5. 10. 1938.

186 Ebenda: Bericht Bezirksbürgermeister Neukölln vom 5. 10. 1938.

187 BA, R 41, Nr. 155, Bl. 130: Sonderbericht (Lippert) vom 5. 1.1939 zum Wirtschaftslagebericht für Berlin, Anhang.

188 CJA Berlin, 75 A Be 2, Nr. 337, unfol.: Brief vom 15.6. 1938. Vgl. Schüler-Springorum, "Elend und Furcht im Dritten Reich", S. 623-624.

189 BA, R 36, Nr. 785, unfol.: OB/IV Z Frankfurt/M. an DGT am 9.6. 1938.

190 Ebenda: OB/IV Z Frankfurt/M. an DGT am 26. 7. 1938.

191 Ebenda: DGT an OB Frankfurt/M. am 1. 8. 1938. 
Gemeindetages. Auf eine Anfrage aus dem Rheinland reagierend ${ }^{192}$, schrieb er, obwohl noch keine zentralen Vorgaben existierten, teile man die Auffassung der DGT-Provinzialdienststelle Rheinland, daß Pflichtarbeit bei Juden generell erwünscht sei. Er verwies nicht nur auf die rechtliche Unbedenklichkeit einer solchen Praxis, sondern zugleich auf die angebliche Erfahrung, daß "gerade Juden bei einer Heranziehung zur Pflichtarbeit auf die weitere Unterstützung verzichten “ würden. ${ }^{193}$

Gegen Ende des Sommers 1938 war es in einigen Städten zu einer Verschärfung der Arbeitsmaßnahmen gekommen. Leipzig, das schon seit 1936 jüdische Pflichtarbeiter einsetzte, beschäftigte mittlerweile monatlich 94 jüdische Arme, davon acht Frauen, und zwar jetzt immer unbefristet. Da der „Gesundheitszustand der männlichen Juden oft zu wünschen übrig ließ ${ }^{\prime}$, richtete man zusätzlich in einer Leipziger Arbeitsanstalt einen isolierten Platz für 35 bis 45 nicht voll arbeitstaugliche, jüdische Männer zum Holzspalten und Nietensortieren ein. Im Oktober 1938 veranlaßte die städtische Arbeitsfürsorge rigorose amtsärztliche Untersuchungen bisher als arbeitsunfähig eingestufter Wohlfahrtsempfänger. Das Ziel war, so formulierte man im Jahresbericht der Arbeitsfürsorge, jüdische „Drückeberger“ heranzuziehen, die sich von „jüdischen Ärzten arbeitsunfähig krankschreiben ließen“. Ein zusätzlicher Versuch des Leipziger Wohlfahrtsamtes, jüdische Pflichtarbeiter in Kooperation mit dem Arbeitsamt zu Schwerstarbeiten in eine Sandgrube und in einen Steinbruch zu schicken, scheiterte wegen zu hoher physischer Anforderungen. ${ }^{194}$

Symptomatisch für die wachsende Verflechtung von rigider Arbeitsmarkt- und Fürsorgepolitik, nicht nur gegenüber Juden, war eine im Frühsommer 1938 in Düsseldorf herausgegebene Anweisung an die Bezirksfürsorgestellen, „in jedem Fall nicht nur die fürsorgerechtliche Hilfsbedürftigkeit, sondern auch die Arbeitseinsatzfähigkeit des Betreffenden" zu überwachen. ${ }^{195}$ Hierfür sollten überall Arbeits- und Fürsorgeverwaltungen eng kooperieren. ${ }^{196}$ Auch Reichsinnen- und -arbeitsministerium betonten in einem Erlaß an die Bezirksfürsorgeverbände, daß

192 In einem Ort im Bezirk Aachen hatte der NSDAP-Ortsgruppenleiter Einspruch gegen die Pflichtarbeit von Juden in gemeindeeigenen Anlagen erhoben, als ein nach Verlust seines Wandergewerbescheins hilfsbedürftig gewordener Jude vom dortigen Wohlfahrtsbüro zu Pflichtarbeiten herangezogen wurde; NW-HStA Düsseldorf, RW 53 DGT, Nr. 473, unfol.: Amtsbürgermeister Baesweiler an DGT-Provinzialdienststelle Düsseldorf am 14. 10. 1938; ebenda: Entwurf DGT Düsseldorf an DGT Berlin am 19.10.1938 sowie BA, R 36, Nr. 784, unfol.: DGT Düsseldorf an DGT Berlin am 19. 10. 1938.

193 BA, R 36, Nr. 784, unfol.: DGT/Abt. III (Schlüter) an DGT Düsseldorf vom 27. 10. 1938. Auch in: NW-HStA Düsseldorf, RW 53 DGT, Nr. 473, unfol.

194 StadtA Leipzig, AFS, Nr. 1939, Bd. 3, Bl. 211-214: AFÜ-Verwaltungsbericht für das Jahr 1938.

195 Vfg. vom 23. 5. 1938; StadtA Düsseldorf, IV 965, unfol.: Vermerk Stadt Düsseldorf/Amt 43 vom 17. 6. 1938.

196 StadtA Dresden, Fürsorgeamt, Nr. 505, Bl. 13-14: Protokoll der Sitzung vom 14. 4. 1938 mit Vertretern des Arbeits- und des Wohlfahrtsamtes Dresden. 
„Arbeitseinsatzfähigkeit" als Hilfskriterium zu dienen habe, um nichtarbeitenden Hilfsbedürftigen die Unterstützung zu versagen. ${ }^{197}$

\section{Ministerialerlasse zur „Rassentrennung “ in öffentlichen Anstalten}

Nicht nur bei der Pflichtarbeit wurden arme Juden streng separiert, auch in Krankenhäusern bzw. in staatlichen oder städtischen Pflegeanstalten war das schon 1937 - wie gezeigt - die Regel. Zu Beginn des Jahres 1938 begann hierzu eine neue Diskussionsrunde im Deutschen Gemeindetag. Infolge einer Intervention des Oberpräsidenten der Provinz Ostpreußen ging es nun um den speziellen Fall der Aufnahme von Jüdinnen in einer von der Provinz unterhaltenen Landesfrauenklinik. Der Oberpräsident in Königsberg forderte, daß lediglich noch von den Wohlfahrtsämtern bzw. von den Krankenkassen überwiesene Frauen aufgenommen werden sollten, oder wenn Lebensgefahr für die Eingelieferten bestehe. Selbstzahlende Kranke müßten prinzipiell an Privatkliniken verwiesen werden, denn das Personal der dortigen Provinzialanstalt verweigere deren Pflege, außerdem dürfe der leitende Arzt als NSDAP-Mitglied geschäftlich nicht mit Juden verkehren, geschweige denn Arztrechnungen an diese ausstellen. Der Oberpräsident bat den Deutschen Gemeindetag, bei den zuständigen Stellen prüfen zu lassen, 1. ob Juden als Selbstzahler zugelassen werden müßten, 2. ob ausländische Juden - außer im Falle von Lebensgefahr - abgewiesen werden könnten und 3. herauszufinden, wie andere Anstalten in diesen Frágen handelten. ${ }^{198}$

Die DGT-Abteilung III übermittelte dem Oberpräsidenten in Königsberg zunächst das Umfrageergebnis über die „Behandlung" von Juden in städtischen Hospitälern vom Frühjahr 1937, versicherte ihm aber, darüber hinaus eine schriftliche Stellungnahme des Reichsinnenministeriums herbeizuführen. ${ }^{199}$ Die Intervention nahm man in der Abteilung zum Anlaß, Ende März 1938 eine neue Umfrage zu starten, diesmal bei den preußischen Oberpräsidenten. ${ }^{200}$ Über diese Recherche zu den Aufnahmebedingungen bei jüdischen Patienten in Landesfrauenkliniken informierte die DGT-Abteilung auch den Reichsinnenminister. Noch einmal betonte man die Dringlichkeit einer raschen Stellungnahme des Ministeriums zu diesen Fragen, da dem eine generelle Bedeutung für städtische Krankenhäuser und öffentliche Anstalten zukomme.201

Die im Frühsommer 1938 beim Deutschen Gemeindetag einlaufenden Antworten der Oberpräsidenten zeigen zum wiederholten Male, wie solche DGT-Umfragen zur Koordinierung und Radikalisierung antijüdischer Maßnahmen beitrugen. Der Oberpräsident der Provinz Hannover schloß sich nämlich sogleich den vom Oberpräsidenten in Ostpreußen aufgestellten Maximen in beiden Hauptpunkten

197 Gemeinsamer Runderlaß des RMdI und des RArbM zum Arbeitseinsatz von Wohlfahrtsunterstützten in der Landwirtschaft vom 12. 5. 1938; RMinBliV., 1938, S. 849.

198 LA Berlin, Rep. 142/7, 3-10-11/Nr. 72, unfol.: OP Ostpreußen (i.V. von Wedelstedt) an DGT Berlin am 13.2.1938.

199 Ebenda: Handschriftl. Vermerk vom 28. 2. 1938 auf Brief OP Ostpreußen an DGT Berlin am 13. 2. 1938, S. 2.

200 Ebenda: Umfrage DGT/Abt. III vom 28. 3. 1938.

201 Ebenda: DGT/Abt. III an RuPrMdI am 28. 3. 1938. 
an: Eine Anstalt könne nur in Fällen von Lebensgefahr oder bei Überweisung durch die Wohlfahrtsämter bzw. Krankenkassen Juden nicht abweisen, in allen anderen Fällen würden die Direktoren jüdische Patientinnen nicht behandeln, insbesondere nicht in der gynäkologischen Abteilung, der Poliklinik und der Schwangerenberatung. ${ }^{202}$ Der Oberpräsident der Provinz Westfalen reagierte in der gleichen Weise auf die Umfrage. Er bekräftigte, daß die ihm unterstellten Landesfrauenkliniken künftig jüdische Patientinnen nur aufnähmen, wenn Lebensgefahr oder Überweisung durch Wohlfahrtsämter bzw. Kassen vorläge. ${ }^{203}$ Aus Brandenburg verlautete, daß seit Jahren keine jüdischen Patienten mehr behandelt worden seien. Selbstzahlende Kranke würden immer an die Berliner jüdischen Einrichtungen verwiesen. Nur in Notfällen könne die Aufnahme nicht abgelehnt werden. ${ }^{204}$ Der Oberpräsident in Merseburg informierte den Gemeindetag, daß in Magdeburg jüdische Patientinnen abgewiesen werden, weil ein jüdischer Facharzt vorhanden sei. In Erfurt hingegen, wo es keinen solchen gebe, habe der Amtsleiter der Kassenärztlichen Vereinigung Deutschlands und Leiter des NS-Ärztebundes „arische“ Gynäkologen ermächtigt, Jüdinnen zu versorgen. Die Direktoren der beiden Landesfrauenkliniken seien aber angewiesen, Jüdinnen nur in die untersten Krankenhausklassen aufzunehmen, und auch nur bei Lebensgefahr oder bereits eingeleiteter Geburt. In die besseren Hospitalklassen sei die Aufnahme nur in seltensten Fällen gestattet. Die Honorare jüdischer Privatpatientinnen müßten von den Ärzten an die NSV abgeliefert werden, um einen persönlichen Gewinn aus der Behandlung von Jüdinnen auszuschließen. ${ }^{205}$ Das schlesische Oberpräsidium teilte mit, daß eine Aufnahme jüdischer Patientinnen und Wöchnerinnen die große Ausnahme darstelle. In den Fällen einer dringend notwendigen Behandlung würden jüdische Kranke und Wöchnerinnen auf der allgemeinen Station, aber nach Möglichkeit separat untergebracht. ${ }^{206}$

Offenbar vom Deutschen Gemeindetag unmittelbar über die Antworten aus den preußischen Provinzen informiert, schickte nun die Kommunalabteilung des Reichsinnenministeriums quasi postwendend die so lange von den Kommunen und dem Gemeindetag geforderte Anweisung. Das Ministerium bestimmte in seinem Erlaß vom 2. Mai 1938, der die vor Ort herrschende Praxis im großen und ganzen, wenn auch leicht verklausuliert, absegnete: "Jüdischen Patienten, auch soweit sie die deutsche Staatsangehörigkeit nicht besitzen, kann die Aufnahme in eine Landesfrauenklinik oder in sonstige öffentliche Krankenanstalten nicht verwehrt werden. Bei Selbstzahlern empfiehlt es sich jedoch, sie zunächst an ein jüdisches Krankenhaus zu verweisen, wenn ein solches erreichbar ist und nicht unmittelbare Lebensgefahr besteht. “207

Der Deutsche Gemeindetag unterrichtete hierüber wenige Tage später die preu-

202 Ebenda: OP in Hannover (i.V. Hartmann) an DGT Berlin am 4. 4. 1938.

203 Ebenda: OP in Münster (i.A. Bartling) an DGT Berlin am 19. 4. 1938.

204 Ebenda: OP Brandenburg (i.V. von Arnim) an DGT am 29. 4. 1938.

205 Ebenda: OP in Merseburg (i.A. Dr. Tießler) an DGT am 6. 5. 1938.

206 Ebenda: OP Schlesien an DGT am 25. 4. 1938.

207 Ebenda: RuPrMdI (i.A. Dr. Cropp) an DGT am 2. 5. 1938. 
Bischen Oberpräsidenten. ${ }^{208}$ Zwar gab es jetzt eine zentrale Regelung zur Aufnahme jüdischer Patienten, nicht aber zur verbreiteten Praxis, diese in städtischen Kranken- und Heilanstalten abgesondert unterzubringen. Staatssekretär Pfundtner (RMdI) legalisierte einige Wochen später auch dieses Vorgehen. Im Erlaß vom 22. Juni 1938, in welchem es hauptsächlich um "gesundheitspolizeiliche Mißstände“ in Krankenanstalten ging, ordnete er an: „Besondere Aufmerksamkeit ist wegen der Gefahr einer Rassenschändung der Unterbringung von Juden in den Krankenanstalten zu widmen. Sie müssen von Kranken deutschen oder artverwandten Blutes räumlich getrennt untergebracht werden. Soweit Juden, die nicht bettlägerig krank sind, in Kranken- usw. Anstalten verbleiben müssen, muß ihre Unterbringung und die Regelung ihrer Bewegung im Hause und im Anstaltsgelände die Gefahr einer Rassenschändung mit Sicherheit ausschließen. Dies gilt erfahrungsgemäß vornehmlich in Heil- und Pflegeanstalten und ganz besonders in Tuberkulose-Krankenhäusern und -Abteilungen, sowie in Tuberkulose-Heilstätten." Die Leiter solcher Anstalten sollten durch die zuständigen Instanzen, also Landesregierungen, preußische Regierungspräsidenten oder Oberbürgermeister, auf ihre Pflicht hingewiesen werden, „dieser Gefahr unter allen Umständen vorzubeugen“. 209

Der Oberpräsident der preußischen Provinz Schlesien forderte infolge dieses Erlasses vom Deutschen Gemeindetag eine Inspektion der Praxis in den anderen preußischen Provinzen. Zwar werde in Schlesien die Forderung nach Vermeidung der „Rassenschändung “ „von den Anstalten selbstverständlich erfüllt", allerdings zweifele man an der Durchführbarkeit der zweiten Forderung, der räumlichen Isolierung. Abgesehen von organisatorischen Schwierigkeiten, befürchte man, daß so eine "Anstalt bald einen schlechten Ruf bekommen" werde. ${ }^{210}$ Daraufhin startete der geschäftsführende Präsident des Deutschen Gemeindetages, Jeserich, im Oktober eine Umfrage in den preußischen Provinzen über die Unterbringung von Juden in öffentlichen Heil- und Pflegeanstalten. ${ }^{211}$ Die Berichte ergaben, daß „Rassenschändung“ überall als ausgeschlossen betrachtet werde, da die Patienten nach Geschlechtern getrennt untergebracht seien. Die räumliche Absonderung der jüdischen Deutschen werde - soweit durchführbar - realisiert. In Westfalen und Sigmaringen scheitere die Isolierung aber an den immer geringer werdenden Zahlen jüdischer Patienten in öffentlichen Anstalten, in Brandenburg, Ostpreußen, Pommern, Schleswig-Holstein und Schlesien hingegen an der heterogenen Zusammensetzung der Kranken nach Alter und Krankheit. Da der Zustand der „arischen“ Kranken meist „gar nicht das Empfinden einer Belästigung durch die Anwesenheit eines jüdischen Kranken" erlaube, sahen Brandenburg, Ostpreußen, Schleswig-Holstein und Sigmaringen eine Extraregelung als nicht notwendig an.

208 Ebenda: Handschriftl. Vermerk vom 6. 5. 1938 auf dem Schreiben RuPrMdI an DGT.

209 BA, R 36, Nr. 1842, Bl. 3-4RS: RMdI-Runderlaß vom 22. 6. 1938. Vgl. Teilabdruck bei Reinke, Judentum, S. 268-269. Erwähnung auch bei Friedlander, Der Weg zum NS-Genozid, S. 426.

210 BA, R 36, Nr. 1842, Bl. 5: OP/Landeswohlfahrtsamt an DGT Berlin am 10. 10. 1938. Vgl. Reinke, Judentum, S. 269.

211 BA, R 36, Nr. 1842, Bl. 7: DGT Berlin (Jeserich) Umfrage vom 20. 10. 1938. 
Bei einer Zusammenlegung innerhalb der jeweiligen Anstalten oder bei der als Alternative von Ostpreußen und Westfalen erwogenen Konzentration jüdischer Patienten in einer Provinzialanstalt sei mit dem Protest des "deutschblütigen“ Pflegepersonals zu rechnen, so die Vorhaltungen aus Sachsen und Brandenburg. Über den Ministerialerlaß weit hinausgehend, schlugen die Provinzialverwaltungen Ostpreußen und Westfalen als Lösung des Problems die Konzentration jüdischer Anstaltsinsassen mehrerer Provinzen in einer öffentlichen Anstalt vor. Sachsen forderte hingegen bereits die Konzentration „aller geisteskranken Juden des Gesamtreiches in einer unter jüdischer ärztlicher Leitung stehenden Anstalt mit ausschließlich jüdischem Pflegepersonal“..212

\section{Ministerialerlasse zur „Rassentrennung “ im Adoptions- und Vormundschaftswesen}

Wie gezeigt, hatte es bislang wegen der „Rassentrennung“ im Vormundschaftsund Pflegewesen zwar viele Diskussionen, jedoch keine zentrale Regelung gegeben. Lediglich bei der Genehmigung neuer Adoptionen sollten bei der Elternauswahl seit längerem rassistische Maßstäbe angelegt werden. In Hamburg überprüfte das Jugendamt aber schon 1937 alle unter seiner Mitwirkung geschlossenen Adoptionsverträge daraufhin, ob „arische" Kinder in jüdische Familien aufgenommen worden waren. Ziel dieser Hamburger Initiative war es, „arische“ Kinder vom „jüdischen Einfluß“ zu befreien, selbst unter Inkaufnahme "menschlicher Tragik". Abgesichert hatte sich das Jugendamt, indem es zuvor das Plazet des zuständigen Oberlandesgerichtes für dieses Vorgehen einholte. Dessen Präsident und die Hamburger Behördenleitung stimmten Ende 1937 überein, daß „es untragbar erscheint, wenn ein arisches Kind in einer Familie aufwächst, deren männlicher Teil ein Volljude ist". ${ }^{213}$

Auch diese Praxis sollte nun legalisiert werden: Am 20. September 1938 ordnete das Reichsinnenministerium über sein Verbot neuer Adoptionen „verschiedener Rassen" von 1937 hinausgehend an, daß jetzt auch bestehende Adoptionsverhältnisse aus dem gleichen Grund „im dringenden öffentlichen Interesse“ aufhebbar seien. Die höheren Verwaltungsbehörden ${ }^{214}$ sollten Aufhebungsanträge stellen,

212 In Sachsen konnte man sich nur eine Absonderung durch die Unterbringung der jüdischen Kranken in Einzelzimmern vorstellen, dann gerate aber die Trennung innerhalb der Anstalt zum Nachteil der „arischen“ Patienten, die in Schlafsälen untergebracht wären. Nassau kritisierte die potentiell für eine Isolierung innerhalb einer Anstalt entstehenden baulichen Kosten. In den vier preußischen Provinzen handelte es bei der Zahl jüdischer Insassen insgesamt um 464 Personen, in Ostpreußen 28, Brandenburg 300 (davon 250 aus Berlin), Schleswig-Holstein 13 und Schlesien 123 jüdische Patienten. Hannover, Hessen und die Rheinprovinz hatten im Oktober noch keine Stellungnahmen abgegeben; ebenda, Bl. 30-31: DGT Berlin Vermerk (undatiert) über Ergebnis der Umfrage vom 20. 10. 1938. Vgl. Darstellung dieser Diskussion mit weiteren Einzelheiten bei Friedlander, Der Weg zum NS-Genozid, S. 426-427. Nur erwähnt ist diese dagegen bei Bock, Zwangssterilisation, S. 210, Anm. 63.

213 Zit. nach Lohalm, Fürsorge und Verfolgung, S. 38.

214 Also die preußischen und bayerischen Regierungspräsidenten, die sächsischen Kreishauptmänner, der Berliner Polizeipräsident und in den übrigen Ländern die Regierungen. 
„wenn ein Vertragsteil Jude oder mit einem Juden verheiratet, der andere Vertragsteil deutschblütig oder Mischling zweiten Grades" war. Auch die Amtsgerichte, die Polizei, die Jugendämter und die Standesbeamten wurden aufgerufen, solche Fälle anzeigen. Bei minderjährigen Kindern müsse bei den Vormundschaftsgerichten ein Pfleger bestellt werden, der den Aufhebungsantrag betreiben mußte. 215

In Berlin lief der Ausgrenzungsprozeß im Vormundschafts- und Pflegewesen zunächst vor allem über die Mittelvergabe. Noch im Frühjahr 1937 hatte die Stadt Berlin für die Unterbringung zweier unehelicher Kinder bei einer Pflegemutter 11 RM gezahlt, die Mutter drei RM dazugesteuert. Den Rest bis zur monatlichen Höhe von 40 RM übernahm das Jüdische Wohlfahrtsamt. ${ }^{216}$ Im Januar 1938 hatte dann das Bezirksamt Prenzlauer Berg die monatliche Unterstützung für ein zu Hause lebendes uneheliches Kind, dessen Vormund die Jüdische Gemeinde war, von $13 \mathrm{RM}$ auf nur noch $8 \mathrm{RM}$ monatlich gekürzt. ${ }^{217}$ Das Landeswohlfahrtsamt bestimmte im Frühjahr 1938, daß für die Hauspflege durch den Jüdischen Frauenbund e.V. die neuen städtischen, ab 1. April 1938 erhöhten Vergütungssätze nicht galten. Anträge auf Vergütung bei jüdischen Hilfsbedürftigen durften von den Bezirkswohlfahrtsämtern nur noch in dringenden Fällen in geringstem Umfang genehmigt werden ${ }^{218}$ Ottilie Reich berichtete im Spätsommer dem in der Jüdischen Gemeinde angestellten Sammelvormund ihrer unehelichen Kinder, deren Vater Häftling im KZ Buchenwald war: „Am 16. September bin ich auf dem Wohlfahrtsamt Berlin Mitte gewesen betreffs Pflegegeld für mein Kind, man sagte mir dort, ich müsse mich an den Vormund des Kindes wenden, da die Stadt Berlin schon genug für arische Kinder zu sorgen hat." 219 Einige Berliner Bezirksämter erstatteten inzwischen auch keine Kosten für die Unterbringung in jüdischen Kinderheimen mehr. Daher mußte die Jüdische Gemeinde die Mutter Gerda Kreiner auffordern, ihren ein Jahr alten Jungen nach Hause zu holen. ${ }^{220}$ Das Bezirksjugendamt Charlottenburg weigerte sich mit der Begründung, es lebten noch genügend Verwandte in Berlin, die Kosten für die Unterbringung eines Kindes im

215 RMinBliV., 1938, S. 1597.

216 CJA Berlin, 75 A Be 2, Nr. 437, Bl. 25: Vermerk Silbermann vom 14. 4. 1937. Hierzu sowie zur Problematik und Situation unehelicher Pflegekinder in Berlin allg. Schüler-Springorum, „Elend und Furcht im Dritten Reich“, S. 625-635.

217 CJA Berlin, 75 A Be 2, Nr. 435, Bl. 23 u. 25: Bezirksamt an Lamm am 12. 9. 1937 und 9.1. 1938.

218 Hauspflege für Juden: 1 Stunde 0,45 RM (gegenüber 0,55 neu), 2 Stunden 0,90 RM (1,10), 3 Stunden 1,35 RM (1,65), 4 Stunden 1,70 RM (2,20), 5 Stunden 2 RM (2,75), mehr als 5 Stunden und für den ganzen Tag 2,50 RM (3,30), für die Nacht 2,70 RM (4 RM), für den Waschtag 3,60 RM (4,40); Dienstblatt der Stadt Berlin, 1938 Teil VII, S. 124, Nr. 114: Vfg. Spiewok (OB/Landeswohlfahrtsamt) vom 27.4.1938; vgl. Gruner, Judenverfolgung in Berlin, S. 48.

219 CJA Berlin, 75 A Be 2, Nr. 424, Bl. 23: Reich an Lamm am 17. 9. 1938. Vgl. SchülerSpringorum, „Elend und Furcht im Dritten Reich“, S. 624-625.

220 CJA Berlin, 75 A Be 2, Nr. 380, Bl. 4: Silbermann (Jüdische Gemeinde) an Kreiner am 22. 9. 1938 . 
Jüdischen Kinderheim Fehrbelliner Straße zu übernehmen. ${ }^{221}$ Das Wohlfahrtsamt Wedding zahlte wenigstens noch einen Anteil von $30 \mathrm{RM}$ am ermäßigten monatlichen Satz von 40 RM für ein Kind im Heim Niederschönhausen, wovon die Mutter allerdings zwei Drittel dem Amt erstattete. Den Rest übernahm die Jüdische Wohlfahrt. ${ }^{222}$

Im Mai 1938 hatte der neue Leiter des Landeswohlfahrtsamtes, Behagel, zudem angeordnet, daß die Berliner Jugendämter Eltern die Pflegeerlaubnis für ein Kind $\mathrm{zu}$ versagen hatten, wenn ein Elternteil und das Pflegekind unterschiedlichen „Rassen“ angehörten.223 Ein Entwurf eines zentralen Erlasses zum Vormundschafts- und Pflegschaftswesen lag Dank der Diskussionen von Kommunen und Deutschem Gemeindetag seit Anfang 1938 im Reichsinnenministerium vor. ${ }^{224}$ Trotz wiederholter Interventionen der Sozialabteilung des Gemeindetages zog sich dessen Herausgabe aber bis zum Herbst des Jahres hin, denn es fehlte die Stellungnahme des Stellvertreters des Führers. ${ }^{225}$ Erst am 17. Oktober gab das Ministerium den lange erwarteten Erlaß über die „Berücksichtigung der Rassengrundsätze bei Bestellung von Einzelpersonen zu Vormündern, Pflegern, Helfern und Beiständen“ heraus. Juden durften jetzt nicht mehr zum Vormund von „Deutschblütigen“ oder „Mischlingen zweiten Grades“ bzw. „Deutschblütige“ nicht mehr zu solchen von Juden und von „Mischlingen“ nur noch in Ausnahmefällen bestimmt werden. ${ }^{226}$ Das bedeutete für die Praxis in den Kommunen, daß die Jugendämter die Vormundschaften für als „jüdisch“ eingestufte Kinder nun entweder an jüdische Einzelvormünder oder an Sammelvormünder der Jüdischen Gemeinden abgaben.227

\section{Exkurs: Zur „Arisierung “ mildtätiger Stiftungen (II)}

Ausgelöst durch die Ende 1936 eingeführten Steuererschwernisse hatte das Thema der jüdischen bzw. "gemischten“ Stiftungen auf der Heidelberger Tagung des DGT-Wohlfahrtsausschusses im Juni 1937 eine prominente Rolle gespielt. Nachdem Martini in seinem Grundsatzreferat bereits Satzungsänderungen gefordert

221 Ebenda, Nr. 354, Bl. 1: Bezirksjugendamt Charlottenburg an Jüdisches Wohlfahrts- und Jugendamt am 2.11. 1938.

222 Ebenda, Nr. 379, Bl. 23: Lamm an Wohlfahrts- und Jugendamt Wedding am 23. 10. 1938.

223 Dienstblatt der Stadt Berlin, 1938 Teil VII, S. 165-166, Nr. 167: Vfg. Behagel (Landesjugendamt) vom 20. 5. 1938; vgl. Gruner, Judenverfolgung in Berlin, S. 50.

224 BA, R 36, Nr. 1442, Bl. 50RS: Handschriftl. Vermerk Zengerling vom 26.1.1938 auf DGT/Abt. III an RuPrMdI am 5. 9. 1937.

225 Ebenda: Handschriftl. Vermerke Zengerlings vom 24. 3. und vom 21.6.1938 sowie ebenda, Bl. 51: DGT/Abt. III (Schlüter) an RMdI am 22. 10. 1938.

226 RMinBliV., 1938, S. 1722. Verbreitet durch den DGT-Nachrichtendienst am 11. 11. 1938. Vgl. auch Abdruck in: Dienstblatt der Stadt Berlin, 1938 VII, S. 381, Nr. 339.

227 In Berlin ging die Vormundschaft bei unehelichen Kindern jüdischer Mütter und narischer" Väter meist gegen Ende 1938 auf die Jüdische Gemeinde über; CJA Berlin, $75 \mathrm{~A} \mathrm{Be}$ 2, Nr. 420, Bl. 2: Jüd. Wohlfahrts- und Jugendamt Weißensee an Zentrale am 13. 3. 1939. Die Bestellung von Einzelvormündern konnte wie in einem Hamburger Fall aber auch zwei Jahre, bis 1940, dauern. Ein solcher Fall ist ausführlich dokumentiert bei Eckler, Vormundschaftsakte, S. $47-60$. 
hatte, um „jüdische Stipendisten" in paritätischen Stiftungen auszuschließen, berichteten Fischer-Defoy (Frankfurt am Main) und Fischer (Essen) über Initiativen zur Aufteilung bzw. Auflösung solcher Stiftungen. Ministerialrat Ruppert stellte abschließend fest, es müsse erwogen werden, „Stiftungsmittel im Wege besonderer gesetzlicher Bestimmungen mit der ausdrücklichen Auflage" zusammenzufassen, „die für Juden bestimmten Mittel zur Errichtung von Anstalten für Juden und ähnliche Zwecke" zu verwenden.228

Doch bis zum Erreichen dieses Ziels sollte noch viel Zeit verstreichen, und so handelte man vor Ort wie gewohnt in eigener Verantwortung. Am 29. November 1937 bat der Bürgermeister von Bad Polzin den Deutschen Gemeindetag um Hilfe, wie er die Stiftung eines jüdischen Kaufmannes aus dem Jahre 1867 zur Förderung armer Polziner aufheben könne. Der Gemeindetag solle doch genaueres über die Praxis in anderen Städten ermitteln. ${ }^{229}$ Nach der Rechtslage, so antwortete die DGT-Hauptabteilung I dem Bürgermeister, sei es nur möglich, Stiftungen aufzuheben, wenn der Stiftungszweck unmöglich geworden sei oder die Stiftung das Gemeinwohl gefährde. Beides sei hier nicht der Fall: „Es kann nicht angenommen werden, daß die Stiftung deshalb das Gemeinwohl gefährdet, weil sie von einem Juden errichtet worden ist. Der heutigen Auffassung würde es aber entsprechen, wenn die Mittel der Stiftung lediglich Juden zugute kommen würden."230 Der Gemeindetag lehnte zwar die geplante Enteignung ab, plädierte aber für eine Separierung der Stiftung.

Andere Kommunen hatten längst auf ihre Weise Tatsachen geschaffen und Stiftungsmittel „arisiert“. Die Stadt Frankfurt am Main verhandelte seit 1937 mit der dortigen Jüdischen Gemeinde um die Trennung gemischter Stiftungen. Dabei blieben aber die zuvor von der Stadt bereits aufgelösten bzw. durch Satzungsänderungen „auf deutsche Volksgenossen“ umgestellten Stiftungen außer Betracht. ${ }^{231}$ Im Januar 1938 fand sich die Jüdische Gemeinde unter dem fortwährenden Druck der Kommune zu der eigentlich illegalen Aufteilung interkonfessioneller Stiftungen bereit. Man verlangte aber die Hälfte des Gesamtkapitals von 1,5 Millionen RM. Doch die Stadt wollte lediglich ein Viertel der Gelder zugestehen, was die jüdische Seite entrüstet ablehnte. Frankfurt insistierte daraufhin sowohl beim Reichsfinanzministerium als auch beim Deutschen Gemeindetag, um die geplante "Arisierung" von Stiftungsmitteln auf anderen Wegen durchzusetzen.232

Die Rechtsabteilung des städtischen Wohlfahrtsamtes München, hatte den Gemeindetag schon 1936 und 1937 mit Anfragen zur Verwaltung jüdischer Stiftungen bedrängt. Doch der Gemeindetag hatte lediglich auf einen in Vorbereitung befindlichen Runderlaß verwiesen. Die Rechtsabteilung erneuerte deshalb ihre An-

228 Lohalm, Fürsorge und Verfolgung, Anhang, Dok. Nr. 1, S. 90-94.

229 LA Berlin, Rep. 142/7, 1-2-6/Nr. 1, Bd. 2, unfol.: Bgm. Bad Polzin an DGT Berlin am 29. 11.1937.

230 Ebenda: DGT/Abt. I (Dr. Schöne) an Bgm. Bad Polzin am 16. 12. 1937.

231 Dokumente Frankfurter Juden, III 69, S. 127: Aktennotiz der Stiftungsabteilung vom 20.1.1938.

232 Kingreen, Raubzüge, S. 22-23. 
frage Anfang Juli 1938233, wofür möglicherweise ein Erlaß des Reichsministeriums für Wissenschaft, Erziehung und Volksbildung vom 2. Juni 1938 den Anlaß geboten hatte. Jener bestimmte, daß sämtliche jüdischen Stiftungen und Vereine, die der Wissenschaft, Erziehung und Volksbildung dienten, in einem Verzeichnis erfaßt und dahingehend überwacht werden sollten, daß kein Kapital „böswillig vermindert oder verschleudert" werde. ${ }^{234}$ Auf die Münchner Anfrage reagierend, fragte der Gemeindetag beim Reichsinnenministerium am 19. Juli jetzt noch einmal an, wie mit jüdischen Stiftungen künftig zu verfahren sei. Das Ministerium kündigte Ende Juli hierzu allgemeine Richtlinien an. ${ }^{235}$ Von dort erhielt man im Gemeindetag Mitte August dann aber die telefonische Auskunft, daß vor einer generellen Regelung noch der Stellvertreter des Führers befragt werden müsse. Die Bearbeitung aller Anträge werde vom Ministerium deshalb bis zu dessen Entscheidung eingefroren. ${ }^{236}$

Da dieses Prozedere der Münchner Stadtverwaltung wahrscheinlich zu lange dauerte, hatte sie unterdessen, im Juli 1938, um eine Aussprache im Bayerischen Innenministerium nachgesucht. Das Stiftungsamt forderte Anfang August dort eine pauschale Genehmigung, jüdische Stiftungen aufzulösen, „daß der Name verschwindet, daß die Stiftung als solche untergeht oder in andere Stiftungen übergeht, und daß man trotzdem dem Stiftungszweck, nämlich der Unterstützung Hilfsbedürftiger gerecht wird“. Doch auch das Bayerische Ministerium lehnte ab: Da das Reichsinnenministerium gesetzliche Regelungen vorbereite, wolle man augenblicklich keine Eingriffe in jüdische Stiftungen zulassen. Allerdings, wie so oft in den letzten Jahren, baute man der städtischen Behörde eine Brücke. Ausnahmen wie Umbenennungen wollte das Ministerium nämlich tolerieren. Damit hatte das Ministerium eine Verfügung der Stadt München vom 13. Juni 1938, daß alle lokalen jüdischen Stiftungen umzubenennen seien, und deren Folgen, quasi legalisiert. ${ }^{237}$ Schon am 28. Juni hatte die Stadt in einer ersten Staffel elf kleinere jüdische Armenstiftungen mit einem Kapital unter 3000 RM in einen extra geschaffenen Fonds „Wohltätigkeitsstiftungen der Hauptstadt der Bewegung " überführt. ${ }^{238}$ Oberbürgermeister Fiehler plante jetzt, weitere Stiftungen diesem städtischen Fonds einzuverleiben. Doch die Landesregierung hatte noch nicht einmal die Einzelgenehmigungen für die ersten „Namensänderungen“ erteilt, weshalb der Oberbürgermeister das Bayerische Innenministerium weiterhin - jedoch erfolglos - belagerte. ${ }^{239}$ Während auf der städtischen Ebene mit der „Arisierung" von mildtätigen Stiftungen Fakten geschaffen wurden, änderte man auf

233 LA Berlin, Rep. 142/7, 1-2-6/Nr. 1, Bd. 2, unfol.: OB/BFV München an DGT am 6.7. 1938.

234 BA, 49.01, Nr. 11787, Bl. 92: RMWiss-Erlaß vom 2. 6. 1938.

235 Adam, Judenpolitik, S. 193. Vgl. LA Berlin, Rep. 142/7, 1-2-6/Nr. 1, Bd. 2, unfol.: DGT/ Abt. I (Döbereiner) an OB/BFV München am 5. 8. 1938.

236 Ebenda: Vermerk DGT/Abt. I vom 22. 8. 1938.

237 Zit. nach Hanke, Juden in München, S. 247-248.

238 Ebenda, S. 318: Anhang.

239 Ebenda, S. 249 u. 318. 
der Ministerialebene mehrfach die Entwürfe für die neuen Richtlinien, so daß deren Herausgabe sich noch um Monate verzögerte.240

\section{Exkurs: Fürsorge und Judenverfolgung in Wien im Sommer 1938}

Vor 1938 hatte es in Österreich 34 Jüdische Kultusgemeinden, 79 Bethausvereine und 357 weltliche Vereine gegeben. ${ }^{241}$ Seit dem "Anschluß" regierte ein Stillhaltekommissar das Vereinswesen ${ }^{242}$ : Nur jüdische Vereine für Geschlossene Fürsorge durften weiterarbeiten, jene für Offene Fürsorge sowie für wohltätige Ausspeisungen mußten aufgelöst werden. Im Sommer ordnete der Stillhaltekommissar an, daß die Israelitische Kultusgemeinde die Notausspeisungen für inzwischen 12000 jüdische Bedürftige in Wien allein vorzunehmen habe. ${ }^{243} \mathrm{Im}$ Unterschied zum Altreich wurden nicht nur viele jüdische Wohlfahrtsvereine liquidiert, sondern die nicht aufgelösten bis Ende September/Anfang Oktober 1938 in die örtlichen jüdischen Kultusgemeinden inkorporiert. An der Spitze des jüdischen Wohlfahrtswesens stand nunmehr die Fürsorgezentrale der Wiener Kultusgemeinde, der auch die Fürsorgeabteilungen der 20, zu diesem Zeitpunkt in Österreich noch existierenden Jüdischen Gemeinden angeschlossen waren. ${ }^{244}$

Infolge der radikalen antijüdischen Maßnahmen, wie Massenentlassungen, zwangsweisen Umsiedlungen aus der Provinz nach Wien, Wohnungskündigungen und Verhaftungen, spitzte sich das Problem der Armut in der jüdischen Bevölkerung im Laufe des Sommers immer weiter zu. Die finanzielle Situation der jüdischen Fürsorge war aufs äußerste angespannt. ${ }^{245}$ Vor allem die sozialen Folgen der Entlassungswellen, die auch „Mischlinge“ mittlerweile in großem Umfang trafen, waren so drastisch, daß das Reichsministerium des Innern sich über den Reichskommissar Bürckel zu einer Intervention veranlaßt sah. Stuckart gab am 1. September $1938 \mathrm{zu}$ bedenken, eine „allgemeine Kündigung der jüdischen Mischlinge würde nur die Bildung eines staatsfeindlichen Proletariats fördern, die

240 Adam, Judenpolitik, S. 193.

241 Central Archives for the History of the Jewish People (im folg. CAHJP) Jerusalem, A/W, Nr. 165/1, Bl. 107: Bericht IKG Wien an Eichmann vom 4. 1. 1939.

242 Rothkappl, Gertrude: Die Zerschlagung österreichischer Vereine, Organisationen, Verbände, Stiftungen und Fonds. Die Tätigkeit des Stillhaltekommissars in den Jahren 19381939, Diss. Wien 1996. Zum folg. auch Gruner, Zwangsarbeit und Verfolgung, S. 31-33 sowie Rosenkranz, Verfolgung, S. 150-151.

${ }^{243}$ CZA Jerusalem, S 26, Nr.1191g, unfol.: Bericht über die Tätigkeit der IKG Wien 19. 5. 1938-1944/45 (sog. Löwenherz-Bericht), S. 1-2; Rosenkranz, Verfolgung, S. 150151. Zur Zahl der Bedürftigen: BA, ZwA Dahlwitz-Hoppegarten, ZA I, Nr. 7358, A. 4., Bl. 367-368: Bericht IKG Wien (Löwenherz) über die letzten drei Monate, vom 29. 6.1938.

244 ÖStA/AdR Wien, Bürckel-Mat, Nr. 1762, unfol.: Brief des RK/Stab-Stillhaltekommissars für Vereine an den RK/Stab vom 4. 10.1938 (abges. am 5. 10.).

245 CAHJP Jerusalem, A/W, Nr. 106, unfol.: Tätigkeitsbericht IKG Wien 13. 3.-31. 12. 1938, S. 22. 
Fürsorgeverbände belasten und überdies den arbeitsmarktpolitischen Notwendigkeiten zuwiderlaufen". 246

In Wien, wo die Mehrheit der österreichischen Juden lebte, trug die kommunale Wohlfahrt anfänglich weiter zur Grundversorgung jüdischer Armer bei. Diese Tatsache, die ja den frühen Ausschlußbestrebungen der Wohlfahrtsämter zuwiderlief, lag in der starken Stellung des Sicherheitsdienstes der SS im Machtgefüge der „Ostmark “, insbesondere nach der Einrichtung der „Zentralstelle für jüdische Auswanderung", begründet. Der SD blockierte antijüdische Maßnahmen anderer Behörden, wenn deren potentielle Folgen die Finanzen jüdischer Organisationen, gerade auf dem Feld der Fürsorge, zu überlasten drohten. Zur Absicherung der Politik von Separierung und Vertreibung achtete der SD in Wien auf eine funktionsfähige Infrastruktur der jüdischen Einrichtungen, noch bevor dies nach dem Novemberpogrom 1938 Maxime im ganzen Reich werden sollte. ${ }^{247}$ Mitte September konnte daher die dortige Jüdische Kultusgemeinde bei Eichmann offen die Beschlagnahme vieler jüdischer Heime und Stiftungen kritisieren. ${ }^{248}$

Am 10. Oktober 1938 fand dann im Wiener Ministerium für innere und kulturelle Angelegenheiten eine Besprechung über die formelle Einführung der Fürsorgepflichtverordnung mit Ministerialvertretern aus Deutschland statt. Im Zuge dieser Übertragung sollte - wie schon im Altreich - auch in der "Ostmark" die Fürsorgepolitik ganz auf die Arbeitsmarkterfordernisse ausgerichtet werden. Von der Öffentlichen Wohlfahrt unterstützte Arbeitsfähige hätten sich künftig regelmäßig bei den Arbeitsämtern zu melden, außerdem Pflichtarbeit zu verrichten. Die Unterrichtung der österreichischen Fürsorgebehörden über diese neuen Maximen sollte das Ministerium ausdrücklich mit dem Hinweis verknüpfen, daß in Berlin die Sozialunterstützung der Juden grundsätzlich mit der Ableistung von Pflichtarbeit verkoppelt sei. 249 Die Fürsorgeämter in der „Ostmark" wurden damit direkt aufgefordert, eine im Altreich bereits traditionelle lokale Diskriminierungspraxis zu übernehmen, und zwar interessanterweise jetzt von zentraler Seite.

\section{Zentrale antijüdische Politik und Vorbereitung einer antijüdischen Fürsorgeverordnung}

Durch die Annexion Österreichs waren fast 200000 Juden in deutsche Herrschaftsgewalt geraten. Damit zerronnen alle bisherigen Vertreibungserfolge der NS-Führung zu einer Schimäre. Auf die geänderte Situation hatten die an der Verfolgung maßgeblich interessierten Reichsinstanzen seit dem Frühjahr 1938 so-

246 ÖStA/AdR Wien, Bürckel-Mat., Nr. 2160/1, Bl. 30 u. RS: RMdI-Schnellbrief (Stuckart) vom 1.9. 1938.

247 Gruner, Zwangsarbeit und Verfolgung, S. 40-42.

248 CZA Jerusalem, S 26, Nr. 1191g, unfol.: Bericht IKG Wien 1938-1944/45 (LöwenherzBericht), S. 4.

249 Teilnehmer waren Landesregierungsrat Dr. Pfeifer vom Ministerium, Dr. Draeger und Herr Scholle von der Reichsanstalt für Arbeitslosenhilfe und Arbeitslosenversicherung; ÖStA/AdR Wien, Bürckel-Materie, Nr. 1937/2/2, unfol.: Ministerium für innere und kulturelle Angelegenheiten an das RMdI (Ministerialrat Krug von Nidda) vom 18. 10. 1938, mit Protokoll der Sitzung am 10. 10. 1938. 
wohl mit einer Radikalisierung als auch mit einer Zentralisierung und Koordination ihres bislang oft uneinheitlichen Vorgehens reagiert. Nach der Erfassung des jüdischen Vermögens bereitete man im Mai 1938 schon die Registrierung von Unternehmen und Betrieben jüdischer Inhaber im Reich vor. Doch nun ging es nicht mehr nur um ihre „Ausschaltung aus der Wirtschaft", so der NS-Terminus, sondern um die zentral gesteuerte "Arisierung" ihrer Gewerbe und Firmen. Ende Mai stand für die NS-Führung fest: „Den Juden sollen Bankkonten, Bargeld, festverzinsliche Wertpapiere und dergl. Vermögensstücke, die unmittelbar keine wirtschaftliche Machtstellung vermitteln, bis auf weiteres belassen bleiben. Sie sollen dagegen nach einer im Reichswirtschaftsministerium erwogenen gesetzlichen Neuregelung verpflichtet werden, Anteile an Betrieben (Aktien, GmbH-Anteile) und sonstigen wirtschaftlichen Unternehmungen bis zu einer noch zu bestimmenden Frist an Deutsche zu veräußern. " Allerdings würden die ehemaligen Besitzer den Preis nicht bar erhalten, sondern als 3,5 prozentige Schuldverschreibung einer noch zu „gründende[n] Bank für die Arisierung des jüdischen Vermögens“. Der Erlös werde „möglichst restlos für Zwecke des Vierjahresplans verwandt". 250

Reichsinnenminister Frick drängte in einem an Göring, das Reichswirtschaftsministerium, den Stellvertreter des Führers sowie an Himmler adressierten Memorandum zur antijüdischen Politik am 14. Juni 1938 ebenfalls auf die „zwangsweise Ausschaltung der Juden" aus der Wirtschaft und die schnelle Enteignung ihrer Betriebsvermögen. Doch Frick wies zugleich auf die absehbar drastischen sozialen Folgen hin: „Die Juden werden durch ihre Ausschaltung aus dem Wirtschaftsleben zum überwiegenden Teil zur Untätigkeit gezwungen und darüber hinaus wird regelmäßig auch ihre Verarmung herbeigeführt werden." Beides wäre nicht nur vom „staatspolitischen Standpunkt aus unerwünscht“, sondern „das zu erwartende starke Anschwellen des jüdischen Proletariats" stelle ein potentiell gefährliches Problem dar. Einzige Lösungsmöglichkeit im NS-Sinn schien dem Innenminister wie bisher die Vertreibung zu sein, die jedoch trotz aller ,innenpolitischen" Verschärfungen nur eine Illusion bleibe, da kein Land gefunden sei, das "für eine Masseneinwanderung der Juden ernstlich in Frage käme". In der $\mathrm{Zu}$ kunft müßten daher die in Deutschland bleibenden Juden, soweit sie „von dem Erlös ihrer übernommenen Betriebs- und sonstigen Vermögenswerte leben können“, streng überwacht werden, und soweit sie hilfsbedürftig würden, sei „die Frage ihrer öffentlichen Unterstützung" zu klären. Eine stärkere Inanspruchnahme der Fürsorgeverbände ließe sich scheinbar nicht vermeiden. ${ }^{251}$

Parallel zu den zentralen Diskussionen hatte Goebbels, dem es vor allem auf die Vertreibung der Juden aus dem Gau Berlin ankam, sich Vorschläge für die antijüdische Politik in der Reichshauptstadt ausarbeiten lassen. Und das, obwohl gerade hier in den letzten Monaten eine Fülle neuer antijüdischer Maßnahmen eingeführt worden war. ${ }^{252}$ Die Stapo(leit)stelle Berlin forderte in einer daraufhin fabrizierten

250 BA, R 36, Nr. 589, Bl. 4: Vermerk Tapolski (DGT/Abt. II) für Jeserich am 30. 5. 1938.

251 Hervorhebungen im Original. AdP, Teil I, Bd. 2 -Microfiche-, Nr. 20700228-37: Schreiben des RMdI vom 14. 6. 1938 (NG-3937).

252 Vgl. Gruner, Judenverfolgung in Berlin, S. 44-48. 
Denkschrift, daß den Berliner Juden künftig der Besuch öffentlicher Theater, Kinos, Gaststätten, Bäder, Parks, Sportanlagen sowie Schulen verboten werden müsse. Obgleich das wie eine Quintessenz bisheriger kommunaler Aktivitäten klang, ging die Berliner Gestapo doch über diese weit hinaus, da sie für den Aufbau separater „jüdischer" Einrichtungen plädierte. Neben radikalen Vorschlägen einer Kopfsteuer und eines vollständigen Gewerbeverbots forderte die Gestapo in der Denkschrift auch, daß durch Gesetzesänderung Juden künftig in der Sozialversorgung Ausländern gleichgesetzt werden sollten. ${ }^{253}$ Das Judenreferat des SD kritisierte die potentiellen Wirkungen der radikalen Berliner Gestapo-Vorschläge, denn es sei nur dann möglich, „die Juden sofort und unnachsichtlich von einer Berufstätigkeit auszuschließen, wenn auf der anderen Seite die geschaffenen Auswanderungsmöglichkeiten groß genug sind, um den Abfluß der jüdischen Erwerbslosen bzw. Nichtbeschäftigten zu gewährleisten “. ${ }^{254}$ Speziell zur Deklassierung der Juden in der Öffentlichen Fürsorge merkte das SD-Judenreferat an: „Diese Maßnahme kann aber nur mit einer parallel laufenden systematischen Steigerung der jüdischen Selbsthilfe erfolgen. Von hier aus wird in dieser Richtung beständig auf die verantwortlichen Stellen Einfluß genommen. Eine sofortige Ausschließung bedürftiger Juden, ohne diese Maßnahmen getroffen zu haben, würde eine Stärkung des Verbrechertums und des Bettlerwesens bedeuten. Die außenpolitischen Auswirkungen sind gleichfalls in Erwägung zu ziehen." 255 Von den Vorschlägen und der Kritik erhielten neben Goebbels und Heydrich bis Ende Juni 1938 auch Reichswirtschaftsminister Walther Funk und sogar Hitler Kenntnis. 256

Grundsätzlich hatte die NS-Führung einen neuen radikalen Kurs in der antijüdischen Politik eingeschlagen, wohl wissend, daß eine Vertreibung aller Juden auf absehbare Zeit nicht erreicht werden konnte. Infolge des forcierten Ausschlusses aus der Wirtschaft sowie der geplanten Enteignung schuf jedoch die absehbar totale Pauperisierung der jüdischen Bevölkerung und damit die potentielle Abhängigkeit Zehntausender, ja Hundertausender von der Sozialfürsorge des NSStaates ein grundsätzliches Fragezeichen für alle neuen antijüdischen Maßnahmen. Dieser Widerspruch zwischen den Verfolgungszielen mußte schnell gelöst werden, denn die Kommunen drängten mit Hilfe des Deutschen Gemeindetages wie gezeigt - auf eine Klärung der Stellung der jüdischen Armen in der Öffentlichen Wohlfahrt, entweder formell durch eine gesetzliche Regelung oder informell über die nach sozialrassistischen Kriterien abgestuften Fürsorgerichtsätze.

Nachdem man im Reichsinnenministerium eine solche Neuregelung lange aufgeschoben hatte, trafen sich aufgrund der veränderten Situation am 29. Juli 1938 Ministerialvertreter, Beamte des Deutschen Gemeindetages mit Abgesandten der Sicherheits- und der Ordnungspolizei, um die künftige Behandlung der jüdischen Armen in der Öffentlichen Fürsorge zu besprechen. Ministerialrat Ruppert, der zu der Sitzung in sein Ministerium eingeladen hatte, legte erstmals den von den

253 Vgl. dazu ausführlich die Edition des Dokuments bei Gruner, Denkschrift, S. 305-341.

254 YV Jerusalem, 051/OSOBI, Nr. 106 (500-1-603), Bl. 13: Vermerk Hagen (SD II 112) für II 1 vom 17. 5. 1938.

255 Ebenda, Bl. 19.

256 Gruner, Denkschrift, S. 305-341. 
Kommunen so lange erwarteten Entwurf einer zentralen Verordnung vor. In der Diskussion plädierte die Gestapo - wie schon zuvor - für radikalste Maßnahmen, sie wollte die „Hilfe der öffentlichen Fürsorge bei Juden auf das zum Leben unerläßliche" beschränkt wissen. Wegen der Furcht vor negativen Reaktionen des Auslandes fand ihr Vorschlag aber zunächst keine Zustimmung. Die Beamten von Polizei, Gemeindetag und Ministerien verständigten sich gleichwohl offenbar über die Eckdaten der geplanten Verordnung, außerdem erstmals über Arbeitszwangsmaßnahmen für erwerbslose Juden. ${ }^{257}$

Nach dieser entscheidenden Sitzung übermittelte Staatssekretär Stuckart (RMdI) bereits am 16. August 1938 den „Entwurf einer Verordnung über die Fürsorge für Juden" an das Reichsarbeitsministerium, das Reichsfinanzministerium, die NSDAP und an das Auswärtige Amt - wegen der Beachtung internationaler fürsorgerechtlicher Abkommen - mit folgender Begründung: „Die gesetzliche Klarstellung des künftig hilfsbedürftigen Juden noch zuzubilligenden Maßes an öffentlicher Fürsorge, die im Zuge des weiteren Ausbaues des für Juden geltenden Rechts nötig ist und auch von den Fürsorgeverbänden gewünscht wird, ist bisher zurückgestellt worden in der Absicht, sie in einer bereits seit längerer Zeit vorbereiteten, umfassenderen Verordnung zur Änderung des Fürsorgerechts aufzunehmen. Da die Vorarbeiten für diese Verordnung noch eine gewisse Zeit in Anspruch nehmen werden, andrerseits aber nach den letzthin vorgenommenen weiteren Beschränkungen der Juden auf wirtschaftlichem Gebiet die Zahl der hilfsbedürftigen Juden voraussichtlich zunehmen wird, kann nunmehr die Regelung der fürsorgerechtlichen Stellung der Juden nicht länger zurückgestellt werden. Sie muß deshalb den Gegenstand einer besonderen, in Kürze zu erlassenden Verordnung bilden." 258

Das Reichsinnenministerium beabsichtigte, und das ging über alle bisherigen Vorschläge weit hinaus, mit dieser Verordnung prinzipiell jüdische Arme aus der Öffentlichen Wohlfahrt auszuschließen und diese an jüdische Wohlfahrtseinrichtungen zu verweisen. Nur wenn die "Gemeinschaft seiner Rasse aus Mangel an Mitteln nicht den notdürftigen Lebensbedarf zur Verfügung stellen kann", so der vom Innenministerium dem Entwurf beigefügte Kommentar, könne ein Jude einen Antrag auf staatliche Versorgung stellen. Die Hilfsbedürftigkeit als Voraussetzung von Zahlungen sei von den Fürsorgebehörden besonders streng zu prüfen. Wenn Juden im Ausnahmefall dann versorgt werden würden, seien sie nicht nur von den privilegierten Versorgungsklassen wie Kleinrentnerhilfe und Gehobener Fürsorge auszuschließen, wie dies einige Fürsorgeverbände in Eigeninitiative ja schon praktizierten, sondern definitiv Ausländern, die kein zwischenstaatliches Abkommen schützte, gleichzustellen. Infolge dieser Deklassierung erhielten jüdische Wohlfahrtsempfänger in Zukunft weniger als die in der Allgemeinen Für-

257 Entwurf der VO mit handschriftl. Vermerk Rupperts vom 28. 7 und einem Aktenvermerk Preisers (DGT) vom 4. 8. über die Sitzung am 29. 7. 1938; nach Adam, Judenpolitik, S. 192 u. 202. Zu den Planungen eines Zwangseinsatzes für erwerbslose Juden vgl. Gruner, Geschlossener Arbeitseinsatz, S. 45-47.

258 AdP, Teil I, Bd. 2 -Microfiche-, Nr. 10312468: RMdI-Schreiben vom 16. 8. 1938. Abdruck bei Lohalm, Fürsorge und Verfolgung, S. 94-96. 
sorge geltenden Sätze ausgezahlt, denn im Sinne der NS-Bevölkerungspolitik bekamen Ausländer z.B. keine Leistungen zur Wiederherstellung von Erwerbsfähigkeit. Zusätzliche Mittel wollte man sowieso nur gewähren, wenn dies im öffentlichen Interesse läge, um „die deutschblütige Umgebung vor Ansteckung zu schützen", oder - wie schon praktiziert - um die Auswanderung der Juden zu fördern. ${ }^{259}$

Der Entwurf selbst sah vor, mit der vom Reichsinnen-, Reichsarbeits- und Reichsfinanzministerium gemeinsam herauszugebenden Verordnung einen neuen Paragraphen in die „Reichsgrundsätze über Voraussetzung, Art und Maß der öffentlichen Fürsorge" einzubauen, der bedürftige Juden grundsätzlich an jüdische Institutionen verwies. $\mathrm{Da}$ aber die schlechte Finanzlage jüdischer Wohlfahrtsstellen allzu gut bekannt war, kam man nicht umhin, die vorgesehene Klausel gleich wieder mit dem Zusatz aufzuweichen, daß - wenn alle jüdischen Mittel erschöpft seien - die Öffentliche Fürsorge helfen müsse, wobei von jüdischen Stellen erbrachte Leistungen voll auf die Sätze der Wohlfahrtsbehörden angerechnet werden sollten. Von den Ämtern dürften dann nach strenger Prüfung, ob die Voraussetzungen einer Hilfsbedürftigkeit vorlägen, an Juden ausschließlich die Mittel für Unterkunft, Nahrung, Kleidung, Krankenpflege, Hilfe für Gebrechliche, Schwangere, Wöchnerinnen und ärztliche Behandlung abgegeben werden. Aus der Kleinrentnerhilfe klammerte der Entwurf der Verordnung Juden explizit aus. ${ }^{260}$ Detailliertere Paragraphen sollten noch, so informierte das Reichsinnenministerium den Deutschen Gemeindetag, später in die umfassende Reorganisation des Fürsorgewesens einfließen. ${ }^{261}$

Das Reichsarbeitsministerium stimmte Anfang September 1938 den diskriminierenden Festlegungen der geplanten Verordnung zu. Man zeigte sich dort besonders mit dem Verfahren einverstanden, Juden „in erster Linie auf die Hilfe der freien jüdischen Wohlfahrtspflege" zu verweisen. Das Ministerium stimmte einem Ausschluß jüdischer Armer aus der Gehobenen Fürsorge und aus der Kleinrentnerhilfe vorbehaltlos zu. Die geplante Diskriminierung der Kriegsbeschädigten, die laut Entwurf ebenfalls ihre Gehobene Fürsorge verlieren sollten, wollte das Ministerium aber nicht mittragen, da beim Berufsbeamtengesetz 1933 für diese Gruppe eine bis dato geltende Ausnahme gemacht worden sei.262 Das Reichsarbeitsministerium flankierte die geplante Verordnung nur wenige Tage später durch einen Erlaß, mit dem es "Jüdische Verkaufsstellen" im ganzen Reich die Annahme kommunaler Wohlfahrtsgutscheine sowie Fettverbilligungsbezugsscheine verbot. Das Reichsinnenministerium informierte die Fürsorgebehörden, daß ,jüdische" Geschäfte vor Ort durch die auf der Grundlage der Dritten Verordnung zum Reichsbürgergesetz vom 14. Juni $1938^{263}$ überall angelegten Ver-

259 AdP, Teil I, Bd. 2 -Microfiche-, Nr. 10312468-72: RMdI-Schreiben vom 16. 8. $1938 \mathrm{mit}$ VO-Entwurf.

260 Ebenda, Nr. 10312469-72: VO-Entwurf.

261 RMdI-Schreiben an DGT vom 16. 8. 1938, nach Adam, Judenpolitik, S. 193.

262 AdP, Teil I, Bd. 2 -Microfiche-, Nr. 20400447-48: RArbM/Abt. IIb (Rettig) an RMdI am 2. 9.1938.

263 RGBl., 1938 I, S. 627. 
zeichnisse jüdischer Gewerbebetriebe zu ermitteln seien.264 Dieser Erlaß diente, wie so viele der Erlasse und Verordnungen des Jahres 1938, in erster Linie der „Legalisierung“ und Vereinheitlichung der informellen Praxis städtischer Ämter.

Die jetzt herrschende Übereinstimmung über die Herausgabe einer Verordnung zum Ausschluß aller Juden aus der Fürsorge zog noch andere Konsequenzen nach sich. In der bereits angesprochenen Diskussion über eine verschärfte Kontrolle jüdischer Sammlungen begann sich nun die Argumentation von SS und Sicherheitspolizei durchzusetzen. Das geschah offenbar unter dem Eindruck der veränderten Verfolgungssituation, denn auf lange Sicht konnten allein die jüdischen Sammlungen die notwendigen Mittel für die in Zukunft allein für die armen Juden verantwortliche jüdische Wohlfahrt bereitstellen. ${ }^{265}$ Wenn aber durch eine Verschärfung der Sammlungsgesetzgebung die Jüdischen Gemeinden nicht genügend Mittel zur Unterstützung ihrer „Rassegenossen“ aufbrächten, dann müßte doch die staatliche Wohlfahrt zahlen, was auf jeden Fall zu verhindern sei. SS und Sicherheitspolizei versicherten dem Reichsinnenministerium, daß die staatspolizeilichen Mittel zur Überwachung aller jüdischen Aktivitäten sowohl geeignet als auch ausreichend seien. ${ }^{266}$ Die Ministerialbeamten konnten dieser Sichtweise inzwischen ohne Probleme folgen, da sie dem Ziel, ein finanzielles Eingreifen des NS-Staates zugunsten der jüdischen Bevölkerung zu unterbinden, ja mit dem Verordnungsentwurf verwaltungsmäßig zugearbeitet hatten.

SS und Sicherheitspolizei kümmerten sich sogar schon um den nach dem avisierten Ausschluß aus der staatlichen Versorgung notwendig werdenden organisatorischen Aufbau einer separaten jüdischen Fürsorge. Beamte des SS-Sicherheitsdienstes hatten im Frühsommer 1938 dem Präsidenten der „Reichsvertretung der Juden in Deutschland“, des Dachverbandes jüdischer Organisationen und Gemeinden, bei einer Vernehmung befohlen, eine „Denkschrift für die Versorgung der jüdischen Hilfsbedürftigen“, speziell der Alten, vorzulegen. Zu dem Anfang Juni überreichten Konzept bemerkte der SD in einem Schreiben an die Gestapo später, daß die jüdische Organisation größten Wert auf die Unterhaltspflicht der Emigranten für ihre zurückbleibenden Angehörigen legen werde. Die Reichsvertretung habe man aufgefordert, einen Plan einzureichen, „nach dem Auswanderer entsprechend dem vorhandenen Vermögen verpflichtet sind, einen festen Betrag [...] bei der Auswanderung bereitzustellen“".267 Damit nahm man die seit Mitte der dreißiger Jahre ventilierte Idee einer Sondersteuer wieder auf. Sicher ausgelöst durch erste Erfahrungen der Wiener Zentralstelle des SD, die ein solches Verfahren informell praktizierte, um die Vertreibung armer Juden zu forcieren. ${ }^{268} \mathrm{Der}$

264 RArbM/II-Runderlaß vom 6. 9.1938 mitgeteilt durch RMdI-Runderlaß; RMinBliV., 1938, S. 1511. Abdruck auch in: Dienstblatt der Stadt Berlin, 1938 I, S. 477.

265 BA, 15. 01, Nr. 27713, B1. 472-475: Schriftwechsel RMdI mit verschiedenen Parteistellen Juli 1938. Vgl. zu folgendem: Gruner, Berichte, S. 309.

266 BA, 15. 01, Nr. 27713, Bl. 476: Schnellbrief RFSS und Chef der deutschen Polizei an RMdI am 23. 9. 1938.

267 YV Jerusalem, 051/OSOBI, Nr. 96 (500-1-490), Bl. 7-9: Vermerk SD II 112 (Hagen) und Hagen an Gestapa Berlin am 17. 10.1938.

268 Diese Vorarbeiten führten später zu der sog. Auswandererabgabe (CdS/II-Erlaß vom 25. 2. 1939) erwähnt in: ebenda, Bl. 16: Vermerk SD II 112 (Hagen) vom 25. 4. 1939. 
Sicherheitsdienst der SS trug der „Reichsvertretung“ außerdem konkret auf, daß neue „Wohnheime für alte Juden so einzurichten wären, daß eine Übernahme durch die deutsche Fürsorge ohne Schwierigkeiten erfolgen könnte“. ${ }^{269}$ Der SD machte den jüdischen Repräsentanten mit dieser Vorgabe unmißverständlich klar, daß man trotz aller Widerstände am gesellschaftspolitischen Ziel einer vollständigen Vertreibung festhielt.

$x * *$

Die Phase zwischen Sommer 1937 und Sommer 1938 brachte den Wendepunkt für die antijüdische Politik auf dem Sektor der Öffentlichen Wohlfahrt. Die vielfältigen lokalen Impulse sollten in der Formulierung einer zentralen Verordnung zur Ausgrenzung jüdischer Bedürftiger von der staatlichen Versorgung münden. Anfang 1937 war eine Forderung nach grundlegenden neuen Richtlinien zur „Behandlung von Nichtariern" aus der Münchner Stadtverwaltung über deren Oberbürgermeister Fiehler und den Deutschen Gemeindetag an das Reichsinnenministerium gelangt. Auf Vorschlag des Ministeriums diskutierte man die Ausgrenzung der Juden als Grundsatzfrage auf der Heidelberger Sitzung des Wohlfahrtsausschusses des Deutschen Gemeindetages im Juni 1937. Die Hardliner aus den städtischen Wohlfahrtsämtern und die Beamten des Gemeindetages bzw. der Ministerien sahen sich einig in ihrem Willen, rasch die städtischen Ausgrenzungspraktiken auf gesetzlichem Wege zu vereinheitlichen. Sie forderten, jüdische Arme in der Öffentlichen Wohlfahrt Ausländern gleichzustellen und damit gegenüber nichtjüdischen Deutschen zu deklassieren. Privilegierte Versorgungsklassen sollten für jüdische Arme ebenso wegfallen wie zusätzliche Leistungen, jüdische Unterstützungsempfänger ausnahmslos Pflichtarbeit leisten. Städtische Maßnahmen sollten das Modell für ein Vorgehen auf Reichsebene bilden. Doch zunächst schob das Reichsinnenministerium ein Gesetz weiter auf die lange Bank, da man die Diskriminierung jüdischer Armer in eine langfristige Reorganisation der Öffentlichen Fürsorge einbinden wollte. Über den Deutschen Gemeindetag setzten jedoch die Kommunen bis zum Frühjahr 1938 beim Ministerium durch, daß die geplante Deklassierung informell über eine sozialrassistische Reform des Richtsatzsystems realisiert werden konnte. Der Stadtstaat Hamburg war die erste Region, die das praktizierte. Mit den dann im Mai 1938 von den Arbeitsgemeinschaften für Wohlfahrtspflege des Deutschen Gemeindetages entworfenen „Würzburger Richtlinien“ sollte als Prinzip für die lokale Praxis verbindlich festgeschrieben werden, daß Juden und andere "Minderwertige“ nur noch in der niedrigen Klasse der Allgemeinen Fürsorge zu versorgen seien. Obwohl das Reichsinnenministerium die Maxime vorbehaltlos anerkannte, wollte es sie aber vorerst nicht verbindlich verbreiten.

Über die pauschale Deklassierung jüdischer Armer hinaus, ging es den deutschen Fürsorgebehörden verstärkt um deren organisatorische Separierung im Wohlfahrtsalltag. Die Zentrale sowie die Landes- und Provinzialdienststellen des

269 Ebenda, Bl. 7-9: Vermerk SD II 112 (Hagen) vom 17. 10. 1938. 
Deutschen Gemeindetages veranstalteten Debatten und Umfragen über die Diskriminierung jüdischer Obdachloser und Behinderter. Die seit 1934 in dessen regionalen Arbeitsgemeinschaften geführten Diskussionen über die „Rassentrennung" im Adoptions- und Vormundschaftswesen und über die Isolierung jüdischer Patienten in öffentlichen Kranken- und Heilanstalten trugen nicht unwesentlich dazu bei, daß im Sommer 1938 mehrere entsprechende Ministerialerlasse veröffentlicht wurden. Wenngleich die seit 1936 vom Deutschen Gemeindetag angeregte umfassende Verordnung zur Separierung der Juden in allen kommunalen Einrichtungen, also auch Bädern, Märkten und Bibliotheken, weiter ausstand, gaben die Kommunen nun sukzessive die Initiative in der antijüdischen Politik, und zwar auch in der Fürsorge, an die Reichsebene ab.

Während in Wien schon in den Wochen nach der „Angliederung“ im März 1938 jüdische Arme ohne Kompromisse durch fast die Hälfte der bezirklichen Wohlfahrtsstellen vom Leistungsbezug ausgeschlossen wurden, bereiteten die deutschen Kommunen per Erfassung und Kennzeichnung deren umfassende Ausgrenzung erst vor. Gewaltakte der Sicherheitspolizei wie die KZ-Einlieferungen Tausender Juden bei den „Asozialen“-Razzien gingen über die bisherige Politik der meisten Kommunen hinaus. Das verweist auf eine zentrale Neuorientierung der Verfolgung. Vier Stränge verflochten sich zu diesem Zeitpunkt auf dem sozialpolitischen Sektor: Die Radikalisierung der Reichsgesetzgebung und die Separierungsmaßnahmen der Kommunen, der Sozialrassismus in der Fürsorgepraxis und die zentralen Pläne einer „völkischen“ Revision der Wohlfahrt. Angesichts der durch immer neue antijüdische Maßnahmen vor allem in Beruf, Gewerbe und Wirtschaft sprunghaft ansteigenden Zahl jüdischer Besitzloser änderte sich die Haltung des Reichsinnenministeriums im Sommer 1938. Doch statt mit staatlichen Hilfen die jüdische Armut, die man inzwischen in der gesamten NS-Führung einhellig als größtes Hindernis für die Vertreibungspläne betrachtete, abzufedern, griff das Ministerium zu einer totalen „Lösung“. In Absprache mit dem Deutschen Gemeindetag und der Sicherheitspolizei entwarf das Ministerium bis August 1938 nun eine Verordnung, die über die kommunalen Erwartungen einer Deklassierung weit hinausging. Darin schloß man jüdische Hilfsbedürftige von der Öffentlichen Wohlfahrt grundsätzlich aus und verwies sie an jüdische Einrichtungen. Nur im Ausnahmefall sollten Juden noch aus öffentlichen Mitteln versorgt werden. Das konnte jedoch nur wenig mehr als eine voluntaristische Antwort auf die soziale Not der jüdischen Bevölkerung sein. Den mittlerweile unauflösbar scheinenden gordischen Knoten der Verfolgungspolitik, daß jede neue antijüdische Maßnahme nur das Vertreibungshindernis Armut potenzierte, versuchte die NS-Führung im heraufziehenden Herbst 1938 im wahrsten Sinne des Wortes mit brachialer Gewalt zu durchschlagen: Mit einem staatlich organisierten Pogrom gegen die noch in Deutschland und Österreich lebenden Juden. 